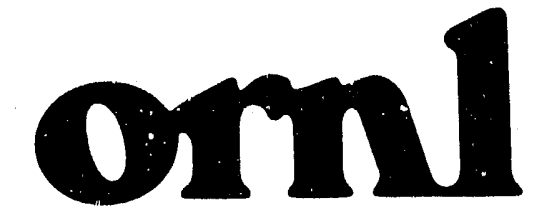

\section{OAK RIDGE NATIONAL LABORATORY}

MARTM. MARELETRA

\section{Received by OSTI}

JAN 221992

\title{
Electromagnetic Pulse (EMP) Survey of the FEMA Region $X$ Federal Regional Center, Bothell, Washington
}

\author{
R. I. Crutcher \\ M. E. Buchanan \\ R. W. Jones
}

\section{MANAGED GY}

MARTIN MARIETTR ENERGY SYSTEMS, INC. 
This report has been reproduced directly from the best available copy.

Available to DOE and DOE contractors from the Office of Scientific and Technical Information, P.O. Box 62, Oak Ridge, TN 37831 ; prices available from (615) 576-8401, FTS 626-8401.

Available to the public from the National Technical Information Service, U.S. Department of Commerce, 5285 Port Royal Rd., Springfield, VA 22161.

This report was prepared as an account of work sponsored by an agency of the United States Government. Neither the United States Government nor any agency thereof, nor any of their employees, makes any warranty, express or implied, or assumes any legal liability or responsibility for the accuracy, completeness, or usefulness of any information, apparatus, product, or process disclosed, or represents that its use would not infringe privately owned rights. Reference herein to any specific cumimercial product, process, or service by trade name, trademark, manufacturer, or otherwise, does not necessarily constitute or imply its endorsement, recommendation, or favoring by the United States Government or any agency thereot. The views and opinions of authors expressed herein do not necessarily state or reflect those of the United States Government or any agency thereof.

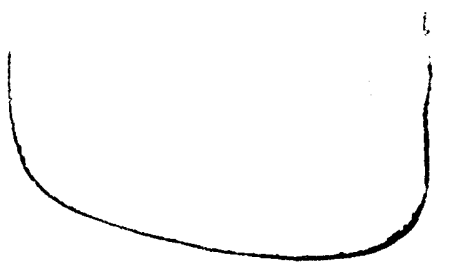




\title{
ELECTROMAGNETIC PULSE (EMP) SURVEY OF THE FEMA P.EGION X FEDERAL REGIONAL CENTER, BOTHELI, WASHINGTON
}

\author{
R. I. Crutcher \\ M. E. Buchanan \\ R. W. Jones
}

Date Published-November 1991

\begin{abstract}
Notice: This document contains information of a preliminary nature. It is subject to revision or correction and therefore does not represent a final report.
\end{abstract}

Prepared for the
FEDERAL EMERGENCY MANAGEMENT AGENCY
Washington, DC 20472

under Interagency Agreement DOE 1459-1086-A1/FEMA EMW-84-E1459

Prepared by the

OAK RIDGE NATIONAL LABGRATORY

Oak Ridge, Tennessec 37831-6285 managed by MARTIN MARIETTA ENERGY SYSTEMS, INC.

for the

U.S. DEPARTMENT OF ENER.GY

under contract DE-ACO5-84OR21400 


\section{TABLE OF CONTENTS}

\section{Page}

LIST OF FIGURES $\ldots \ldots \ldots \ldots \ldots \ldots \ldots \ldots \ldots \ldots \ldots \ldots$

LIST OF FEMA DRAWINGS $\ldots \ldots \ldots \ldots \ldots \ldots \ldots \ldots \ldots \ldots \ldots \ldots$

I. GENERAL $\ldots \ldots \ldots \ldots \ldots \ldots \ldots \ldots \ldots \ldots \ldots \ldots \ldots \ldots \ldots \ldots$

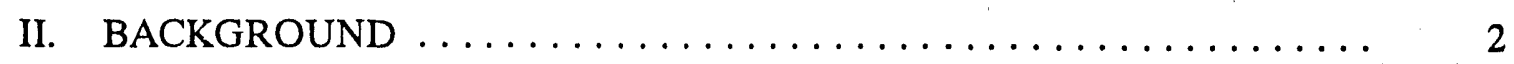

III. POWER SYSTEM PROTECTION $\ldots \ldots \ldots \ldots \ldots \ldots \ldots \ldots \ldots$

A. Electrical Power Distribution System ................. 2

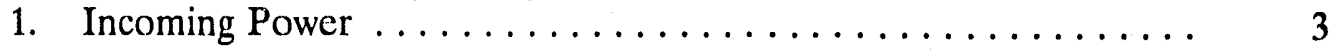

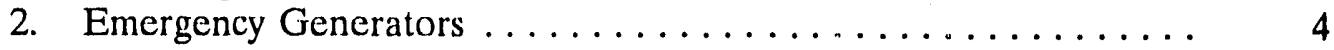

3. Motor Control Center ................... 4

4. Distribution Panels ..................... 5

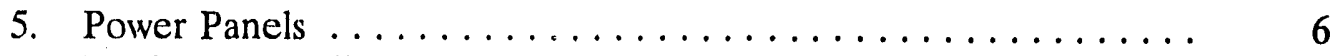

6. Radio Room Filters $\ldots \ldots \ldots \ldots \ldots \ldots \ldots \ldots \ldots \ldots \ldots . \ldots \ldots$

7. Radio Room Panels ...................... 10

B. Electrical Motors and Life-Support Systems ............. 11

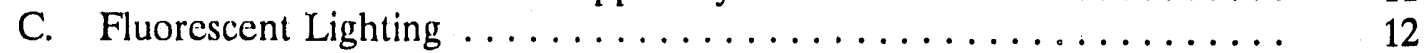

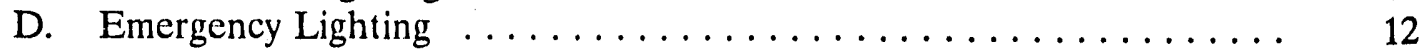

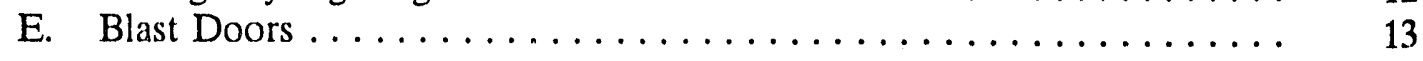

IV. SHIELDED RADIO OPERATIONS ROOM ............. 13

V. ANTENNA AND RADIO SYSTEM ................ 14

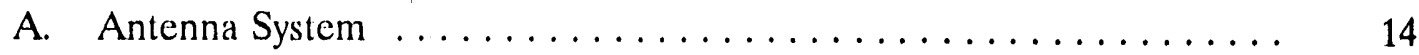

B. Shielded Room Coaxial Penetrations .................. 16

C. Radios and Communications Center Equipment ............ 18

VI. TELEPHONE AND CONTROL LINES ................ 20

A. FRC Telephone Cable Protection $\ldots \ldots \ldots \ldots \ldots \ldots \ldots \ldots \ldots$

B. Shielded Room Penetration Protection ................. 21

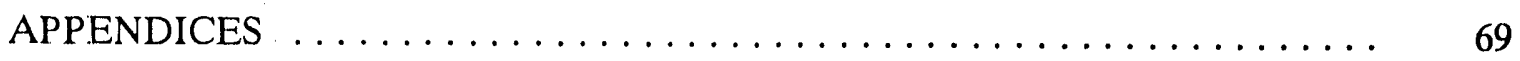




\section{LIST OF.FIGURES}

Figure

Page

1 Main power panel with commercial power disconnects, manual transfer switches, and feeder disconnects $\ldots \ldots \ldots \ldots 22$

2 Bus bars for installation of MOVs $\ldots \ldots \ldots \ldots \ldots \ldots \ldots \ldots \ldots \ldots \ldots$

3 Bus bars on distribution switch end of the power center $\ldots \ldots \ldots \ldots 23$

4 Grounding system in main power center $\ldots \ldots \ldots \ldots \ldots \ldots \ldots$

5 Typical connection for building ground network $\ldots \ldots \ldots \ldots \ldots \ldots$

6 Front of transfer switch cabinet with panel door open ........... 24

$7 \quad$ Emergency generator No. $2 \ldots \ldots \ldots \ldots \ldots \ldots \ldots \ldots \ldots \ldots \ldots$

8 Flexible conduits for the generator status monitor $\ldots \ldots \ldots \ldots \ldots$

9 Motor control center $\ldots \ldots \ldots \ldots \ldots \ldots \ldots \ldots \ldots \ldots \ldots \ldots$

10 Incoming wiring connection for the motor control center $\ldots \ldots \ldots 26$

11 Power bus bars in the chiller distribution center $\ldots \ldots \ldots \ldots \ldots \ldots$

12 Power distribution panel DP1 $\ldots \ldots \ldots \ldots \ldots \ldots \ldots \ldots \ldots \ldots$

13 Power distribution panel DP2 $\ldots \ldots \ldots \ldots \ldots \ldots \ldots \ldots \ldots \ldots$

14 Power distribution panel DP3 $\ldots \ldots \ldots \ldots \ldots \ldots \ldots \ldots \ldots \ldots$

15 Power distribution panel DP4 $\ldots \ldots \ldots \ldots \ldots \ldots \ldots \ldots \ldots$

16 Power distribution panel DP6 .................... 29

$17 \quad$ Power panel A $\ldots \ldots \ldots \ldots \ldots \ldots \ldots \ldots \ldots \ldots \ldots \ldots \ldots$

$18 \quad$ Power panel B $\ldots \ldots \ldots \ldots \ldots \ldots \ldots \ldots \ldots \ldots \ldots \ldots \ldots \ldots$

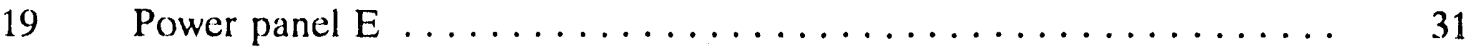

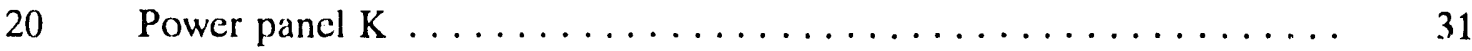

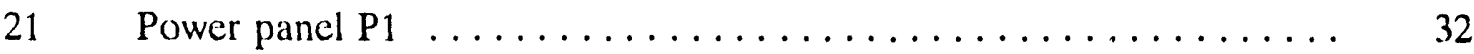

22 Power panel P2 in the kitchen area $\ldots \ldots \ldots \ldots \ldots \ldots \ldots \ldots \ldots \ldots$ 


\section{LIST OF FIGURES (continued)}

23 Power panel $\mathrm{P3}$ in the laundry room $\ldots \ldots \ldots \ldots \ldots \ldots \ldots$

$24 \quad$ Power panel $\mathrm{R} 1 \ldots \ldots \ldots \ldots \ldots \ldots \ldots \ldots \ldots \ldots \ldots$

25 Power panel $\mathrm{R} 2$ in the upstairs hallway $\ldots \ldots \ldots \ldots \ldots \ldots \ldots$

26 Power panel $\mathrm{R} 3$ in the upstairs hallway $\ldots \ldots \ldots \ldots \ldots \ldots \ldots$

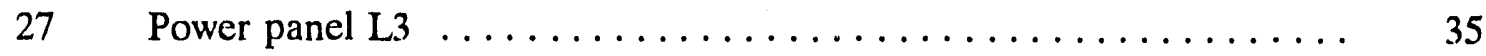

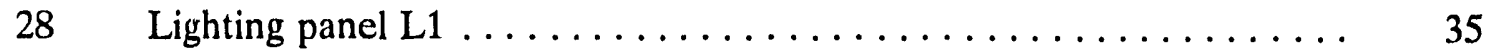

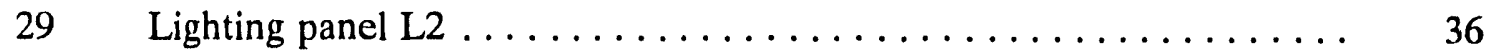

$30 \quad$ Fire alarm breaker panel $\ldots \ldots \ldots \ldots \ldots \ldots \ldots \ldots \ldots \ldots \ldots$

31 Telephone system power panel $\ldots \ldots \ldots \ldots \ldots \ldots \ldots \ldots \ldots$

32 Lighting filter for the shielded communications room $\ldots \ldots \ldots \ldots \ldots$

33 Input terminals for the lighting filter $\ldots \ldots \ldots \ldots \ldots \ldots \ldots$

34 Output terminals for the lighting filter $\ldots \ldots \ldots \ldots \ldots \ldots$

35 Wiring for the input side of the main power filter . . . . . . . . 39

36 Terminals for the output side of the main power filter $\ldots \ldots \ldots \ldots$

37 Power distribution panel DP5 in the shielded room $\ldots \ldots \ldots \ldots \ldots 40$

38 Power panel $C$ in the shielded room $\ldots \ldots \ldots \ldots \ldots \ldots \ldots$

39 Power panel $D$ in the shielded room $\ldots \ldots \ldots \ldots \ldots \ldots \ldots$

40 Circuit breakers for the Harris transmitter racks $\ldots \ldots \ldots \ldots \ldots \ldots . . .41$

41 Transformer terminals for the Harris transmitter racks $\ldots \ldots \ldots \ldots \ldots \quad 42$

42 Control switch for the air makeup heater $\ldots \ldots \ldots \ldots \ldots \ldots \ldots$

$43 \quad$ Chiller control panel $\ldots \ldots \ldots \ldots \ldots \ldots \ldots \ldots \ldots \ldots \ldots \ldots$

44 Contactor for the primary chiller water pump $\ldots \ldots \ldots \ldots \ldots \ldots$

45 Contactors for chiller circulating pumps 6 and $7 \ldots \ldots \ldots \ldots 4$ 


\section{LIST OF FIGURES (continued)}

46 Contactor for an air duct heater $\ldots \ldots \ldots \ldots \ldots \ldots \ldots \ldots$

47 Contactor for an air duct heater $\ldots \ldots \ldots \ldots \ldots \ldots \ldots \ldots \ldots$

48 Day tank and pump for the generator fuel supply $\ldots \ldots \ldots \ldots \ldots$

49 Air compressor for the door seal bladder to the shielded room . . . . . 46

$50 \quad$ Battery-powered floodlight used in the Bothell FRC ......... 46

$51 \quad$ Inside of the battery-powered floodlight $\ldots \ldots \ldots \ldots \ldots \ldots \ldots \ldots$

52 Typical fluorescent emergency light $\ldots \ldots \ldots \ldots \ldots \ldots \ldots \ldots$

53 Control for the automatic blast doors $\ldots \ldots \ldots \ldots \ldots \ldots \ldots \ldots$

54 Inside of the air ventilation duct for the shielded room $\ldots \ldots \ldots \ldots$

55 Honeycomb filter for the return air ventilation duct $\ldots \ldots \ldots \ldots \ldots 49$

56 Personnel door to the shielded radio room $\ldots \ldots \ldots \ldots \ldots \ldots$

57 Inside of the connection vault for the antenna coaxial cables $\ldots \ldots \ldots 50$

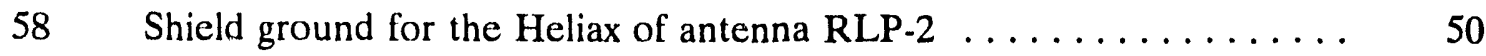

59 Base of the tower for antenna RLP $2 \ldots \ldots \ldots \ldots \ldots \ldots \ldots \ldots$

60 Power box for the rotor of antenna RLP $-2 \ldots \ldots \ldots \ldots \ldots \ldots$

61 Wiring and control box for antenna RLP-2 $\ldots \ldots \ldots \ldots \ldots \ldots \ldots$

62 Base of the support tower for the Spira-cone antenna $\ldots \ldots \ldots \ldots \ldots 2$

63 Control and terminal box for antenna RLP $-1 \ldots \ldots \ldots \ldots$

64 Base of the tower for antenna RLP-1 $\ldots \ldots \ldots \ldots \ldots \ldots \ldots$

$65 \quad$ Balun for antenna FLP-1 $\ldots \ldots \ldots \ldots \ldots \ldots \ldots \ldots \ldots \ldots \ldots$

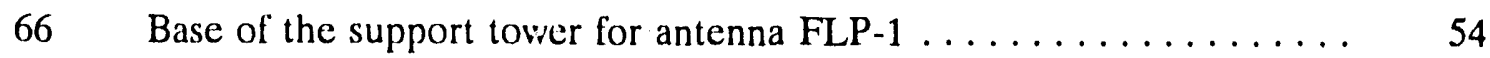

67 Fan doublet antenna with a balun on the center post $\ldots \ldots \ldots \ldots 5$

68 A $10-\mathrm{kW}$ balun of the type used for the fan doublet antennas . . . . . . 55 


\section{LIST OF FIGURES (continued)}

69 Rotor box for the new $\log$ periodic antennas $\ldots \ldots \ldots \ldots$

70 High-power coaxial penetrations on the outside of the shielded room .. 56

71 High-power coaxial penetrations on the inside of the shielded room ... 57

72 Low-power coaxial penetrations on the outside of the shielded room . 57

73 Low-power coaxial penetrations on the inside of the shielded room ... 58

$74 \quad$ Rear of the $\mathrm{rf}$ switching matrix $\ldots \ldots \ldots \ldots \ldots \ldots \ldots \ldots$

75 Control transformer for the $\mathrm{rf}$ switching matrix $\ldots \ldots \ldots \ldots \ldots$

$76 \quad$ Rear of the Harris RF-745-02 equipment $\ldots \ldots \ldots \ldots \ldots \ldots$

77 Harris $\mathrm{A} 1$ and $\mathrm{A} 2$ equipment racks $\ldots \ldots \ldots \ldots \ldots \ldots \ldots \ldots$

$78 \quad$ KWT-6 No. 1 and auxiliary equipment rack No. $1 \ldots \ldots \ldots \ldots$

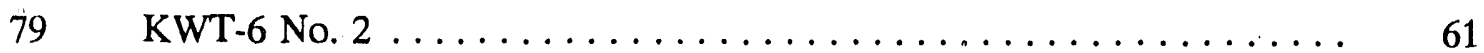

80 Auxiliary equipment rack No. $2 \ldots \ldots \ldots \ldots \ldots \ldots \ldots \ldots$

$81 \quad$ Public Information Officer radio $\ldots \ldots \ldots \ldots \ldots \ldots \ldots \ldots \ldots \ldots \ldots$

$82 \quad$ Corps of Engineers radio $\ldots \ldots \ldots \ldots \ldots \ldots \ldots \ldots \ldots \ldots \ldots \ldots$

$83 \quad$ Duty Officer Radio $\ldots \ldots \ldots \ldots \ldots \ldots \ldots \ldots \ldots \ldots \ldots$

$84 \quad$ Receive multicouplers and active preselectors $\ldots \ldots \ldots \ldots \ldots \ldots$

$85 \quad$ Rear of the main operating console $\ldots \ldots \ldots \ldots \ldots \ldots \ldots \ldots$

$86 \quad$ Rear of the test and teletype equipment rack $\ldots \ldots \ldots \ldots \ldots \ldots \ldots$

$87 \quad$ Rear of the modem bay cabinet $\ldots \ldots \ldots \ldots \ldots \ldots \ldots \ldots \ldots$

88 Punch blocks and heat coils for the telephone room . . . . . . . . 65

89 Telephone terminal blocks $\ldots \ldots \ldots \ldots \ldots \ldots \ldots \ldots \ldots \ldots$

90 Terminal boxes TB2-TB4 at the shielded room penetration ........ 66

91 Terminal box inside the shielded room $\ldots \ldots \ldots \ldots \ldots \ldots \ldots$ 


\section{LIST OF FIGURES (continued)}

$92 \quad$ Spare terminal box with protectors $\ldots \ldots \ldots \ldots \ldots \ldots \ldots \ldots$

93 Inside view of the cable with no penetration protection $\ldots \ldots \ldots \ldots$

94 Ground bus penetration for the telephone lines to the shielded room .. 68 


\section{LIST OF FEMA DRAWINGS}

FEMA

No.

Page

0024-001 Federal Regional Center, Bothell, Washington, single line electrical power diagram ................ 94

0024-002 Federal Regional Center, Bothell, Washington, EMP detector control circuitry $\ldots \ldots \ldots \ldots \ldots \ldots \ldots \ldots . \ldots . \ldots 9$

0024-003 Federal Regional Center, Bothell, Washington, shielded room floor plan and equipment layout . . . . . . . . . 96

0024-004 Federal Regional Center, Bothell, Washington, antenna range layout $\ldots \ldots \ldots \ldots \ldots \ldots \ldots \ldots \ldots \ldots \ldots \ldots \ldots$

0024-005 Federal Regional Center, Bothell, Washington, tower ground radial details $\ldots \ldots \ldots \ldots \ldots \ldots \ldots \ldots \ldots$

0024-006 Federal Regional Center, Bothell, Washington, radial connection details $\ldots \ldots \ldots \ldots \ldots \ldots \ldots \ldots \ldots$

0024-007 Federal Regional Center, Bothell, Washington,

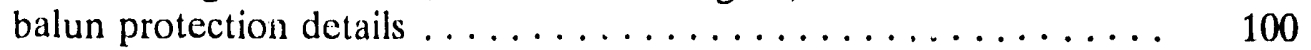

0024-008 Federal Regional Center, Bothell, Washington, coaxial penetration layout $\ldots \ldots \ldots \ldots \ldots \ldots \ldots \ldots$

0024-009 Federal Regional Center, Bothell, Washington, control line penetrations and protection 


\section{GENERAL}

The purpose of this report is to develop an engineering design package to protect the Federal Emergency Management Agency (FEMA) National Radio System (FNARS) facilities against the effects of high-altitude electromagnetic pulses (HEMPs). This report refers to the FEMA Federal Regional Center (FRC) in Bothell, Washington.

It is highly probable that there will be a heavy dependence upon high-frequency (hf) radio communications for long-haul communications following a nuclear attack on the continental United States, should one occur. To maintain the viability of the FEMA hf radio network during such a situation, the FNARS facilities must take measures to protect against the effects of HEMP that are likely to be created in a nuclear confrontation.

The equipment under stress has already been designed and built so that little opportunity exists for equipment design changes that could raise the threshold levels at which malfunctions occur. The solution must then be to reduce HEMP-induced stresses on the system by means of tailored retrofit hardening measures using commercial protection devices when available.

It is the intent of this report to define the particular hardening measures that will minimize the susceptibility of the network components to HEMP effects. To the extent economically viablis, protective actions have been recommended for implementation, along with necessaty chainges or additions, during the period of the FNARS upgrade program.

This report addresses electromagnetic pulse (EMP) effects only, and disregards any condition in which radiation effects may be a factor. It has been established that, except for the source region of a surface burst, EMP effects of high-altitude bursts are more severe than comparable detonations in either air or surface regions. Any system hardened to withstand the more extreme EMP environment will survive the less severe conditions. The threatening environment will therefore be limited to HEMP situations. (In this report, HEMP will be referred to as EMP.)

This report identifies the systems in the facility considered critical for emergency operation. Eacii of these systems is analyzed for EMP coupling paths, and upon establishing this path into the system, the system is then analyzed for its failure threshold. The protection of a system from an EMP is most easily obtained by the elimination or restriction of the EMP coupling paths. EMP coupling paths are identified as directly connected, directly induced, and/or secondarily induced paths. Directly connected EMP paths are provided by power distribution systems, telephone lines, control cables, water pipes, etc. Directly induced EMP paths include doors, windows, ventilation systems, cooling systems, and any other opening into the facility. Secondarily induced EMP paths are associated with currents being induced into metal conductors in the vicinity of other conductors carrying EMPs. The elimination or restriction of these EMP coupling paths into the facility is of primary importance in protecting the FNARS facility.

To identify the critical systems in the facility and the EMP coupling paths into these systems, an EMP survey of the facility was conducted. Results of the survey are presented 
along with recommendations for tailored retrofit hardening measures to be implemented to protect the facility from EMP.

\section{BACKGROUND}

An electromagnetic pulse survey of the FEMA Region X FRC in Bothell was conducted May 22-25, 1989, by M. E. Buchanan and R. I. Crutcher of the Oak Ridge National Laboratory (ORNY) on behalf of FEMA. Technical support was furnished by Fred Bretsch, Andrew Hendrickson, and Gary Coon of FEMA Region X.

The initial site survey was used to obtain firsthand information necessary to assess exposure potential, adequacy, and/or deficiencies in present protection measures and to determine the amount of documentation and drawings available for use in the EMP protection engineering design package. The primary emphasis was placed on obtaining information about the protection of the actual FNARS Radio Room (Communications Shielded Enclosure Room). The original EMP protection was installed during the early 1970s. Because of the lapse of time since the irstallation of EMP protective devices and because new equipment has been added, an updated EMP survey is necessary.

An EMP survey report for the Region X FRC was prepared by Fred Bretsch during July 1985 in preparation for the upgrade of the FNARS equipment. Mr. Bretsch's report provided beneficial data that have been incorporated into this report.

\section{POWER SYSTEM PROTECTION}

\section{A. Electrical Power Distribution Systcm}

The Federal Regional Center at Bothell is a two-story underground building. The FNARS Radio Room/Communications Shielded Enclosure of the FRC is in a metal enclosure on the second floor of the building. Electrical power for the FRC is furnished by a commercial grid of $12,400-\mathrm{V}$ three phase, which is supplied by lines running underground from the street. A pad-mounted transformer with 500-kVA capacity reduces the power to $277 / 480-\mathrm{V}$ grounded wye. The electrical po'ver system provides an excellent direct connection EMP coupling path to critical communication equipment, and it must be considered in the development of the EMP engineering design protection plan. EMP protective measures for power connections are designed to proteci against both common-mode (phase-to-ground) transients and differential-mode (phase-to-phase) transients. Localized protection distributed over the power system uses metal oxide varistors (MOVs) in the main breaker panel and critical power distribution panels. These devices are to be installed on the load side of any three adjacent breakers (phases) with the device lead length as short as possible. FEMA Dwg. 0024-001 is a single-line electrical power distribution diagram showing recommended EMP protector cievice installation locations.

The materials list in Appendix A-1 will assist in identifying the specific protectors shown in various diagrams of the survey (see FEMA drawings). The basic protector number is shown inside the circle on the diagram, with the number of units required below and left of the circle. For example, the motor control center shown in FEMA Dwg. 0024-001 indicates the symbol ${ }_{3}(4)_{4}$. Checking the materials list, we see that this is 
an MOV transient suppressor (4), a V480HE450 (q), and that three each are required at this location (3).

All EMP transient arresters and jumpers recommended and shov'n in this report are to be located such that minimal lead lengths are required for their installation. Induced EMD transient currents have exceptionally fast leading edge gradients, and protector lead inductance can result in significant inductive voltage drops, reducing a protector's effectiveness if it is not properly installed.

FEMA Dwg. 0024-001 is a single-line electrical power distribution diagram showing the locations for instuilation of recommended EMP protection devices for the electrical power system at the FRC. These EMP suppressors will reduce the direct EMP coupling paths through the electrical power system to critiral areas in the facility. FEMA Dwgs. 0024-001 through 009, Figs. 1 through 94, and Appendix B describe the locations and methods for installing the protection devices.

\section{Incoming Power}

The main power disconnect, manual transfer switches, and feeder disconnects are in the power panel shown in Fig. 1. The main disconnect is positioned on the right of the panel. Moving left, the controls for generator No. 1 are in the next two panels. Panels 3 and 4 contain the controls for generator No. 2. Finally, the feeder disconnect panel is situated on the extreme left of the power center. A common bus bar feeder system transverses the length of the power center, effectively placing the load side of the commercial power breaker in parallel with the load side of the two generator transfer switches. The first level of EMP protection will be installed on the load side of the main breaker, connected to the bus bars on the main disconnect switch end of the bars. These bus bars are shown from the rear of the cabinet in Fig. 2. V275HE250 MOVs should be installed at this point from each of the phases to ground to provide common-mode protection. A ground bus is available in the bottom of the cabinet but is not shown in the figure. A piece of 3-in. copper strap can be used to extend the ground bus up the left side of the cabinet, allowing the wiring to the MOVs to be kept short. The MOVs can be mounted on the left side, with the hot lead going to the connection bolt on the bus bar and the ground lead connecting to the copper strap. Differential-mode protection should be provided by installing V480HE450 MOVs from phase to phase at the bus bars. The MOVs can be mounted on the side of the cabinet in a manner similar to the commonmode protectors. A typical installation is depicted in Appendix B-1. Because high voltages and large currents exist in this cabinet, an electrician who is skilled in working on high-power systems should perform the installation of the MOVs on the bus bars in the main power center.

The rear of the power control center on the distribution end is shown in Fig. 3. Second-stage common-mode protection is obtained by installing V275HE250 MOVs on the distribution system from each phase to ground at this point. Second-stage differential-mode protection should be added by installing V480HE450 MOVs from phase to phase. While the second-stage protection is electrically in parallel with the first, sufficient length exists along the bus to allow independent operation of the protection devices. Furthermore, installation of the devices immediately prior to distribution will provide protection for several lines. The V275HE250 and V480HE450 MOVs should be 
mounted on the rear of the front panel as indicated by point a. The ground leads of the MOVs can connect to the neutral bus bar at the existing bolt hole indicated by $b$. Connections to the phases should be accomplished by attaching leads at the bolts indicated by $\mathrm{c}$. Proper location of the MOVs will allow lead lengths to be kept to a minimum.

Figure 4 shows the grounding system in the main power panel. Note that each of the conduits entering from the concrete floor is connected to a copper grounding conductor. This conductor bonds the terminating ends of the conduit to the local ground bus in the cabinet. The grounding arrangement seen in this figure is typical of the grounding in each of the power cabinets. A typical connection to the building ground wire is shown in Fig. 5 where the perimeter ground cable at the ceiling has a branch that connects to a transformer case. All transformers and power panels in the basement equipment room connect to the ground bus in this manner.

The front of the generator transfer switch with the panel door open is shown in Fig. 6. The entire front panel area of the power control center is either on hinged panels or slide-out racks. The bonding between the front panels and the frame should be improved to ensure shielding of the control components in the cabinets. A recommended approach is to install a braid jumper on the hinge side of the 16 doors of the cabinet. These jumpers should be installed by first drilling a hole through the panel to allow a bolt to pass and removing a spot of paint on the inside surface of the door at the point of connection. Coat the surface of the connestion area with conductive cement before clamping the braid under a washer and nut on the back side of the door panel. Connection to the cabinet frame can be accomplished in a similar manner.

\section{Emergency Generators}

The emergency power system for the FRC is composed of two generators in the mechanical equipment room on the lower level of the building. Both generators are KATO $350-\mathrm{kW}$ units and are wired for 277/480-V, 3-phase, 4-wire grounaed wo. These generators are manually started from a compressed air supply and require no battery chargers. Figure 7 shows generator No. 2. The power wiring runs through rigid conduit from the floor into the wiring junction box. The only flexible conduit on the generators is used for status monitoring. These flexible conduits are shown in Fig. 8 and should be paralleled with No. 4 AWG conductive jumpers. Use a ground clamp to attach the wire on the conduit end and a grounding lug to attach to the box on the generator end. Nylon wire ties can be used to hold the wire to the flexible conduit. The generators are essentially identical, and the conduit should be jumpered on both generators.

\section{Motor Control Center}

Referring to the single-line power diagram on FEMA Dwg. 0024-001, the building distribution system branches from the main switch gear area. Major branches from the switch gear include the motor control center and the power distribution panels.

The motor control center is shown in Fig. 9. The modular slide construction of the cabinet does not provide a method of obtaining a satisfactory ground for mounting protection devices in each control module. To ensure proper connections, the protection 
devices should be installed on the incoming wiring to the cabinet bus bar structure. Figure 10 shows the details for the wiring connections. Common-mode protection should be installed by connecting V275HE250 MOVs from each phase to ground at that point. Mount the MOVs to the cabinet wall and connect the hot terminal of each MOV to the wire connection terminal, one MOV per phase. A piece of 3-in. copper strap can be used to extend the ground bus vertically to allow shorter ground connections to the MOVs. Differential-mode protection should be installed by adding V480HE450 MOVs from phase-to-phase. The neutral should be protected by installing a single V275PA40A MOV from neutral to ground. Mount the MOVs on the cabinet wall in a manner to keep the lead length as short as possible. A typical installation is depicted in Appendix B-1.

The bus bars in the chiller power distribution center are shown in Fig. 11. Power to the chillers should be protected by installing V275PA40A MOVs from each phase to ground and V480HE450 MOVs from phase to phase at the bus bars. The HE-series MOVs provide a higher energy capability than is required in this panel but must be used to obtain electrically floating terminals for phase-to-phase connections. The MOVs can be mounted on the side of the cabinet and short jumper wires connected to each bus bar.

\section{Distribution Pancls}

Distribution panel DP1 is shown in Fig. 12. This panel has existing V130LA10A MOVs that should be removed. Install V130PA20A MOVs from each phase to case ground on the load side of the breaker that had been used for the LA-series MOVs. Neutral protection should be provided by installing a V130PA20A MOV from the neutral to ground. Use sheet metal screws or pop rivets to ${ }^{r}$ unt the PA-series MOVs. Differential-mode protection should be added by installing V230LA20A MOVs from phase to phase on the load side of the three breakers used for common-mode protection. Insulate the wire leads of the new LA-series MOVs with heat-shrinkable tubing or Teflon sleeving. Appendix B-2 provides guidance for a typical installation of this type.

Distribution panel DP2 is shown in Fig. 13. This panel contains 277/480-V circuits and presently has two V130LA10A MOVs connected in series from each phase to ground. These MOVs should be removed and common-mode protection provided by installing V275PA40A MCVs from the load side of three adjacent breakers (phases) to case ground. Differential-mode protection should be provided by installing V480LB20A MOVs from phase to phase on the load side of the three breakers. The neutral should be protected by installing a single V275PA40A MOV from neutral to ground. Use either pop rivets or sheet metal screws to attach the PA-series MOVs to the case. Insulate the leads of the LB-series MOVs with Teflon sleeving or heat-shrinkable tubing. The mating surfaces of the cover and box are coated with conductive epoxy, which should be left in place.

Figure 14 shows distribution panel DP3, which is a 120/208-V panel. The circuits fed from this panel should receive common-mode protection by installing V130PA20A MOVs from the load side of three adjacent breakers to case ground. Differential-mode protection should be added by installing V230LA20A MOVs from phase to phase on the load side of adjacent breakers. Install one V130PA20A MOV from neutral to ground to provide protection of the neutral. Follow the instructions for the previous panels concerning mounting of the protectors and insulating of the leads. 
Figure 15 shows dis ribution panel DP4. The circuits fed from this panel are presently protected by Vi.30LA10A MOVs installed from each phase to ground. The common-mode protection should be upgraded by installing V130PA20A MOVs from each phase to case ground. Differential-mode protection should be added by installing V230LA20A MOV's from phase to phase on the load side of the three adjacent breakers. The neutral should be protected with a V130PA20A MOV installed from neutral to ground. The PA-series MOVs should be mounted with either sheet metal screws or pop rivets. Insulate the leads of the LA-series MOVs with Teflon sleeving or heat-shrinkable tubing.

Distribution panel DP6 is shov $\pi$ in Fig. 16. This panel does not presently contain protection and should have V275PA40A MOVs installed on the load side of three breakers, from each phase to ground. Additionally, V480LB20A MOVs should be installed from phase to phase on the load side of the three breakers. Install a V275PA40A MOV from neutral to ground for neutral protection. Insulate the MOV leads and mount the devices as recommended in the discussions for other panels.

\section{Power Panels}

Power panel $\mathrm{A}$ is shown in Fig. 17. The box has an $\mathrm{rf}$ gasket installed on the cover lip but does not have MOVs installed. This panel should receive common-mode protection by installing V130PA20A MOVs from the load side of three adjacent breakers (phases) to case ground. A V130PA20A MOV should be installed from neutral to ground to reduce transients on the neutral of the box. Mount the PA-series MOVs to the case, using either sheet metal screws or pop rivets. Differential-mode protection should be added by installing V230LA20A MOVs from phase to phase on the load side of three adjacent breakers. Use heat-shrinkable tubing or Teflon sleeving to insulate the wire leads of the LA-series MOVs. A pictorial detail of the protector installation is given in Appendix B-2.

Power panel B, shown in Fig. 18, has conductive epoxy on the edges of the cover, and V130LA10A MOVs are installed. The V130LA10A MOVs should be removed and replaced with V130PA20A MOVs, connected from each phase to case ground. Additionally, a V130PA20A MOV should be installed from neutral to ground, and V230LA20A MOVs should be installed from phase to phase on the load side of three adjacent breakers. Insulate the wire leads of the LA-series MOVs with heat-shrinkable tubing or Teflon sleeving. Mount the PA-series MOVs with sheet metal screws or pop rivets.

Figure 19 shows the inside of power panel E. This panel does not presently have EMP protection, and the circuits fed from this panel should receive common-mode protection by installing V130PA20A MOVs from the load side of three adjacent breakers (phases) to case ground. Differential-mode protection should take the form of V230LA20A MOVs installed from phase to phase on the load side of three adjacent breakers. Establish neutral protection by installing a V130PA20A MOV from neutral to ground. Mount and insulate the MOVs, using the procedures described for the other panels. 
Distribution panel K, shown in Fig. 20, supplies power to the outside antenna rotors, pop-up antennas, and the antenna silo sump pumps. The existing V130LA10A MOVs are not presently connected to the circuit breaker terminals. The LA-series MOVs should be replaced with V130PA20A MOVs installed from three adjacent breakers to case ground. V230LA20A MOVs should be installed from phase to phase on the load side of three adjacent breakers. The neutral should be protected with a V130PA20A MOV installed from neutral to ground. Insulate the wire leads of the LA-series MOVs with heat-shrinkable tubing or Teflon sleeving. Mount the PA-series MOVs with either sheet metal screws or pop rivets. Details of the mounting and connection are given in Appendix B-2.

Power panels $\mathrm{H}, \mathrm{F}$, and $\mathrm{G}$ are additional panels that are fed from panel DP1 but are not shown in figures. Each of these panels should receive common-mode protection by installing V130PA20A MOVs from the load side of three adjacent breakers to case ground. Differential-mode protection should be pruvided by adding V230LA20A MOVs from phase to phase on the load side of three adjacent breakers. A V130PA20A MOV installed from neutral to ground will protect the neutral. Use pop rivets or sheet metal screws to mount the PA-series MOVs to the case ground. Insulate the leads of the LA-series $\mathrm{MOVs}$ with heat-shrinkable tubing or Teflon sleeving.

The inside of power panel P1 is shown in Fig. 21. The EMP protection presently installed consists of a V130LA10A MOV installed from phase to ground on two phases and three V130LA10A MOVs installed in parallel from one phase to ground. These devices should be removed and the common-mode protection upgraded by installing V130PA20A MOVs from the load side of the three adjacent breakers to case ground. Differential-mode protection should be added by installing V230LA20A MOVs from phase to phase on the load side of three adjacent breakers. The neutral should be protected by installing a V130PA20A MCV from neutral to ground. Insulate and mount the MOVs as described for other panels. The mating surfaces of the cover for this power panel have conductive epoxy applied, which should remain.

Power panel P2, adjacent to the kitchen area, is shown in Fig. 22. This panel presently has no protection installed. The circuits fed from this panel should receive common-mode protection by installing V130PA20A MOVs on the load side of three acjacent circuit breakers, from phase to case ground. The circuits should receive differential-mode protection by installing V230LA20A MOVs from phase to phase on the load side of three adjacent breakers to case ground. Protect the neutral from transients by installing a V130PA20A MOV from neutral to case ground. Mount the PA-series MOVs to the case ground with sheet metal screws or pop rivets. Insulate the wire leads of the LA-series MOVs with heat-shrinkable tubing or Teflon sleeving.

Figure 23 shows power panel P3, which is in the laundry room. Common-mode protection should be added to this panel by installing V130PA20A MOVs from the load side of three adjacent breakers (phases) to case ground. The neutral should be protected by installing a V130PA20A MOV from neutral to case ground. Mount these MOVs with pop rivets or sheet metal screws. Differential-mode protection should take the form of V230LA20A MOVs installed from phase to phase on the load side of three adjacent breakers. Insulate the leads of the LA-series MOVs with Teflon sleeving or heat-shrinkable tubing. 
Fanel R1 is a 120/208-V panel shown in Fig. 24 and is presently protected by V130LA10A MOVs from phase to ground. The common-mode protection in this panel should be upgraded by removing the LA-series MOVs and installing V130PA20A MOVs from each of the three phases to case ground. Differential-mode protection should be added by installing V230LA20A MOVs from phase to phase on the load side of three adjacent breakers to case ground. Neutral protection should be added by installing a V130PA20A MOV from neutral to ground. Mount the MOVs and insulate the leads as described for other power panels.

Power panel R2, shown in Fig. 25, is in the upstairs hallway. This panel is presently protected on two phases by V130LA10A MOVs. The MOV on the third phase was disconnected but left in place. The protection should be upgraded by removing all existing MOVs and installing V130PA20A MOVs from the load side of three adjacent breakers (phases) to case ground. A V130PA20A MOV should be installed from neutral to ground. Mount these MOVs to case ground, using pop rivets or sheet metal screws. Differential-mode protection should be added by installing V230LA20A MOVs from phase to phase on the load side of three acjacent breakers. Insulate the leads of these MOVs with Teflon sleeving or heat-shrinkable tubing. A mesh gasket, installed on the lip of the power panel, should be left in place.

The last panel on this distribution circuit is panel R3. This panel, shown in Fig. 26, is in the upstairs hallway. Present EMP protection installed in this panel consists of V130LA10A MOVs from each phase to ground and a mesh gasket on the box lip that mates with the cover. The common-mode protection should be upgraded by installing V130PA20A MOVs in place of the LA-series MOVs. Differential-mode protection should be added by installing V230LA20A MOVs from phase to phase on the load side of three adjacent breakers. Neutral protection should be added by installing a V130PA20A MOV from the neutral to case ground. Mount the MOVs and insulate the leads as described elsewhere in the text. Appendix B-2 r rovides guidance for a typical installation of this type.

Panel L3 is a 120/208-V panel that is fed from DP4. This panel, shown in Fig. 27, is presently protected with V130LA10A MOVs. The protection should be upgraded by removing the LA-series MOVs and installing V130PA20A MOVs from the load side of three adjacent breakers to case ground. Additionally, V230LA20A MOVs should be installed from phase to phase on the load side of three adjacent breakers. A V130PA20A MOV should be installed from the neutral to case ground. Insulate the leads of the LA-series MOVs with Teflon slecving or heat-shrinkable tubing. Mount the PA-series MOVs with sheet metal screws or pop rivets.

Figure 28 shows the inside of lighting panel L1. The panel presently has two V130LA10A MOVs in series installed on each 277-V line. These MOVs should be removed and replaced by V275PA40A devices installed on the load side of three adjacent breakers from phase to ground. Neutral protection should be added by installing a V275PA40A MOV from neutral to ground. Mount the PA-series devices to the case with sheet metal screws or pop rivets. Differential-mode protection should be added by installing V480LB20A MOVs from phase to phase on the load side of three adjacent breakers. Use Teflon slecving or heat-shrinkable tubing to insulate the wire leads of these MOVs. 
The outside of lighting panel L2 is shown in Fig. 29. This panel previously had V130LA10A MOVs installed in series on the 277-V lines but these MOVs were disconnected. The old MOVs should be removed from the box and replaced with V275PA40A MOVs installed on the load side of three adjacent breakers from line to ground. Differential-mode protection should be added by installing V480LB20A MOVs from phase to phase on the load side of three adjacent breakers. The neutral should be protected with a V275PA40A MOV installed from neutral to ground. Insulate the leads and mount the MOVs in the manner described for other panels. The lip of this panel box has a wire mesh gasket that mates with the cover plate.

Figure 30 shows the fire alarm breaker panel that is adjacent to the switch gear. This panel has two phases from the $277 / 480-\mathrm{V}$ bus and should be protected from common-mode transients by installing V275PA40A MOVs from the load side of the breaker to case ground on each of the two phases. Differential-mode protection should be implemented by installing a single V480LB20A MOV from phase to phase on the load side of the panel. The neutral for this box is not connected.

The power panel for the telephone sysiem and battery chargers is shown in Fig. 31 . The equipment should receive common-mode protection by installing V130PA20A MOVs from the load side of the circuit breakers to case ground. Differential-mode protection should be added by installing V230LA20A MOVs from phase to phase. A V130PA20A MOV should be installed from the neutral to ground. Use sheet metal screws or pop rivets to mount the PA-series MOVs. The leads of the LA-series MOVs should be insulated with either heat-shrinkable tubing or Teflon sleeving.

\section{Radio Room Filters}

The filter box for the penetration of the lighting power into the shielded room is shown in Fig. 32. The filter is a $25-\mathrm{A}, 120-\mathrm{V}$ assembly that is installed on a $277-\mathrm{V}$ line. The filter should be replaced by one rated for a working voltage of $277 \mathrm{~V}$ to avoid the possibility of a shorted filter should a transient occur. The terminals for the incoming power are shown in Fig. 33. The MOVs that are presently installed are LA-series devices rated at $420 \mathrm{~V}$. These MOVs are wired across a jumper in such a manner that the protector is shunted by the wire. When the filter is replaced, the present protectors should be removed and V275PA40A MOVs installed from each input terminal to the case ground. The output of the filter is shown in Fig. 34 with V275LA20A MOVs installed from each line to ground. When the filter is replaced, V275PA40A MOVs should be installed on the output side, from each line terminal to case ground.

The power wiring leading into the shielded radio room is filtered at the entry bulkhead. Figure 35 shows the wiring on the input side of the filter. The input should be protected by installing V130PA20A MOVs from each of the three phases to case ground. The output terminals of the filter are shown in Fig. 36. V130LA10A MOVs were once installed on the output terminals, but one MOV has been burned and the others have been disconnected. These MOVs should be replaced with V130PA20A devices installed from each phase to ground. The filter itself has broken insulators on the feedthrough connections. The filter housing has holes in the shielding where screws have penetrated, compromising the effectiveness of the filter against radiated EMP. It is recommended that the filter be replaced before the MOVs are installed. 


\section{Radio Room Panels}

Power for equipment in the shielded enclosure is fed by distribution panel DP5 on the inside wall of the shielded room opposite the power filter. Figure 37 shows the inside of the distribution panel with the ncoming wiring entering through the conduit in the rear. Common-mode protection should be provided by installing V130PA20A MOVs on the load side of three adjacent circuit breakers, from phase to ground. Differential-mode protection should be added by connecting V230LA20A MOVs from phase to phase on the output side of three adjacent breakers. A V130PA20A MOV should be added from neutral to ground to protect from transients on the neutral. Additionally, a mesh gasket should be installed on the lip of the box where it mates with the cover. Approximately $7 \mathrm{ft}$ of gasket material will be required.

Power panel $\mathrm{C}$, installed inside the shielded room, is shown in Fig. 38. This panel should have V130PA20A MOVs installed from the load side of three adjacent breakers to case ground for common-mode protection. Install V230LA20A MOVs from phase to phase on the load side of three breakers to provide differential-mode protection. A single V130PA20A MOV should be installed from the neutral to ground. Mount the PA-series MOVs to case ground, using either sheet metal screws or pop rivets. Use Teflon sleeving or heat-shrinkable tubing to insulate the wire leads of the LA-series MOVs.

Figure 39 shows the inside of power panel D in the shielded room. This panel does not presently have protective devices. Circuits fed from this panel should be protected from common-mode transients by installing V130PA20A MOVs on the load side of three adjacent breakers from phase to ground. Differential-mode protection should be provided by installing V230LA20A MOVs from phase to phase on the load side of three adjacent breakers. Neutral protection should consist of a V130PA20A MOV installed from neutral to ground. Mount the MOVs as described for the other panels.

The circuit breakers for one of the Harris transmitter racks are shown in Fig. 40. The power to these breakers is fed directly from the distribution panel DP5 in the shielded enclosure. The power transformers and factory-installed MOVs are shown in Fig. 41. The MOV arrangement consists of V275PA40 MOVs installed from phase to ground and V275LA20 MOVs installed from phase to phase. This MOV protection assembly is connected to the $240-\mathrm{V}$ tap on the transformer bank, rather than directly across the power line. The incoming power is $120 / 208 \mathrm{~V}$ and does not have protection installed at the transmitter. Installing the MOVs on a transformer tap allows a generic design that sizes the protectors independently of the supply voltage, but maximum protection in not achieved in this manner. A recommended approach is to install V130P.A20A MOVs on the incoming power lines at the transmitter, with one MOV from each phase to chassis ground for common-mode protection. V230LA20A MOVs should be installed from phase to phase. This protection can be installed in addition to the existing MOVs because the inductance of the transformer will separate the action of the MOVs. Both the Harris Group 1 and Harris Group 2 equipment should be protected in this manner. 


\section{B. Electrical Motors and Life-Support Systems}

The motor control center that powers many of the motor and life-support loads for the FRC is shown in Fig. 9. The modularity of the control contactors restricts the availability of a good ground for locating protective devices on the line side of the contactor, as is the normal practice. Because each contactor plugs into the bus bar network of the control center, a suitable compromise for common-mode protection is to install one set of V275HE250 MOVs at the connection point for the incoming wiring, as shown in Fig. 10. Differential-mode protection should be in talled by adding V480HE450 MOVs from phase to phase. The neutral should be protected by installing a single V275PA40A MOV from neutral to ground. The installation of these MOVs is discussed in Sect. III.A.3 under electrical power protection.

The control switch for the air makeup heater for incoming air is shown in Fig. 42. The switch operates at $277 / 480-\mathrm{V}$ three phase and the circuits are presently protected by two V130LA10A MOVs installed in series on each phase. These devices should be removed and the common-mode protection upgraded by installing a V275PA40A MOV from each phase to case ground. Additionally, V480LB20A MOVs should be added from phase to phase. Insulate the leads of the LB-series MOVs with Teflon sleeving or heat-shrinkable tubing.

The chiller controls, shown in Fig. 43, receive power from the panel that will be protected as indicated in Sect. III.A.3 (see Fig. 11). Because the wiring is routed in conduit, it is not necessary to protect the power at each of the chillers. The bundle of unused wires in the control conduits should be removed, however, to avoid coupling of EMP into the operational control wiring. The second chiller should likewise have all unused wiring removed.

Figure 44 shows the contactor for the primary chiller water pump. The pump should be protected by installing a V275PA40A MOV on each phase from the line side of the contactor to case ground. Differential-mode protection should be added by installing V480LB20A MOVs from phase to phase on the line side of the contactor. The contactor coils are presently protected by a V130LA10A MOV installed across each coil. These MOVs provide sufficient protection and should remain in place. An identical contactor is used for the backup chiller pump. The backup chiller should have V275PA40A MOVs installed on the line side of the contactor from phase to ground and V480LB20A MOVs installed from phase to phase on the line side of the contactor. Each contactor coil on the backup system is presently protected by a V130LA20A MOV that should be left in place.

The contactors for chiller circulating pumps 6 and 7 are shown in Fig. 45. These pumps should be protected from common-mode transients by installing V275PA40A MOVs on the line side of each contactor, from each phase to case ground. The pumps should have differential-mode protection added by installing V480LB20A MOVs from phase to phase on the line side of the contactor. Insulate the leads of the LB-series MOVs with heat-shrinkable tubing or Teflon slecving. The power to these contactors is supplied from panel DP2. 
Figure 46 shows the contactor for one of the duct heaters on the air handling system. V130LA10A MOVs are presently installed on the load side of the contactor from each phase to ground and from each side of the contactor coil to ground. The heating elements themselves are not particularly sensitive to transient surges, but arcing from the element to ground at the support insulators could cause failure of the element. The existing V130LA10A MOVs are considered sufficient to prevent arcing at the insulators. A second type of heater contactor is shown in Fig. 47. The coil for the contactor is protected with V130LA10A MOVs installed from each terminal to ground. The lines feeding the heater elerients should be protected by installing V130LA10A MOVs from each phase to ground on the load side of the contacter. Installation of the MOVs on the load side of the contactor is permissible because this heaters represent a primarily resistive load. These heater control boxes are representative of six other control boxes. All of the boxes presently have V130LA10A MOVs installed on the contactor coils but need V130LA10A MOVs installed on the power lines.

The day tank and pump for the generator fuel supply is shown in Fig. 48. The power leads to the pump are routed in conduit from the motor control center where protectors will be located. No connection points for protectors are available closer to the motor.

Figure 49 shows the air compressor used to fill the bladder for the door seal into the shielded enclosure. The power to this compressor should be protected by installing a plug-in MOV at the receptacle that powers the compressor. A three-way cube tap will be required when installing the MOV.

\section{Fluorescent Lighting}

The fluorescent lights in the Bothell FRC should be EMP-protected by installation of MOVs in the fixtures to be protected (see Appendix B-3). The fluorescent lamps in the FRC have $277-\mathrm{V}$ ballasts and should be protected by installing V275LA20A MOVs inside the fixture housing across the ac power leads to the ballast with one MOV from line to neutral and one MOV from line to fixture ground. Use heat-shrinkable tubing to insulate the bare leads on the MOVs. The FRC personnel identified 623 fluorescent lights that should be protected.

\section{Emergency Lighting}

The emergency lighting in the FRC consists of both battery-powered floodlights and battery-powered fluorescent lamps. A typical battery-powered floodlight is shown in Fig. 50 with an inside view of the terminal strips shown in Fig. 51. A portion of the emergency lights such as those in the equipment room had EMP protection installed. Others in the rest room and lunchroom did not have any protection. The lights with protection had V130LA10A MOVs installed on the 120-Vac input with one MOV from hot to neutral and one MOV from neutral to ground. The MOVs should be removed and reinstalled from hot to neutral and hot to ground. Those lights without EMP protection should have MOVs installed from hot to neutral and hot to ground. Use heat-shrinkable tubing on the bare MOV leads to prevent accidental short circuits. A total of 32 of these lamps should be protected. 
A typical fluorescent emergency light is shown in Fig. 52. The light uses a Teledyne Big Beam model EFB-40 emergency backup ballast in conjunction with the regular ballast. Power to the light is from a 277-V circuit that connects to the emergency ballast. These lights should be protected by installing V275LA20A MOVs from line to neutral and line to case ground at the wire nut connections between the ballast and the power line. The white wire is the neutral and the black/orange connection is the $277-\mathrm{V}$ line. Use heat-shrinkable tubing to insulate the bare leads on the MOVs. The FRC has 50 of these fluorescent emergency lights to protect.

\section{E. Blast Doors}

The FRC has pneumatically activated blast doors that control the outside air for the building ventilation system. An EMP detector provides an automatic control for these doors.

The EMP detector for the blast door control is shown in Fig. 53. The incoming ac power line has V130LA10A MOVs installed from hot to neutral and from hot to ground. The control lines have 1.5KE7.5C hipolar zeners from line to ground on those conductors that carry $6 \mathrm{~V}$ and a $1.5 \mathrm{KE} 16 \mathrm{C}$ bipolar zener diode installed from line to ground on the signal output line. The aboveground EMP detector is protected with P6KE8.2C bipolar zeners on the four $6-\mathrm{V}$ lines and a $1.5 \mathrm{KE} 16 \mathrm{C}$ bipolar zener on the signal output line, from conciuctor to ground. A schematic dicigram of the charger with the installed protection devices is shown in FEMA Dwg. 0024-002. The enclosure has been coated with silver conductive cement on the lip edge and on the corresponding portion of the door. The previously installed EMP protective devices are in place on the blast door control system, and no additional protection will be provided.

The blast doors are activated from a compressed air supply controlled by solenoids. The solenoids are rated at $24 \mathrm{Vdc}$ with a current of $1.4 \mathrm{~A}$. The coils should be protected by installing one V39ZA6 MOV across the coil winding and one V39ZA6 MOV from the high side of the line to the solenoid case ground. Eight of these valves are installed in the FRC.

The solenoids for the blast doors are activated from a battery-powered 24-Vdc supply. The battery charger should be protected by installing V130LA10A MOVs from hot to neutral and hot to ground on the primary side of the transformer. The charger output should have V39ZA6 MOVs installed from positive to negative and positive to ground.

\section{SHIELDED RADIO OPERATIONS ROOM}

The EMP shielded radio room is fabricated from welded steel panels that form an L-shaped chamber as illustrated in FEMA Dwg. 0024-003. A sliding metal door with a pneumatic bladder sealing mechanism allows personnel entry into the room. All electrical power lines are connected through filters, and signal lines are routed through single entry panels that have provisions for installing 'ransient suppression on each conductor. The heating and air conditioning ventilation ducts have waveguide and honeycomb cutoff filters at the wall penetrations to the room. 
Figure 54 shows the inside of the air duct that furnishes ventilation to the shielded room. The air duct has internal metal baffles that reduce the cross section of the air duct so that it acts like a waveguide filter to EMP freq"encies. Visual inspection indicated that the air duct baffles were in good condition.

The honeycomb filter for the return air ventilation duct is shown in Fig. 55. This honeycomb duct filter is clean, and visual inspection indicates that the filter is in good condition.

The personnel door to the shielded radio room opens and closes by sliding horizontally in a track. The edges of the door, shown in Fig. 56, are coated with a porous conductive metal coating that mates to the conductive door facing when the door is closed and the pneumatic bladder is activated. The rubber bladder for the door of the Region $\mathrm{X}$ FRC has a leak and does nol hold air. An auxiliary air compressor was installed by FRC personnel to maintain air pressure to keep the door sealed. The rubher bladder should be repaired or replaced so that an EMP-tight seal can be maintained for longer periods of time.

The penetrations for the power into the shielded room are discussed in Sect. III of this report. The coaxial cable penetrations and the associated protectors are described in Sect. V. The single entry panels and protection for the telephone, data, control, and communications lines are discussed in Sect. VI.

\section{ANTENNA AND RADIO SYSTEM}

\section{A. Antenna System}

The antenna system for the Bothell FRC is distributed around the area outside the facility. A layout of the antenna system is given in FEMA Dwg. 0024-004. There are eight outside antennas capable of being driven from the 10-kW Harris single-sideband (SSB) transmitters. These antennas include rotatable log periodics (RLPs), fixed log periodics (FLPs), two blast-hardened pop-up antennas, fan doublet antennas, and a full-size Spira-cone. Additionally, several antennas are dedicated to other vhf and uhf equipment.

The coaxial cables from the antennas to the vault are generally $1-1 / 4$ or $1-5 / 8$ in. Heliax. These cables are currently adapted to $7 / 8$-in. Heliax in the vault before entering the shielded room. A view of the inside of the vault is given in Fig. 57. One of the Heliax adapter flanges is shown in the foreground. A junction box for the control lines of the north RLP-1 is in the background. The RLP-1 junction box has gas gaps installed between each line and ground. Protectors are not required at this point, but the existing devices will be left installed. The rust on the lip of the box should be removed and the lip coated with conductive epoxy cement before installing the box cover. Other junction boxes in the vault do not have protectors installed, but the box covers should be installed. A plug-in MOV will be provided for the receptacle that powers the sump pump.

The grounding of the towers, baluns, and antenna equipment at the Region X FRC is in need of a general upgrade. Many of the towers have only one ground wire, and the condition of the grounding network beneath the carth's surface is unknown. It is 
recommended that a grounding counterpoise, composed of six radials of 60 - $\mathrm{ft}$ sections of 5/8-in. copper tubing, be installed under each tower or antenna. The 5/8-in. copper tubing constitutes a lower impedance conductor and provides better mechanical strength and physical survivability of the counterpoise grounding network than would be obtained from small tubing or copper wire. Typical layout examples for counterpoise installations are shown in FEMA Dwg. 0024-005. Fan doublets and broadband dipoles should have counterpoises installed under each tower. Rotatable log periodics, the Spira-cone, and other single-tower installations should have one counterpoise under the tower. The copper tubing from the radials should be brought to the tower structure and fastened as illustrated in FEMA Dwg. 0024-006. Baluns near the ground should have the radials connected to the balun housing. Other applications should bring the radials together in a bundle and employ a copper strap or No. 4 AWG copper wire from this hub to the antenna device. Any existing ground rods near the towers can be connected to the counterpoise hub, but the counterpoise will constitute the major grounding mechanism.

The shield ground for the Heliax from RLP-2 is shown in Fig. 58. An Andrew grounding kit has been installed on the Heliax and a piece of braid extended down the tower leg to the grounding connection. Figure 59 shows the base of the tower where the braid connects to a piece of copper tubing that goes into the ground. This type of coaxial shield grounding is desirable, and Andrew grounding kits should be installed on the shields of each Heliax cable at the base of the tower. However, the integrity of the ground for the tower and shield should be upgraded using the recommendations presented previously in this section.

The power box for the rotor of RLP-2 is shown in Fig. 60. The box presently has V130LA10A MOVs installed. These should be removed and a V130PA20A MOV installed from the load side of the breaker to case ground. The V130LA10A MOVs should be installed from line to neutral and neutral to ground on the load side of the breaker. Similar protection should be installed for the other RLP antennas.

The control wiring for the rotor on RLP-2 is shown in Fig. 61. This box should have V130LA10A MOVs installed from each conductor to ground.

Figure 62 shows the base of the Spira-cone tower. Andrew grounding kits should be installed on the shields of the two Heliax cables at the point the cables leave the tower. The tower is presently grounded with a No. 4 AWG solid conductor that ties to a ground system off the edge of the concrete pad. The grounding of the tower should be improved in accordance with the recommendations presented in this section. The cable bundle on the concrete pad is a $6 / 3$ cable from the FRC to the Spira-cone that will be used for power in a utility box. A V130PA20A MOV should be installed from hot to ground and V130LA10A MOVs installed from hot to neutral and neutral to ground in the terminating box.

The control box for RLP-1 is shown in Fig. 63. The control lines are presently protected with CG-230 gas gaps and $5-\Omega$ resistors in series installed between each conductor and ground. These protectors should be removed and replaced by V130LA10A MOVs installed from each conductor to case ground. The rust and corrosion in the box and on the terminals should be cleaned at the time that protection is upgraded. 
Figure 64 shows the base of the tower for RLP-1. The tower has a single ground wire that connects to the conduit and a grounding network. Upgrade of the tower grounding is recommended.

The balun for FLP-1 is shown in Fig. 65. An open transmission feed line connects the antenna to the balanced side of the balun. The antenna side of the balun should be protected with UGT-7.5 gas tubes installed from each terminal to case ground. Each gas tube should be shunted with a $100-\mathrm{k} \Omega, 100-\mathrm{W}$ resistor to provide a de static drain. FEMA Dwg. 0024-007 provides details of a typical protector installation for baluns of this type. The ground connection to the conduit was loose at the time of the survey and should be tightened. The general antenna grounding recommendations presented in this report should be applied to this antenna.

The base of the support tower for FLP-1 is shown in Fig. 66. The tower presently has one ground wire that attaches to the base and connects to an undetermined grounding network. The grounding for the tower should be upgraded, using the guidelines presented in FEMA Dwgs. 0024-005 and 0024-006.

Figure 67 shows a fan doublet antenna with the balun mounted near the top of the center post. Grounding for each tower should be checked and upgraded as necessary. The balun on the antenna is similar to the one shown in Fig. 68. The balanced terminals of the balun should be protected by installing UGT-7.5 gas tubes from each terminal to case ground. A $100-\mathrm{k} \Omega, 100-\mathrm{W}$ resistor should be used to shunt the de path across each gas tube. FEMA Dwg. 0024-007 supplies details for protection of this type of balun.

The rotor box for one of the new RLP antennas is shown in Fig. 69. The incoming power terminals should have V130LA10A MOVs installed from line to neutral and line to ground. The control lines should be protected by installing V130LA10A MOVs from each conductor to case ground.

\section{B. Shielded Room Coaxial Penctrations}

Coaxial penetrations into the shielded radio room of the FRC are through a single-entry area near the power and signal entry points. Coaxial penetrations are divided into high-power and low-power lines, with type LC-HN feedthroughs for the higher power Heliax cables and type $\mathrm{N}$ bulkhead connectors for the lower power cables. Protection devices are not presently installed on the coaxial lines entering the enclosure. The layout for the penetration configuration is shown in FEMA Dwg. 0024-008.

Protection for the high-power coaxial penetrations from the rf switching matrix will be sized to handle the $10-\mathrm{kW}$ peak envelope power (PEP) output from the Harris transmitters. Several inputs to the matrix are from lower power transmitters that supply 125 or $500 \mathrm{~W}$. Staged protection will be utilized for equipment that is routed through the rf matrix. The first-level protection at the bulkhead will be sized for the $10-\mathrm{kW}$ transmitters. These protector values for the high-power lines should be $6 \mathrm{kV}$, based on a $10-\mathrm{kW}$ transmitter output driving a 5()- $\Omega$ line with a voltage standing wave ratio (VSWR) of $4: 1$. Each individual transmitter that is routed through the matrix will have a secondary protector sized for the appropriate clamping voltage, based on the transmitter power. This secondary protector should be installed at the output of the transmitter. 
Figure 70 shows the high-power coaxial penetrations on the outside of the shielded room. The connectors are type $\mathrm{HN}$, and 7/8-in. Heliax extends between the bulkhead plate and the connection vault on the outside of the FRC. The 7/8-in. cable is used to provide flexibility for the interconnections in the limited space between the shielded room and the building wall. However, the peak voltage breakdown rating of $7 / 8$-in. Heliax is marginai when considering the transients that may arise during an EMP event or lightning strike. When a coaxial gas tube arrester fires, the low impedance reflects the transient back along the transmission line and sets up standing wave voltages. These voltages, added to the existing $10-\mathrm{kW}$ transmitter power, can exceed the breakdown voltage of the cable or its connectors. A larger Heliax that is capable of withstanding higher peak voltages is recommended in place of the existing 7/8-in. conductors. Additionally, the penetrations for these high-power cables should be upgraded to EIA-type flanges and coaxial flange protectors with a $6-\mathrm{kV}$ rating. Appendix $\mathrm{C}$ of this report contains calculations and data sheets for sizing the coaxial cables and connectors for the Harris equipment.

The penetrations for the high-power Heliax cables on the inside of the shielded room are shown in Fig. 71. The connectors on this side of the penetration are type LC and are mated to 7/8-in. Heliax that extends to the switching matrix. Again the 7/8-in. Heliax provides flexibility but has an insufficient peak voltage rating. Figure 71 shows two penetrations that do not have cables attached. All unused coaxial penetrations should have a termination installed. A connector with an internal shorting jumper is ideal for this application. Note also that no coaxial protectors are currently installed on these antenna lines, either inside or outside of the bulkhead.

Personnel at the Region X FRC expressed a desire to have the high-power coaxial penetrations upgraded. This upgrade would replace the existing LC-HN penetrations with EIA-type flanges. Additionally, an interest was expressed in having the number of high-power penetrations increased from 10 to 20. A detailed design for a general upgrade of the FRC penetrations is presently being pursued. If an upgrade is performed, it will be issued as an addendum to this report.

The use of HN-LC penetrations for the high-power coaxial lines is generally consistent at all of the FRCs. Likewise, the use of 7/8-in. Heliax inside the shielded room seems to be consistent from one facility to the next. However, the details of the actual penetrations are unique to each facility, depending on the physical layout of the building and the shielded room. Because the difficulties associated with this upgrade are similar at all of the Regional FRCs, it is recommended that any changes be agreed upon by all Regional personnel involved in order to develop a standardized installation within FEMA.

The eight low-power type $\mathrm{N}$ penetrations through the bulkhead are shown on the outside of the room in Fig. 72, while Fig. 73 shows the same penetrations on the inside of the room. Note that coaxial protectors are not installed on either side of the bulkhead. FEMA Dwg. 0024-008 supplies information for the protection of these coaxial lines.

Protection details for the individual pieces of radio equipment are presented in Sect. V.C. of this report. However, the listing of the coaxial protectors that are installed at the bulkhead will be presented at this time for clarity. 
The vlf receiver should be protected at the bulkhead with an FCC-450-3.3-L coaxial protector. The satellite vhf, satellite uhf, Duty Officer Radio, and Marine Radio should each have FCC-250-75-N coaxial protectors installed at the bulkhead. The Public Information Officer radio should have an FCC-250-230-N protector installed at the bulkhead. Finally, the Corps of Engineers radio should have an FCC-250-350-N coaxial protector installed at the bulkhead entry to the shielded room. The specific details of these radios and other protective measures are given in Sect. V.C.

\section{Radios and Communications Center Equipment}

The shielded radio room is arranged with a console area, an equipment area, a high-power area for the Harris Group 1 and 2 equipment and switching matrix, and a maintenance area. Receivers, transceivers, and various controllers are in the consjie area in the front of the room.

An rf switching matrix allows the FRC personnel to connect the outputs of different transmitters to any of ten antenna lines. The matrix is arranged so that the antenna lines enter the matrix at the top and are routed to form the columns of the matrix. The transmitter outputs form the rows of the matrix and electrically controlled plungers connect the appropriate cross points. The back of the matrix is shown in Fig. 74. The incoming antenna lines have UGT-4.0 gas discharge tubes from center conductor to ground at the rear of the coaxial connectors. These tubes are undersized for a $10-\mathrm{kW}$ transmitter working into a 4:1 VSWR. The 4-kV tubes should be removed and replaced by UGT-6.0 devices installed from the center conductor to ground. The control transformer for the rf matrix is shown in Fig. 75. The transformer has a 120-Vac input that should be protected by installing V130LA10A MOVs from hot to neutral and hot to ground at the terminal strip. Lugs should be installed on the wire leads of the MOVs, and either heat-shrinkable tubing or Teflon sleeving should be used to insulate the leads.

Figure 76 shows the rear of the Harris RF-745-02 Group 1 and Group 2. The $1-\mathrm{kW}$ driver stage connects through a coaxial cable to the $10-\mathrm{kW}$ power amplifier, but the driver can be configured to operate in a $1-\mathrm{kW}$ mode to the antenna. An FCC-250-1000-N coaxial protector should be installed on the coaxial line at the connector to the driver. The receiver inputs should have an $\mathrm{N}$-type coaxial protector installed on the receiver side of the transmit/receive switch. A protector is presently being developed for use on the hf receivers at the FRCs and will be supplied when available. Both the Group 1 and Group 2 equipment should be protected in this manner.

The Harris A1 and A2 equipment racks are shown in Fig. 77. Rack A1 contains a 1-kW driver which should be protected with an FCC-250-1000- $\mathrm{N}$ coaxial protector installed on the connector to the driver. A BNC-type coaxial protector designed for the FRCs should be installed on the receiver side of the transmit/receive switch. The A2 rack contains four receivers that should be protected with the BNC version of the new hf coaxial protector that is being designed for use at the FRCs. Both cabinets should have plug-in MOVs installed in the power strips.

Figure 78 shows the KWT-6 No. 1 and the auxiliary equipment rack No. 1. The KWT- 6 has a BNC connector on the frequency generator and should be protected with an FCC-450-3.3-BNC coaxial suppressor. The transmitter has a 1-kW output and should 
have an FCC-250-1000-N coaxial protector installed at the output of the transmitter. Two Collins monitor receivers have RCA-type connectors and should be protected with the $\mathrm{RCA}$ version of the new coaxial protector that is being designed for the hf receivers at the FRCs. The satellite communications unit has both vhf and uhf coaxial lines. Each line should have an FCC-450-3.3-L diode bridge installed inside the unit 0 , the receiver side of the transmit/receive switch. The transmit line of each should have an FCC-250-75-N protector installed at the bulkhead feedthrough to the shielded room. Power in the KWT-6 rack should be protected by installing V130LA10A MOVs across the power terminals. The auxiliary equipment rack should have a plug-in MOV installed in the power strip.

The Collins KWT-6 No. 2 unit is shown in Fig. 79. The receiver should be protected with a BNC version of the new coaxial protector being developed for the hf radios at the FRCs. The transmitter should have an FCC-250-1000-N coaxial protector installed at the output to the transmitter. Protect the ac power into this rack by installing V130LA10A MOVs across the power terminais.

Figure 80 shows the auxiliary equipment rack No. 2. The Motorola Micom S is a $125-\mathrm{W}$ SSB radio that operates over $2-18 \mathrm{MHz}$. This radio should have an FCC-250-470-UHF protector installed at the rear of the radio. A Collins receiver in the same rack should have an RCA phono plug version of the new style hf protector that is being developed. The Marine radio operates with 25-W FM output in the 154-160 MHz band. This radio should be protected with an FCC-250-75-N inline coaxial protector installed at the bulkhead feedthrough to the room. The Fluke vlf receiver should have an FCC-450-3.3-N coaxial protector installed at the bulkhead feedthrough to the room. Power to this rack should be protected by installing a plug-in MOV in the power strip in the rear of the cabinet.

The Public Information Officer radio is shown in Fig. 81. This radio is a GE MASTR Executive II unit with $45-\mathrm{W}$ output in the $460-\mathrm{MHz}$ band. The transmitter should be protected by installing an FCC-250-230-N inline coaxial protector at the bulkhead to the shielded room. The receiver should have an FCC-450-3.3-L diode bridge installed on the receive side of the transmit/receive switch.

Figure 82 shows the Corps of Engineers Motorola Micor radio that operates with $115 \mathrm{~W}$ at $163 \mathrm{MHz}$. The transmitter should be protected by installing an FCC-250-350-N inline coaxial protector at the bulkhead penetration to the shielded room. The receiver should have an FCC-450-3.3-Phono protector installed on the receive side of the transmit/receive switch.

The Duty Officer Radio (DORS) is shown in Fig. 83. This radio operates in the $139-140-\mathrm{MHz}$ band with $25 \mathrm{~W}$ of $\mathrm{rf}$ power output. The transmitter should be protected by installing an FCC-250-75-N inline coaxial protector at the bulkhead penetration to the shielded room. The receiver should be protected by installing an FCC-450-3.3-L diode bridge on the receive side of the transmit/receive switch.

The rear of the receive multicouplers and active preselectors are shown in Fig. 84. The input to the multicouplers should be protected with the BNC version of the new hf coaxial protector that is being designed for the FRC receivers. The receive preselectors 
should be protected with the UHF version of the same protectors. A plug-in MOV will be supplied for the power strip in the rack.

The rear of the main operating console is shown in Fig. 85. The power to the console should be protected by installing a plug-in MOV in each of the two power strips.

Figure 86 shows the rear of the test and teletype equipment rack. The power strip to the cabinet should have a plug-in MOV installed. The rear of the modem bay cabinet is shown in Fig. 87. This cabinet should likewise have a plug-in MOV installed in the power strip. The audio patch and test rack and the work bench area should each have one plug-in MOV installed in the power strips.

Every cabinet in the shielded room is connected to a green ground wire that runs in the wire duct in the floor. The connections between this conductor and each cabinet should be inspected to verify that the junction is tight.

\section{TELEPHONE AND CONTROL LINES}

The signal, control, and telephone lines into the EMP shielded radio room enter through a single-entry area near the power and coaxial penetrations. Several entry boxes are employed for the penetrations with the terminals in the boxes, using either screw-type barrier strips or telephone-type punch blocks. Every signal or control pair entering the shielded room must have a transient protector installed from conductor to ground to limit the voltage that is conducted into the room. The arrangement of the lines and the recommended protectors are shown in FEMA Dwg. 0024-009.

\section{A. FRC Telephone Cable Protection}

The Region X FRC has a dedicated telephone room which houses the telephone switch gear and termination blocks for both internal and external telephone wiring. Figure 88 shows punch blocks on the right and heat coil protectors in the box on the left. The heat coils were the only protection devices found in the facility. Neither carbon discharge protectors or gas gap protectors were found on any of the incoming cable bundles.

Although not covered under the scope of the EMP upgrade, it is recommended that protection be upgraded on the incoming telephone lines. Commercially available telephone-type gas gap protector blocks should be installed on the incoming lines to the facility and on selected lines within the facility. FRC personnel indicated the need for three 25-pair protector blocks. When installed, the ground from the protector blocks should be connected to the building ground bus.

Figure 89 shows a portion of the existing telephone terminal blocks. The terminal block hanging in the upper left corner of the figure is an unterminated cable that runs to the shielded enclosure. This cable should either be properly terminated or removed to avoid conducting EMP currents to the shiclded room cable entry area. 


\section{B. Shiclded Room Penctration Protection}

Figure 90 shows terminal boxes TB2-TB4 with protectors installed. FEMA Dwg. 0024-009 gives the layout for the terminal boxes and the general function of the cables and the installed protection. TB1 has telephone cables that are currently protected by CG-230 gas gaps. Additional punch blocks should be added in this box to accommodate six pairs that are not currently protected. TB2 contains the control lines for the pop-up antennas. These lines are currently protected with V130LA10A MOVs from each conductor to ground. Miscellaneous control for remote antennas are routed through TB3. These lines are presently protected by assorted values of MOVs and zener diodes. The control lines for two log periodic antenna systems are on the terminals of TB4. These lines have $115 \mathrm{~V}$ applied and are protected with V130LA10A MOVs. TB5 contains data lines to and from external sources and are not currently protected. The voltage levels on these lines should be determined, and the appropriate protectors should be installed.

The terminal box on the inside of the shielded room is shown in Fig. 91. These terminals are the inside equivalent of the outside boxes. No protectors will be installed on these inside terminals; however, the unused wiring pairs should be removed.

A spare box with protected terminals is shown in Fig. 92. The box presently has gas gaps, but the protectors should be sized to provide the lowest clipping level possible for the signal lines that are installed in the box. The cable that is routed through the box without protection should be removed. The inside view of the cable is shown in Fig. 93. The cable comes through a conduit in the wall without any transient protection. The cable is not currently in use and should be removed and the conduit penetration plugged with metal caps.

Figure 94 shows the ground bus penetration for the telephone lines in the shiclded room. This bus is isolated from the room ground but has two V130LA10A MOVs in parallel between the telephone ground and the room ground. These MOVs should be removed and replaced by a V130PA20A MOV installed from the ground bus to the cabinet (room) ground.

A general upgrade is recommended for improving the telephone, control, and signal line penetrations into the shielded room. Additional punch block space should be added to accommodate protector installation on all conductors entering the shielded room. The wiring should then be reorganized to place associated functions with similar voltages into the same panel areas. Cables should be routed through the sides of the penetration box rather than the front of the box to allow the covers to be installed on all boxes. Every cable pair entering the room should be identified to allow properly sized protectors to be installed based on the voltages on each pair. 


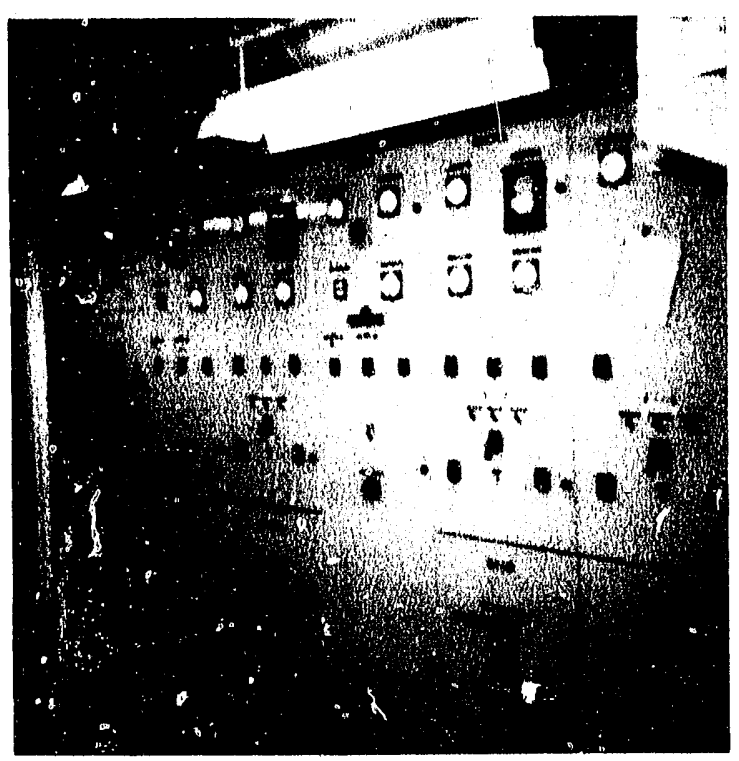

Fig. 1. Main power panel with commercial power disconnects, manual transfer switches, and feeder disconnects. MOVs will be installed in the rear of this panel.

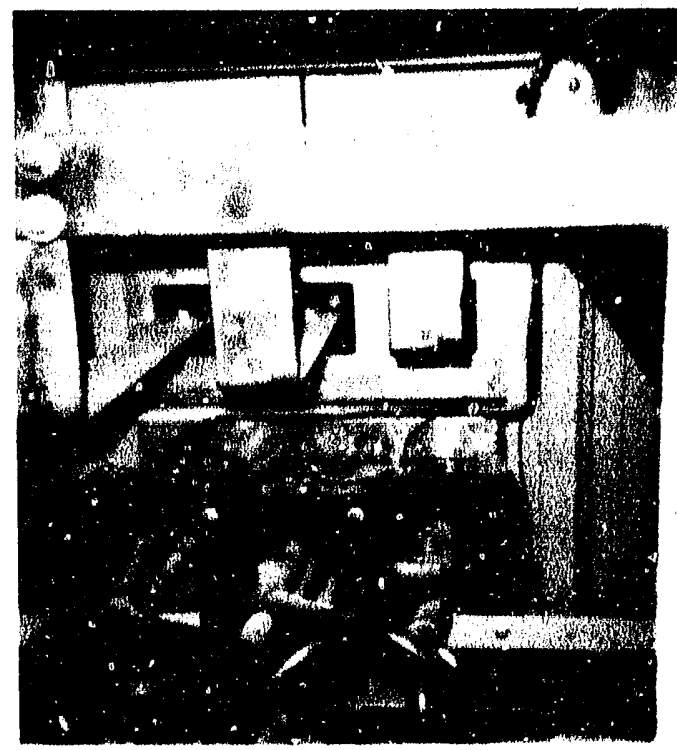

Fig. 2. Bus bars for installation of MOVs. Install V275HE250 MOVs from each phase to ground and V $480 \mathrm{HE} 450$ MOVs from phase to phase on each bus bar at the main disconnect switch end of the cabinet. 


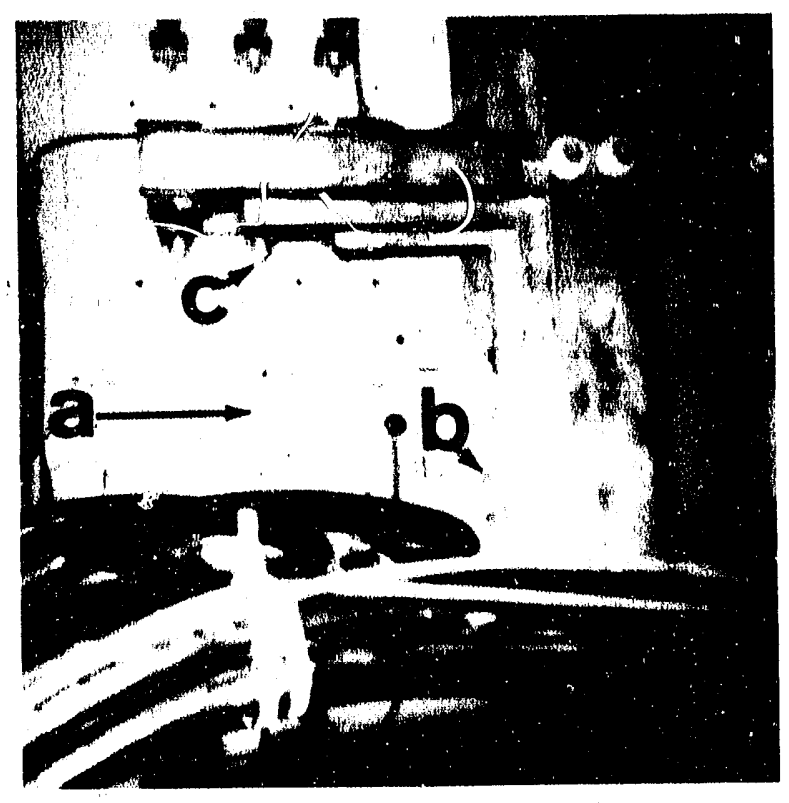

Fig. 3. Bus bars on distribution switch end of the power center. Install

V275HE250 MOVs from each phase to ground and V480HE450 MOVs from phase to phase on each bus bar. Mount the MOVs on the panel as indicated by a. Connection to the neutral bus bar can bc: established at point $b$. Connections to the phases can be made at the bolts indicated at $\mathbf{c}$.

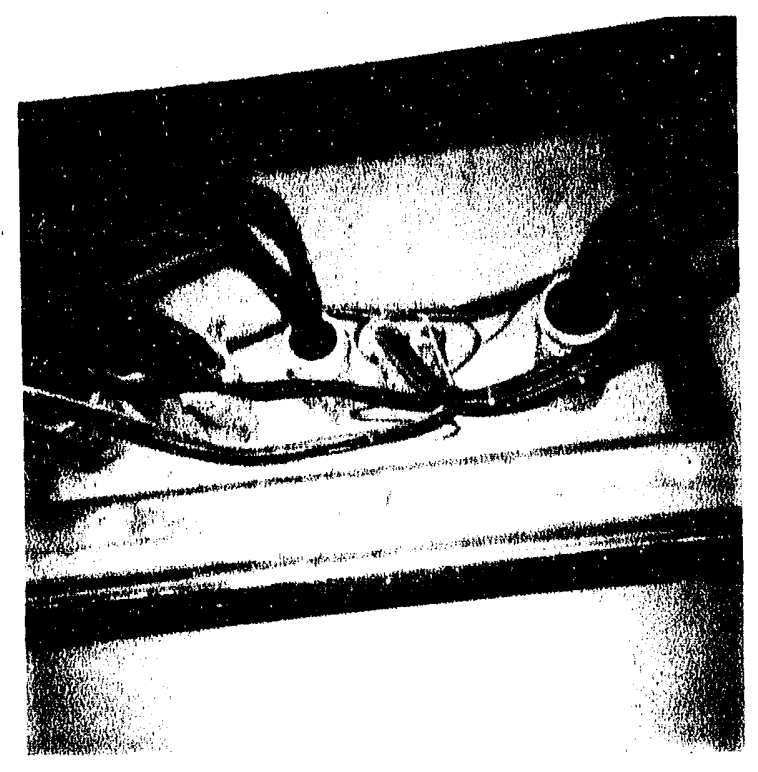

Fig. 4. Grounding system in main power center. Each conduit is bonded to a copper conductor that ties to the ground within the panel. This is typical of all conduits in the cabinet. 


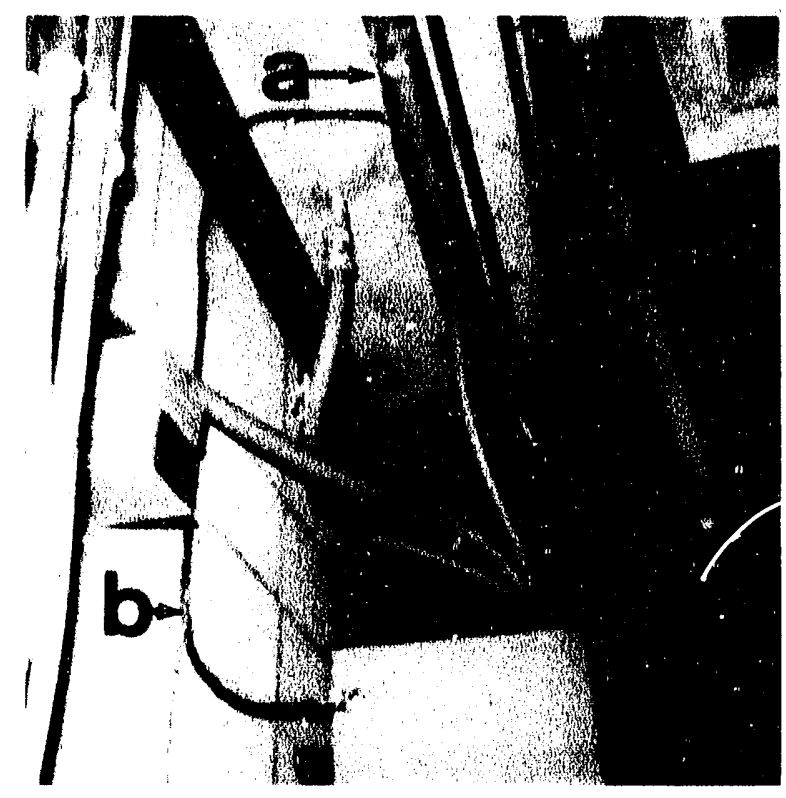

Fig. 5. Typical connection for building ground network. A perimeter grounding cable runs along the ceiling, as indicated by a, with branches that drop and connect to the transformers and power panels, as shown at $b$.

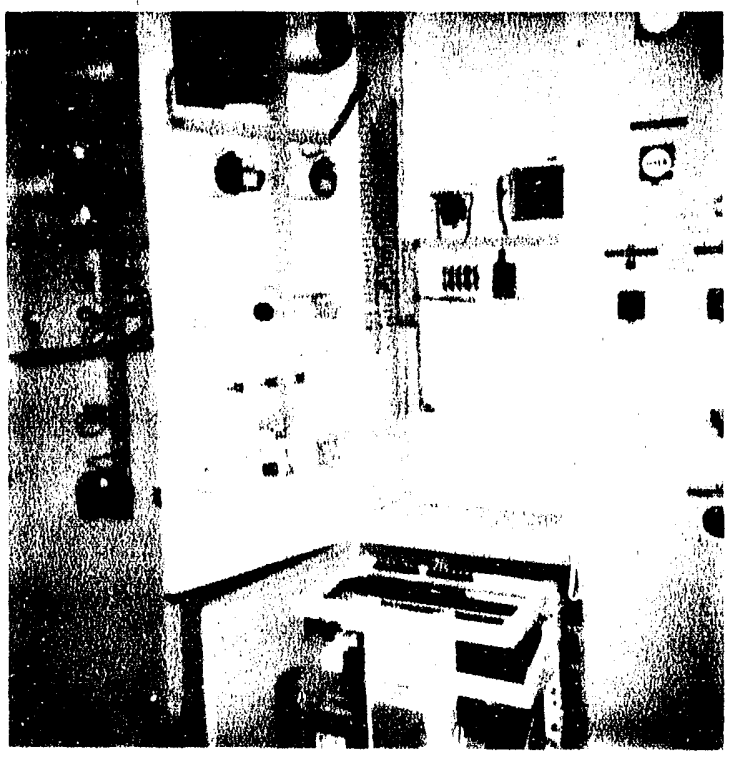

Fig. 6. Front of transfer switch cabinet with panel door open. Improve the bonding to the 16 doors with a short braid jumper between the cabinet frame and each door. Use bolts and washers to connect the braid to the panels. 


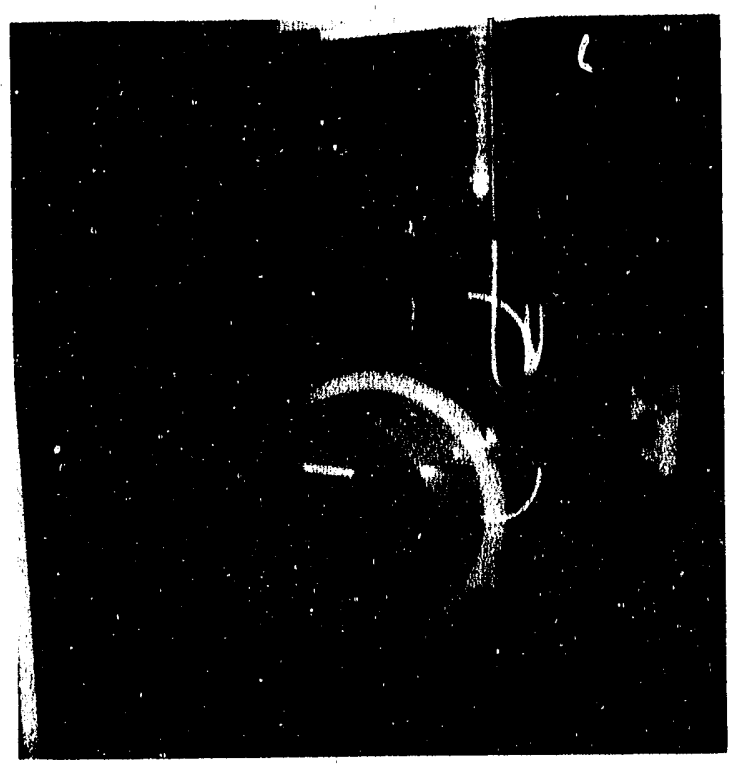

Fig. 7. Emergency generator No. 2. The wiring is routed through rigid conduit and does not require conductive jumpers to be installed. Generator No. 1 is similar.

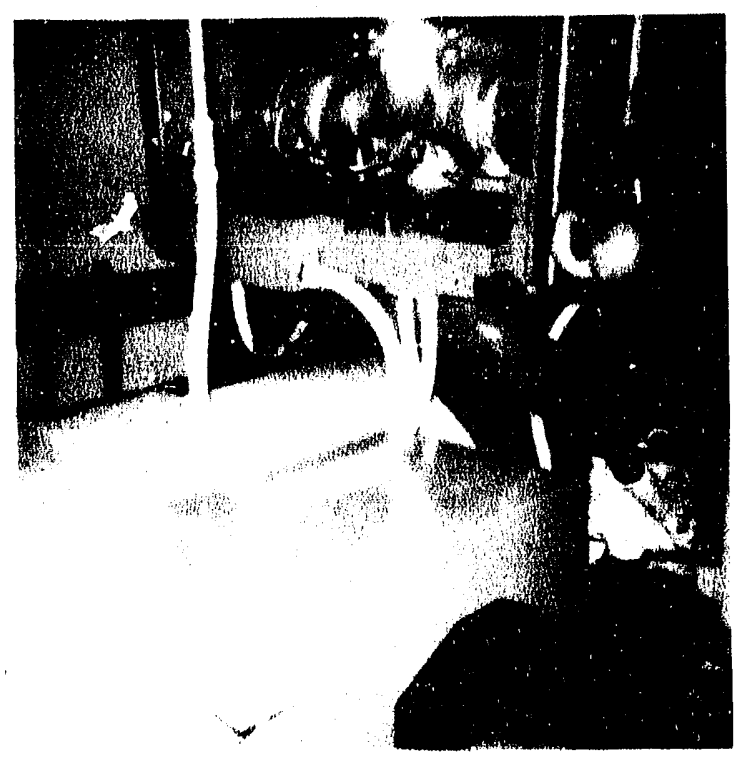

Fig. 8. Flexible conduits for the generator status monitor. These conduits should be jumpered with No. 4 AWG copper conductors. Attach the conductor with clamps on the conduit end and lugs on the box end. 


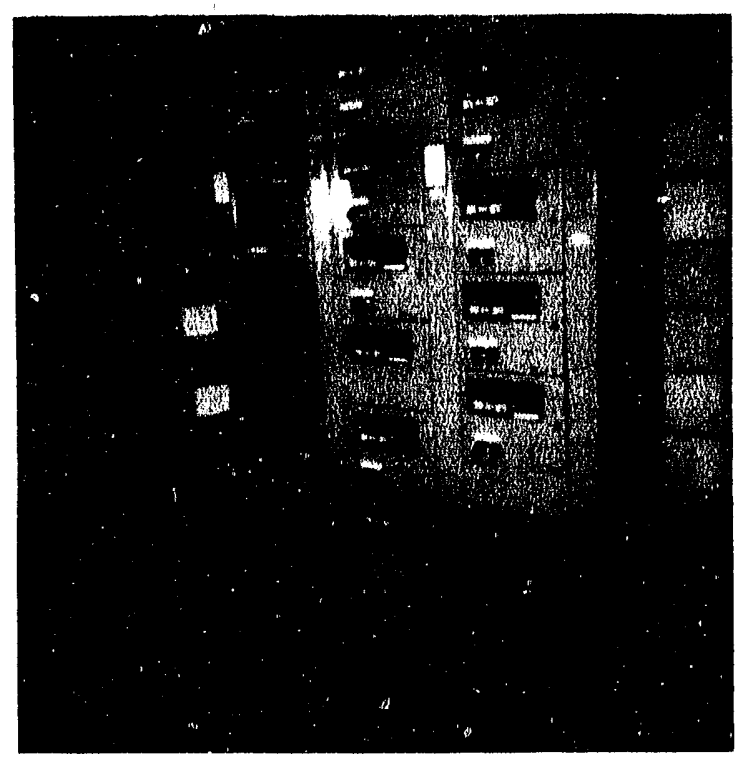

Fig. 9. Motor control center.

Protection will be installed at the connection between the wires and the bus bars in the lower right access area.

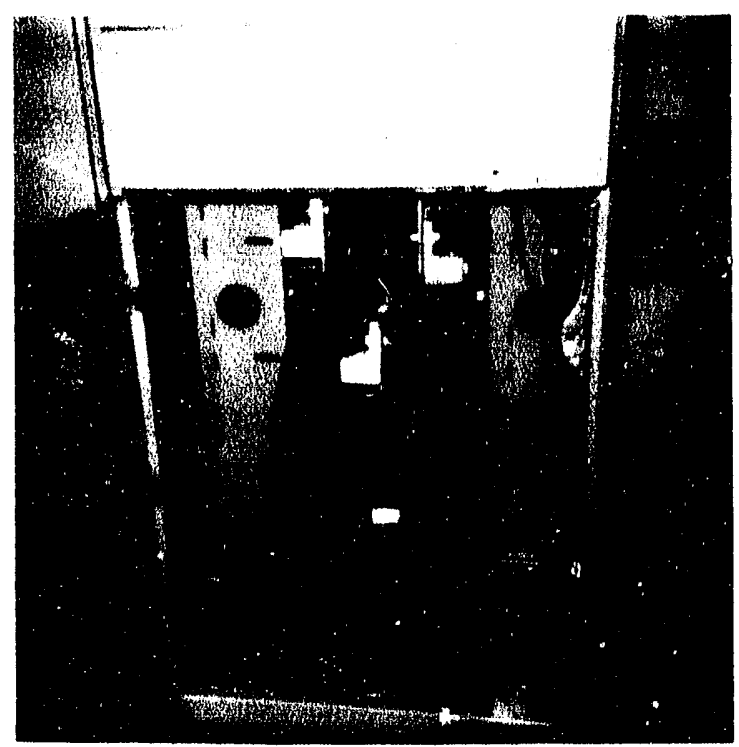

Fig. 10. Incoming wiring connection for the motor control center. Install V275HE250 MOVs from each phase to ground and V480HE450 MOVs from phase to phase at the terminal connections. 

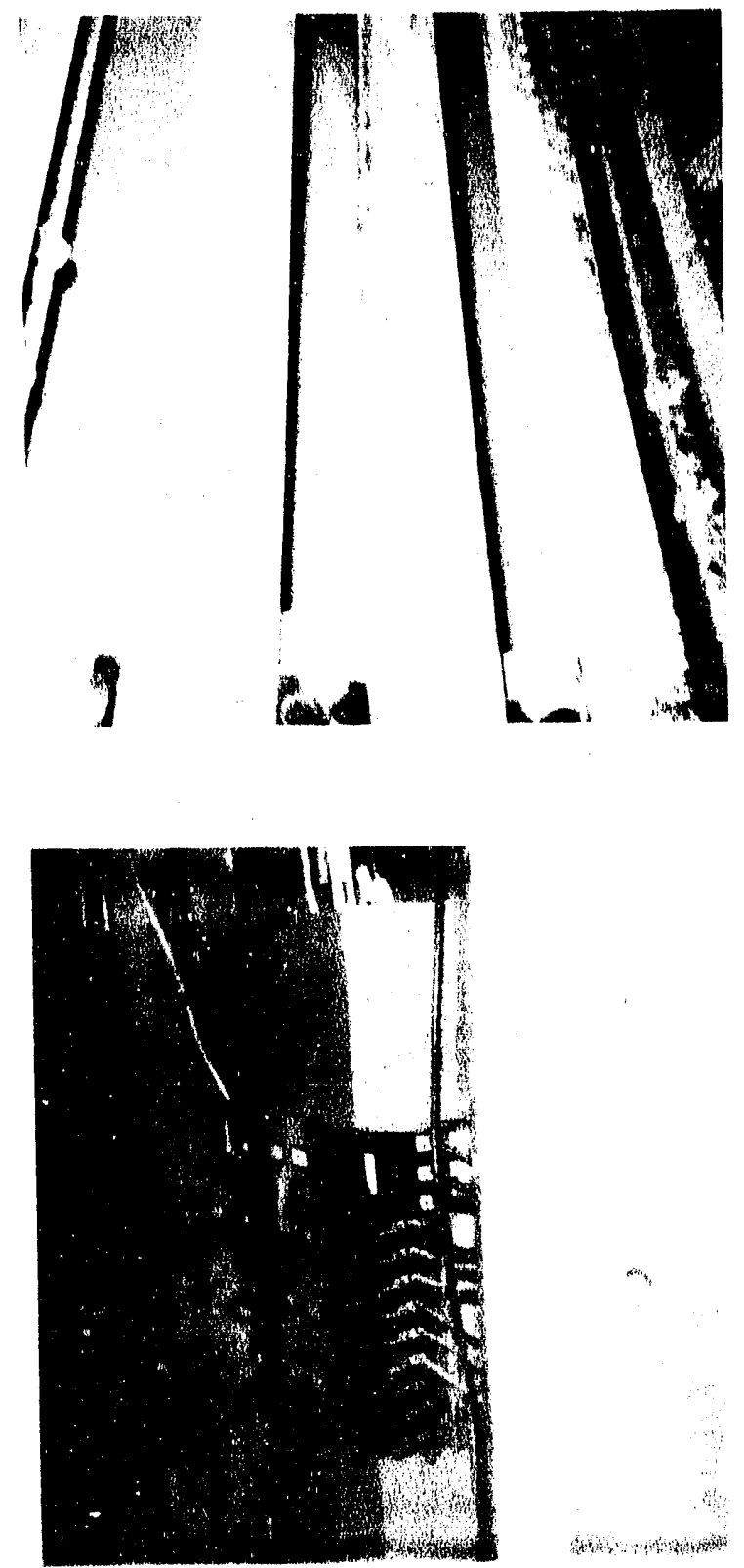

Fig. 11. Power bus bars in the chiller distribution center. Install V275HE250 MOVs from each phase to ground and V480HE450 MOVs from phase to phase. Mount the MOVs on the side of the panel and connect to the bus bars with short jumpers.
Fig. 12. Power distribution panel DP1. Remove the existing V130LA10A MOVs. Install V130PA20A MOVs from the load side of three adjacent breakers (phases) to case ground. Install V230LA20A MOVs from phase to phase on the load side of three adjacent breakers. Install a V130PA20A MOV from neutral to case ground. 


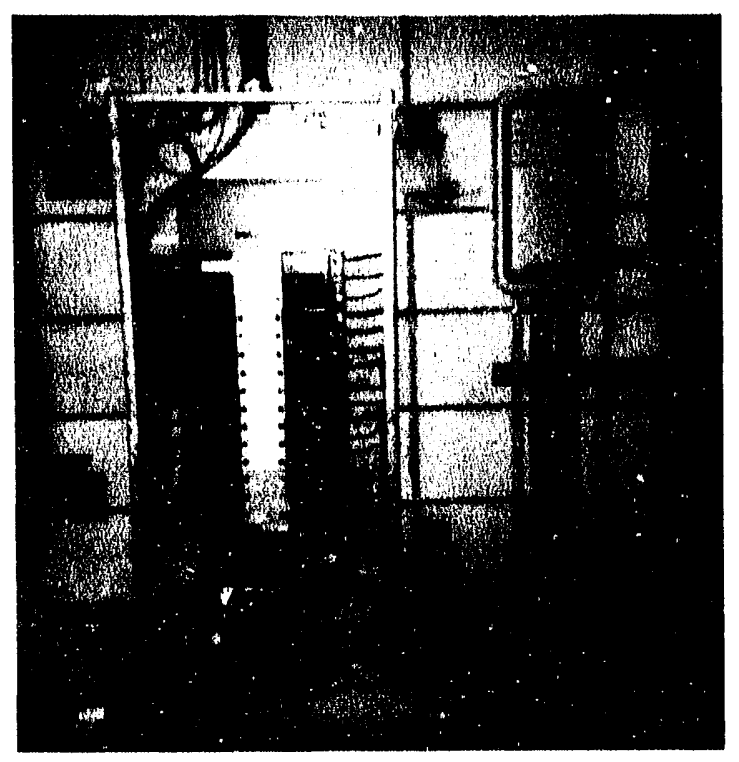

Fig. 13. Power distribution panel DP2. Remove the existing series strings of V130LA10A MOVs. Install V275PA40A MOVs from the load side of three adjacent breakers to ground. Install V480LB20A MOVs from phase to phase on the load side of the three breakers. Install a V275PA40A MOV from neutral to case ground.

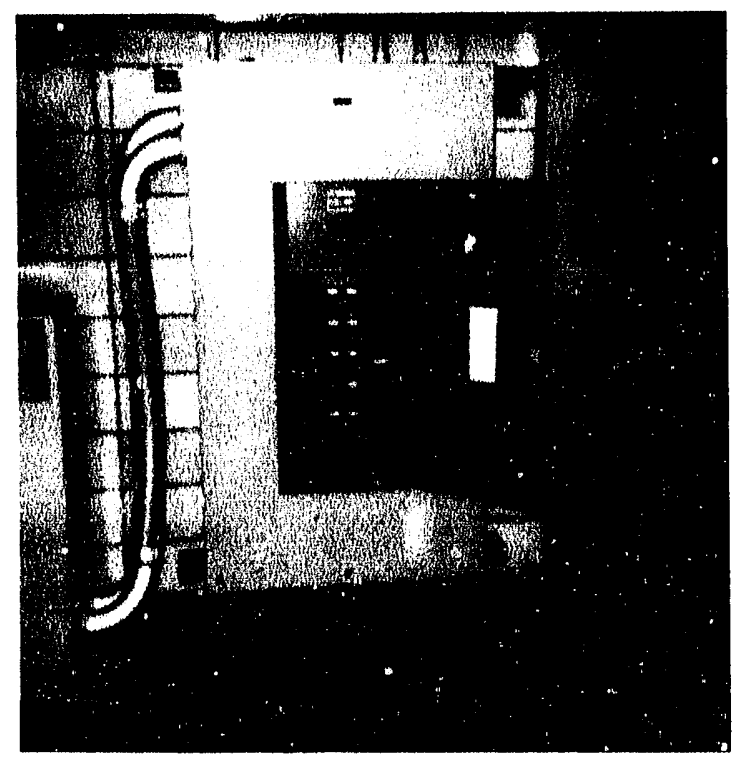

Fig. 14. Power distribution panel DP3. Install V130PA20A MOVs from the load side of three adjacent breakers to case ground and from neutral to case ground. Install V230LA20A MOVs from phase to phase on the load side of three adjacent breakers. 


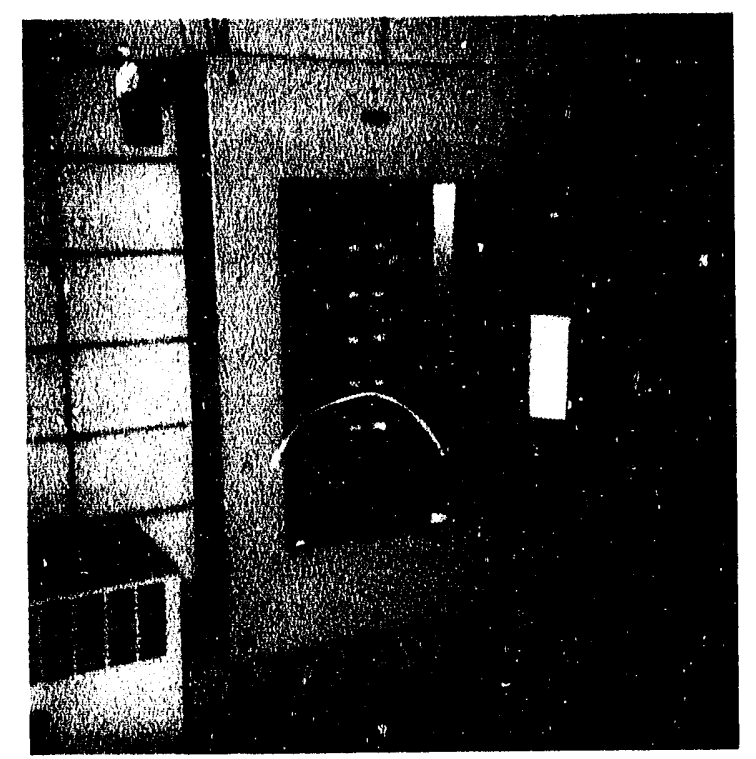

Fig. 15. Power distribution panel DP4. Remove the existing V130LA10A MOVs and replace with V130PA20A MOVs installed from the load side of three adjacent breakers (phases) to case ground. Add differential-mode protection by installing V230LA20A MOVs from phase to phase on the load side of three adjacent breakers. Add a V130PA20A MOV from neutral to ground.

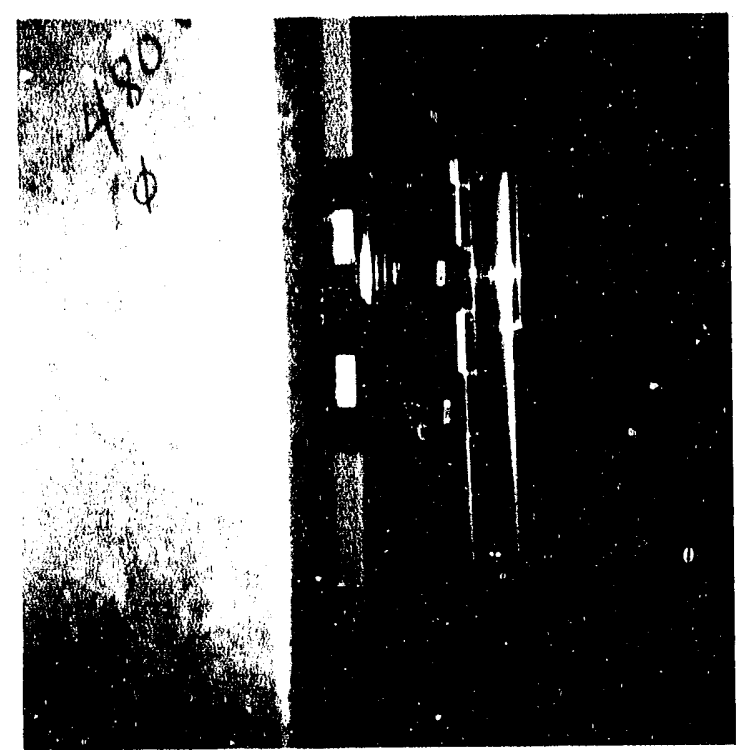

Fig. 16. Power distribution panel DP6. Install V275PA40A MOVs from the load side of three adjacent breakers to case ground and from neutral to ground. Install V480LB20A MOVs from phase to phase on the load side of three adjacent breakers. 

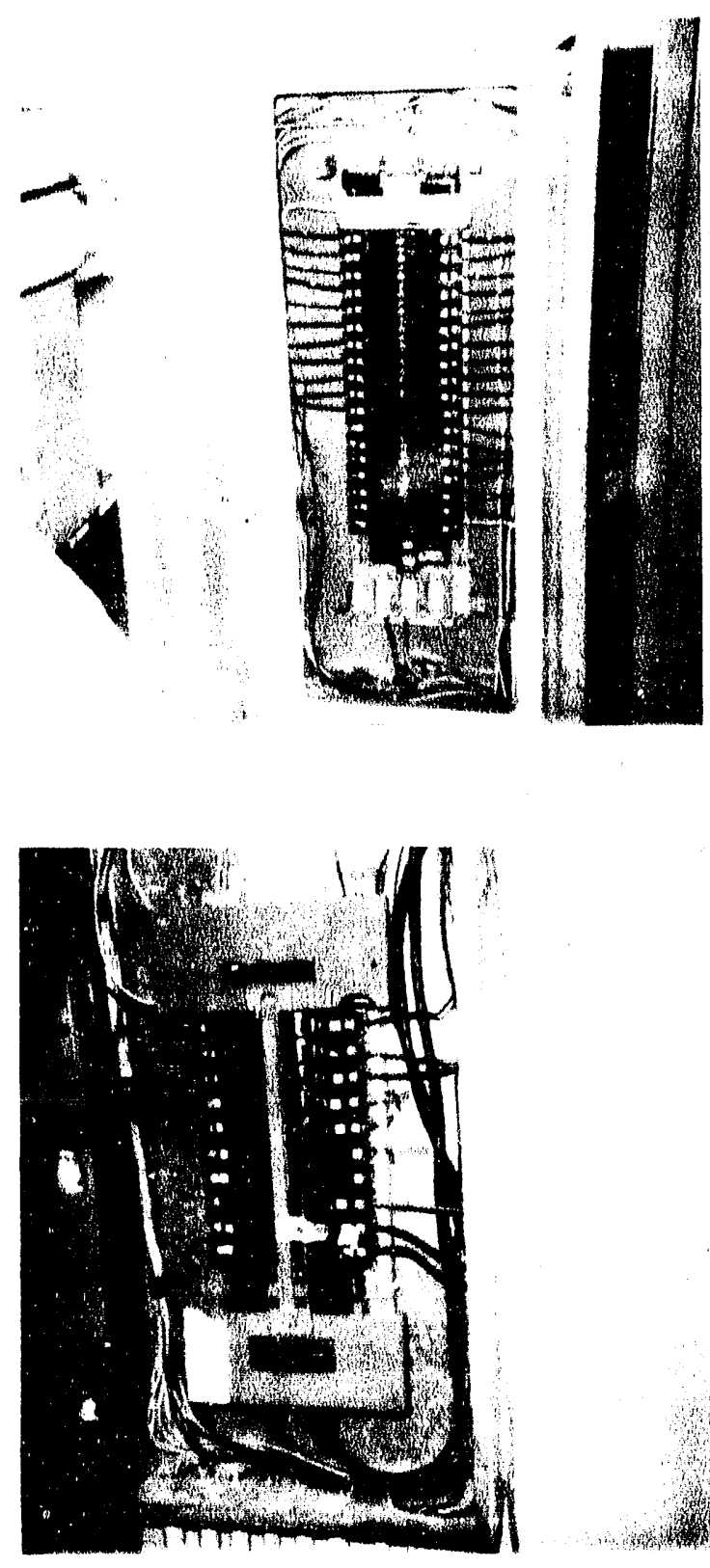

Fig. 17. Power panel A. Install V130PA20A MOVs from the load side of three adjacent breakers to case ground and V230LA20A MOVs from phase to phase on the load side of the three breakers. Install a V130PA20A MOV from neutral to ground.
Fig. 18. Power panel B. Remove the existing V130LA10A MOVs and replace with V130PA20A devices installed from the load side of three adjacent breakers (phases) to case ground. Install V230LA20A MOVs from phase to phase on the load side of three adjacent breakers. Install a V130PA20A MOV from neutral to ground. 


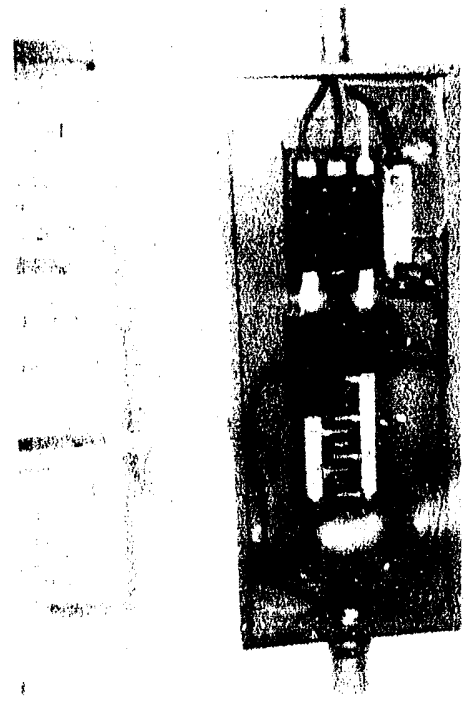

Fig. 19. Power panel E Establish common-mode protection by installing V130PA20A MOVs from phase to ground on the load side of three adjacent breakers. Differential-mode protection should be added by installing V230LA20A MOVs from phase to phase on the load side of three adjacent breakers. Install a V130PA20A MOV from neutral to ground.

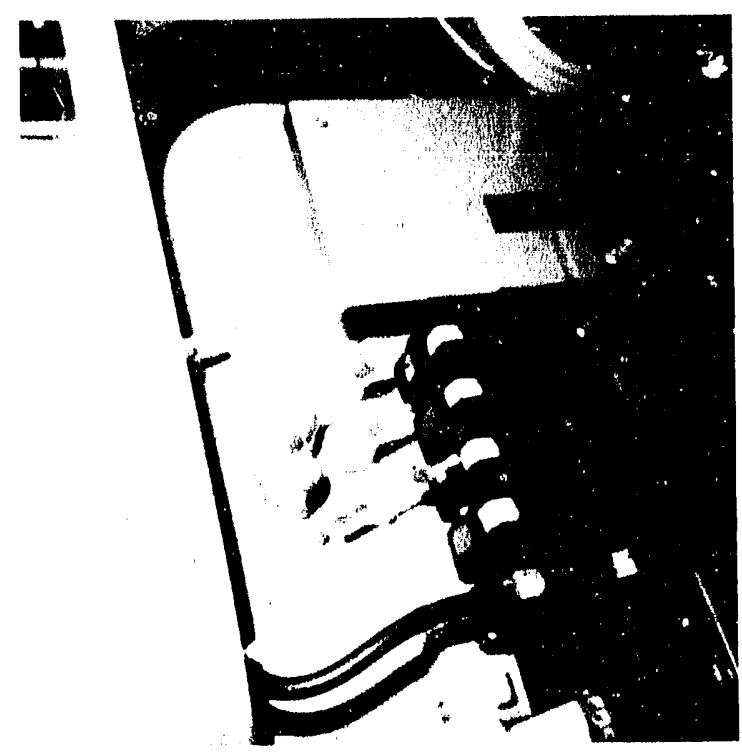

Fig. 20. Power panel $K$ Remove the existing V130LA10A MOVs that are not connected and install V130PA20A devices from the load side of three breakers to case ground and from neutral to ground. Install V230LA20A MOVs from phase to phase on the load side of three adjacent breakers. 


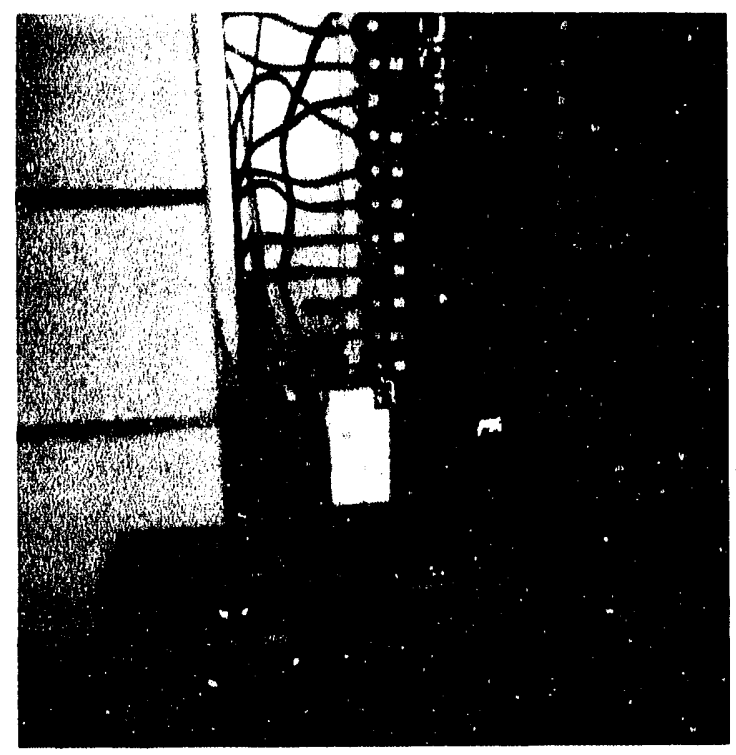

Fig. 21. Power panel P1. Remove the existing V130LA10A MOVs and upgrade the protection with V130PA20A devices installed from the load side of three adjacent breakers (phases) to ground. Install V230LA20A MOVs from phase to phase on the load side of the same three breakers. Add neutral protection by installing a V130PA20A MOV from neutral to ground.

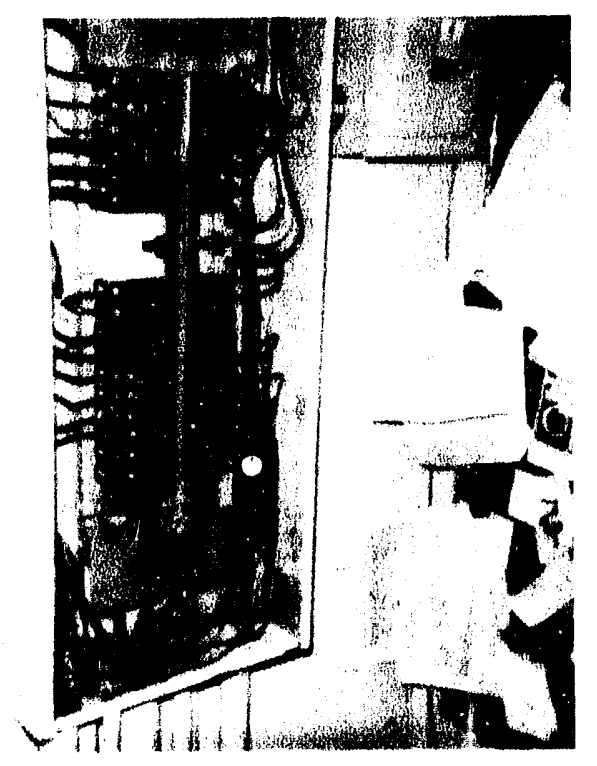

Fig. 22. Power panel $P 2$ in the kitchen area. Add common-mode protection by installing V130PA20A MOVs from the load side of three adjacent breakers to case ground. Install V230LA20A MOVs from phase to phase on the load side of three adjacent breakers to provide differential-mode protection. A V130PA20A MOV should be installed from neutral to ground. 
Fig. 23. Power panel $P 3$ in the laundry room. Install V130PA20A MOVs from the load side of three adjacent breakers to case ground and from the neutral to case ground. Install V230LA20A MOVs from phase to phase on the load side of three adjacent breakers.

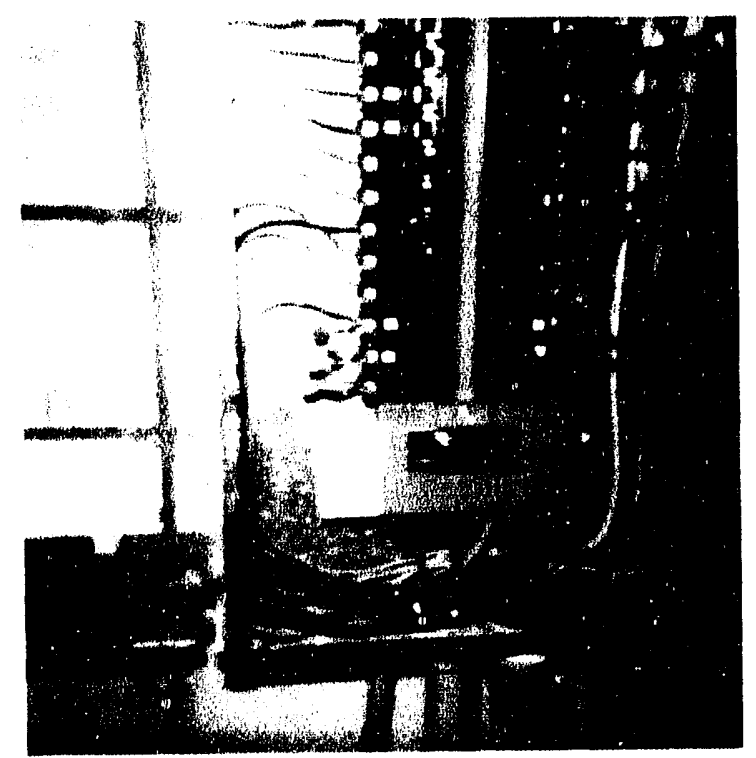

Fig. 24. Power panel R1. Remove the existing V130LA10A MOVs and replace with V130PA20A MOVs installed from each phase to ground on the load side of three adjacent breakers (phases). Install V230LA20A MOVs from phase to phase on the load side of the three breakers. Install a V130PA20A MOV from neutral to ground. 


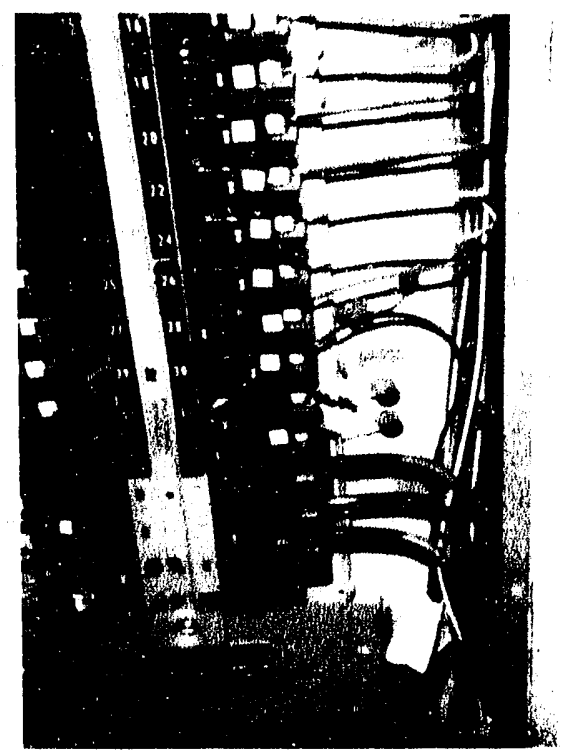

Fig. 25. Power panel $R 2$ in the upstairs hallway. Remove the existing V130LA10A MOVs and install V130PA20A devices from the load side of three adjacent breakers to case ground and from neutral to ground. Install V230LA20A MOVs from phase to phase on the load side of the same three breakers.

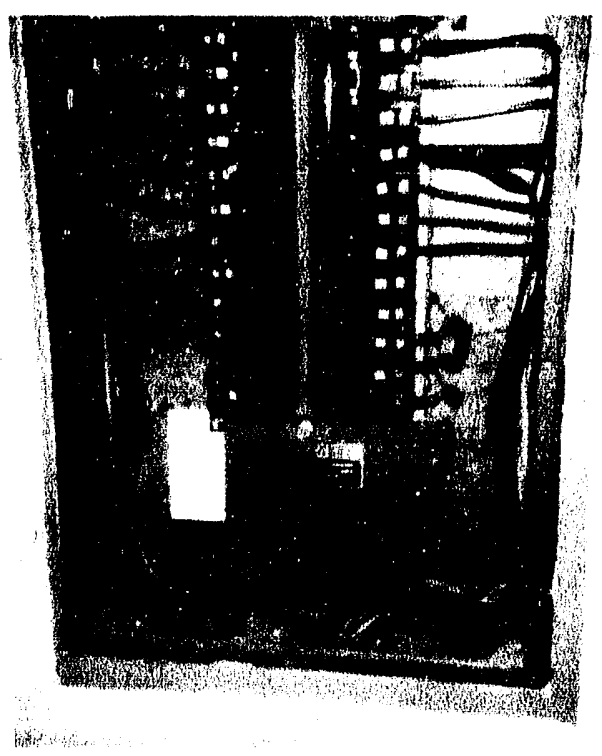

Fig. 26. Power panel R3 in the upstairs hallway. The existing V130LA10A MOVs should be removed and replaced. with V130PA20A devices installed from phase to ground on the load side of three adjacent breakers. Install differential-mode protection by adding V230LA20A MOVs from phase to phase on the load side of the same three breakers. Add a V130PA20A MOV from neutral to ground. 


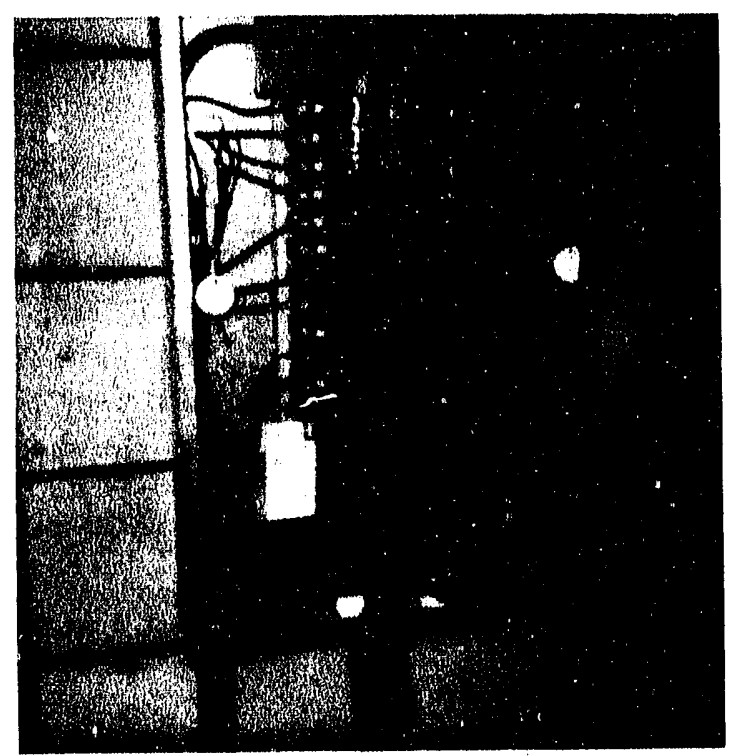

Fig. 27. Power panel L3. The existing V130LA10A MOVs should be removed. Upgrade the protection by installing V130PA20A MOVs from the load side of three adjacent breakers (phases) to case ground and V230LA20A MOVs from phase to phase on the load side of the same three breakers. Install a V130PA20A MOV from neutral to ground.

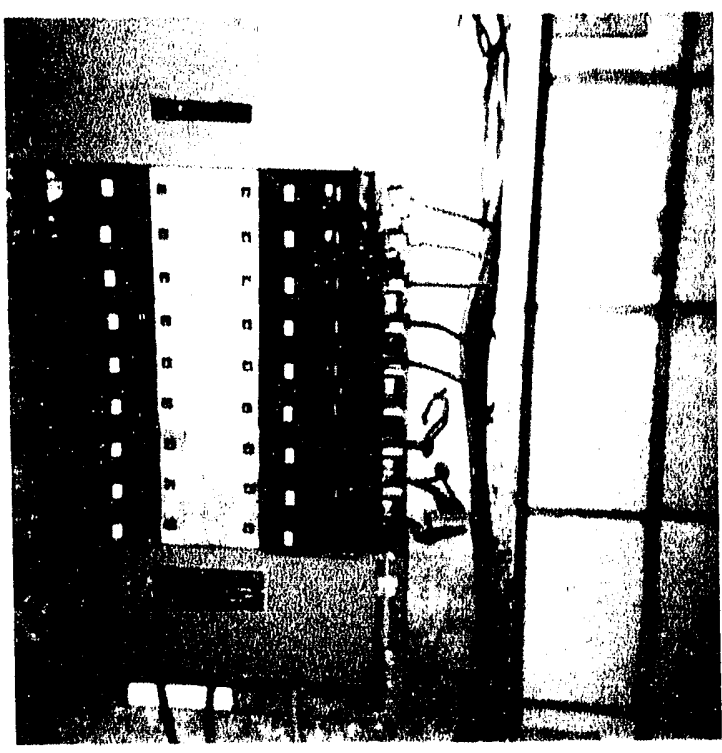

Fig. 28. Lighting panel L1. Remove the existing series strings of V130LA10A MOVs. Install V275PA40A MOVs from each phase to case ground on the load side of three adjacent breakers. Install V480LB20A MOVs from phase to phase on the load side of the same three breakers. Install a V275PA40A MOV from neutral to case ground. 


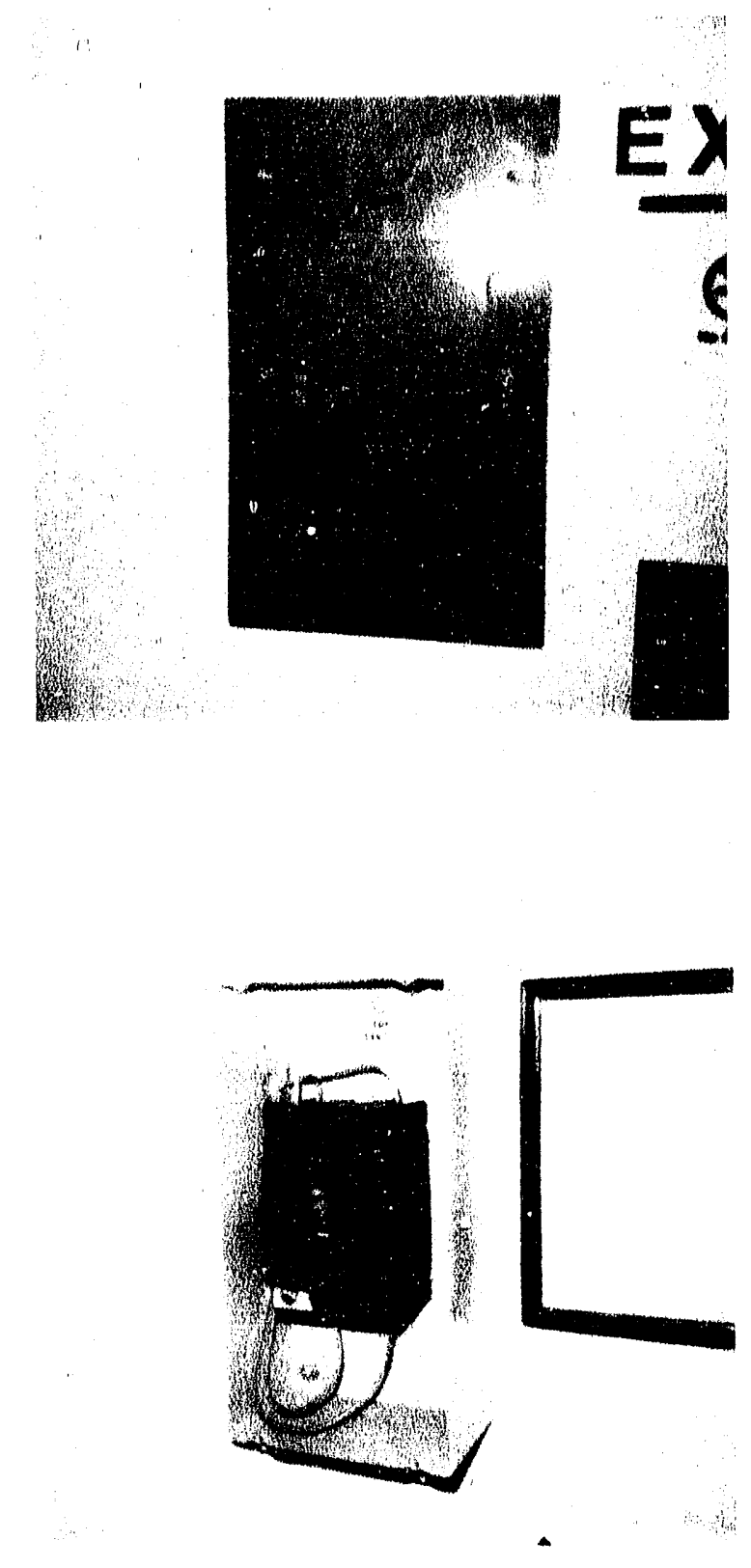

Fig. 29. Lighting panel L2. Remove the old (disconnected) strings of MOVs and replace with V275PA40A MOVs installed from the load side of three adjacent breakers to case ground. Add V480LB20A MOVs installed from phase to phase on the load side of the same three breakers. Install a V275PA40A MOV from neutral to ground.

Fig. 30. Fire alarm breaker panel. Install V275PA40A MOVs from the load side of the two breakers to case ground and a single V480LB20A MOV across the line on the load side of the breakers. 


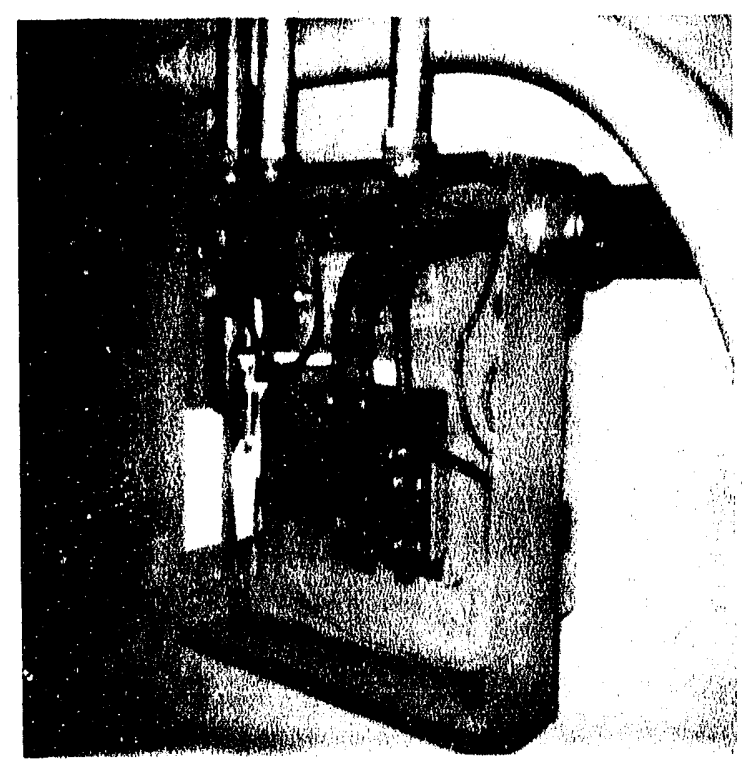

Fig. 31. Telephone system power panel. Install V130PA20A MOVs from phase to ground on the load side of three adjacent breakers. Install V230LA20A MOVs from phase to phase on the load side of the same three breakers. Install a V130PA20A MOV from neutral to ground.

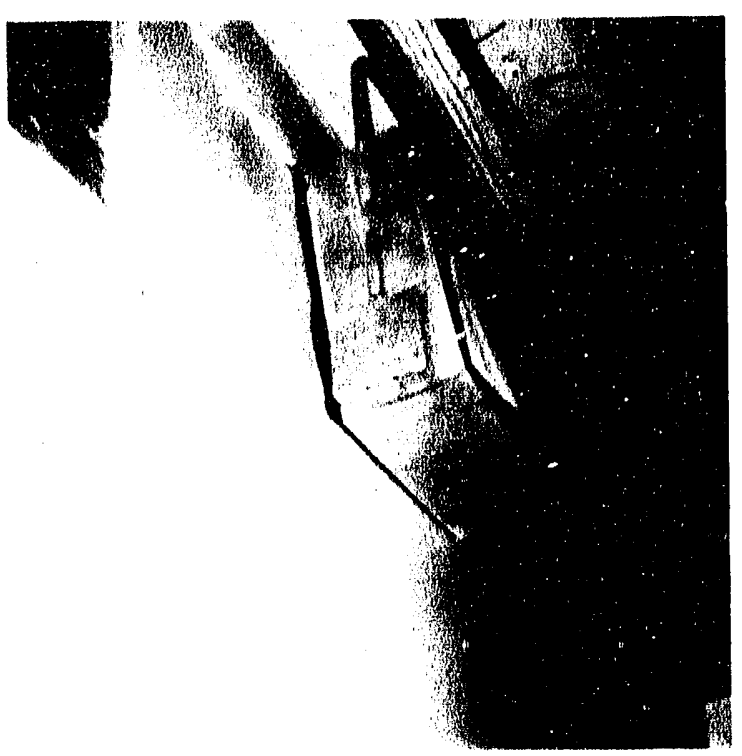

Fig. 32. Lighting filter for the shielded communications room. The filter is a $120-\mathrm{V}$ unit installed on a $277-\mathrm{V}$ line and should be replaced with one rated for the line voltage. 


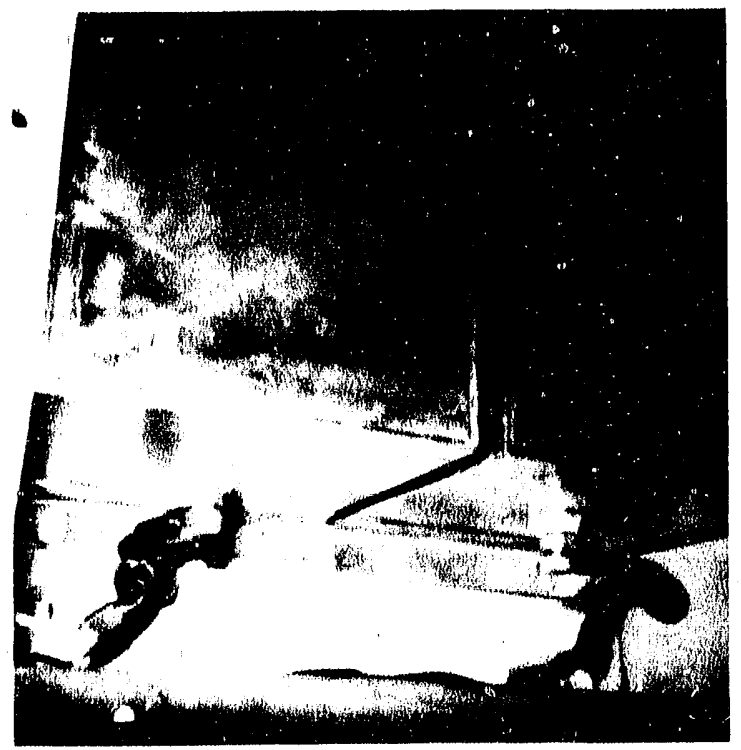

Fig. 33. Input terminals for the lighting filter. The existing 420-V MOVs are installed across a jumper wire and serve no purpose. When the filter is replaced, the terminals should be protected with V275PA40A MOVs installed from each input terminal to case ground.

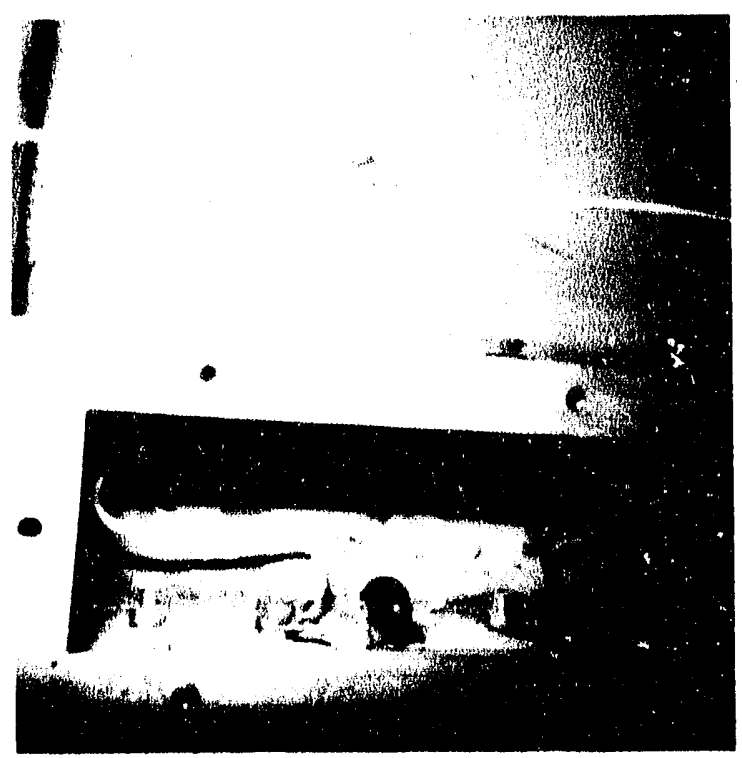

Fig. 34. Output terminals for the lighting filter. The terminals presently have V275LA20A MOVs installed from each te-minal to ground. The new filter should be protected with V275PA40A MOVs installed from each terminal to case ground. 


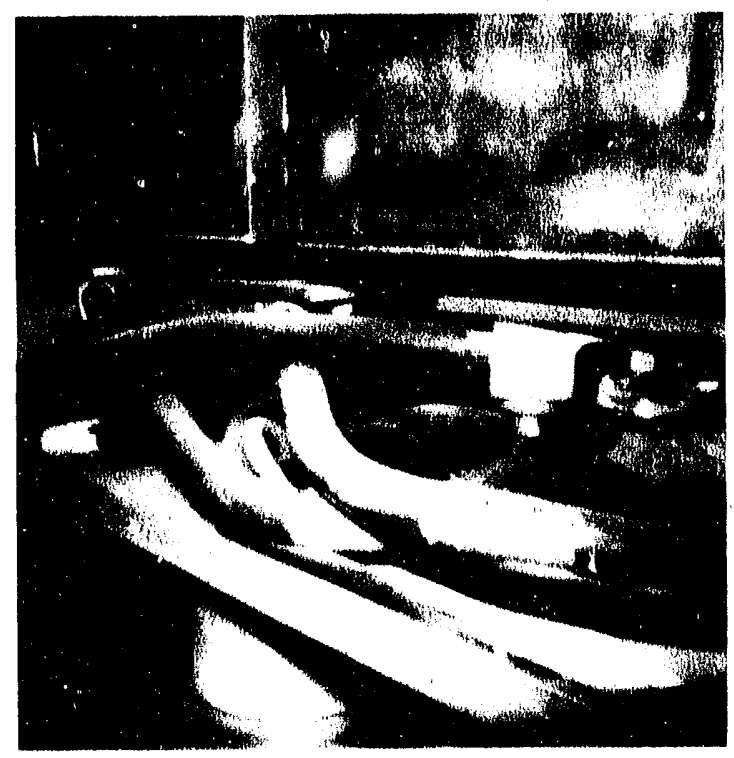

Fig. 35. Wiring for the input side of the main power filter. The input should be protected by installing V130PA20A MOVs from each terminal to case ground.

Fig. 36. Terminals for the output side of the main power filter. The existing V130LA10A MOVs are not connected and should be removed. Install V130PA20A devices from each phase to case ground. 

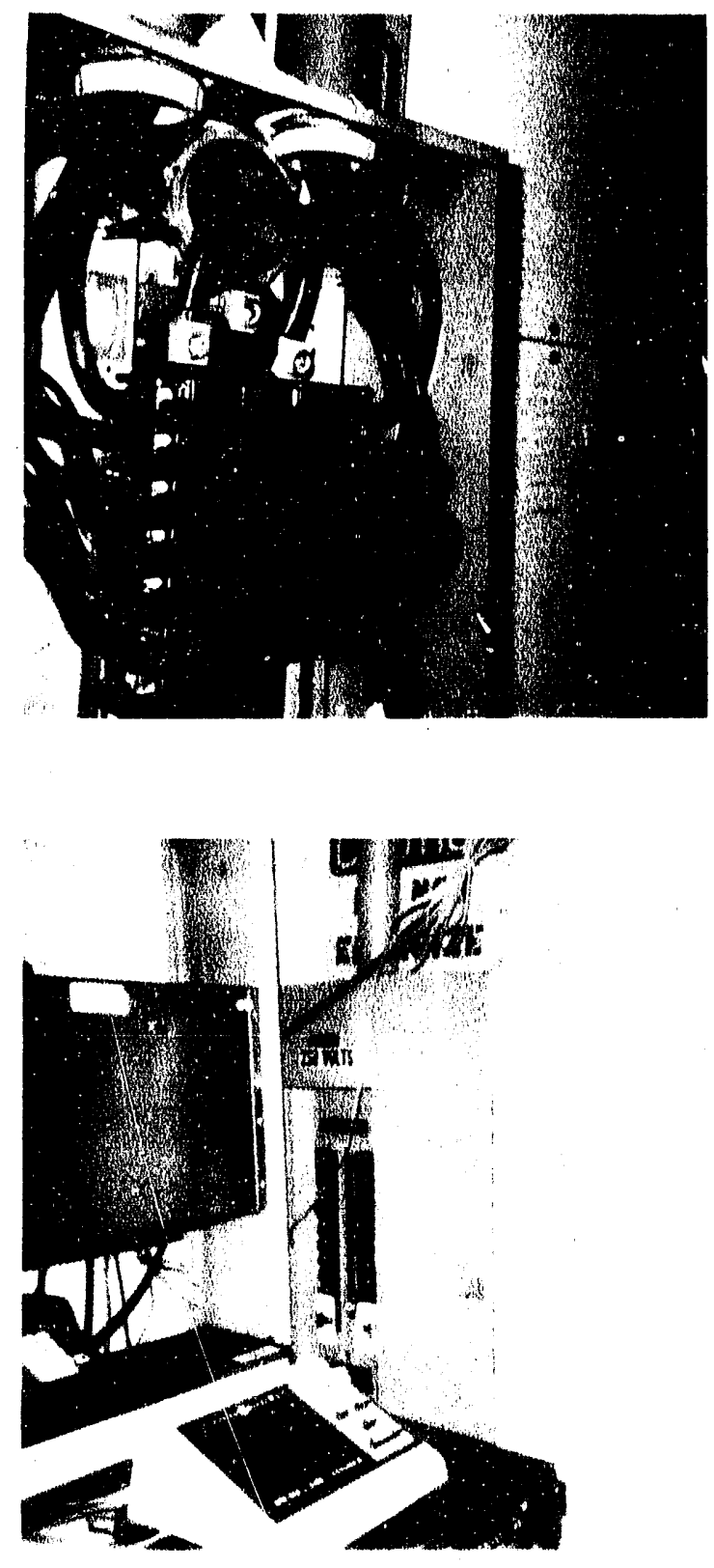

Fig. 37. Power distribution panel DP5 in the shielded room. Install V130PA20A MOVs from the loaci side of three adjacent breakers (phases) to case ground and from neutral to case ground. Install V230LA20A MOVs from phase to phase on the load side of the same three breakers. A mesh gasket should be installed on the lip of the panel where it mates with the cover.
Fig. 38. Power panel $\mathrm{C}$ in the shielded room. This panel should have common-mode protection installed by adding V130PA20A MOVs from phase to ground on the load side of three adjacent breakers. Differential-mode protection should be added by installing V230LA20A MOVs from phase to phase on the load side of the same three breakers. Install a V130PA20A MOV from the neutral to ground. 


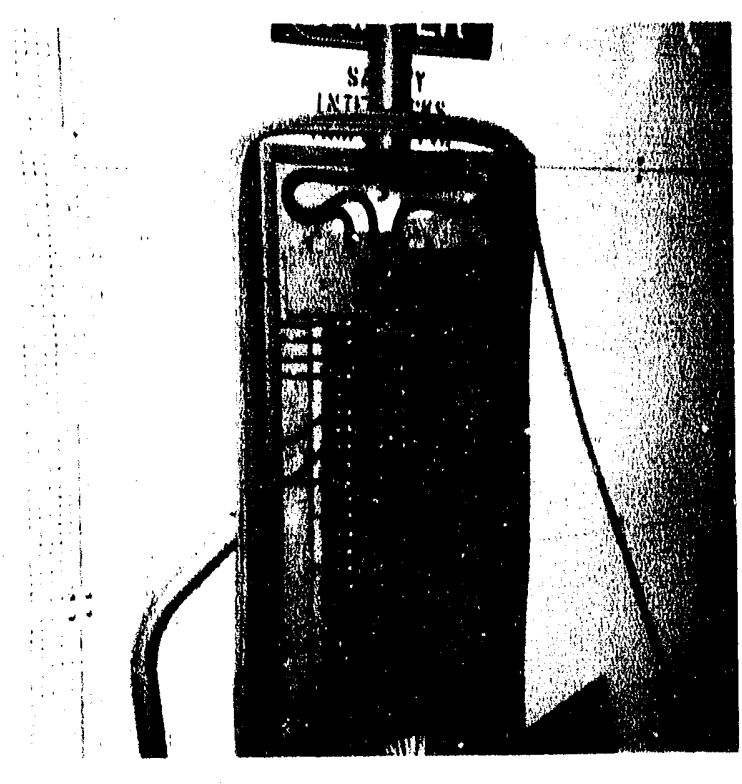

Fig. 39. Power panel $D$ in the shielded room. Install V130PA20A MOVs from phase to ground on the load side of three adjacent breakers and V230LA20A MOVs from phase to phase on the same three breakers. Install a V130PA20A MOV from neutral to ground.

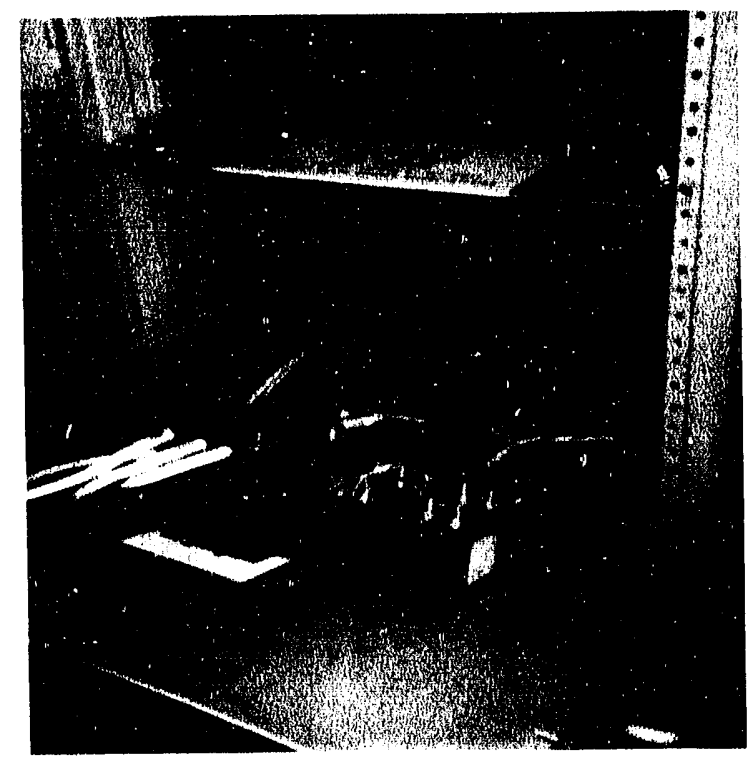

Fig. 40. Circuit breakers for the Harris transmitter racks. The power to these breakers is fed directly from DP5. 


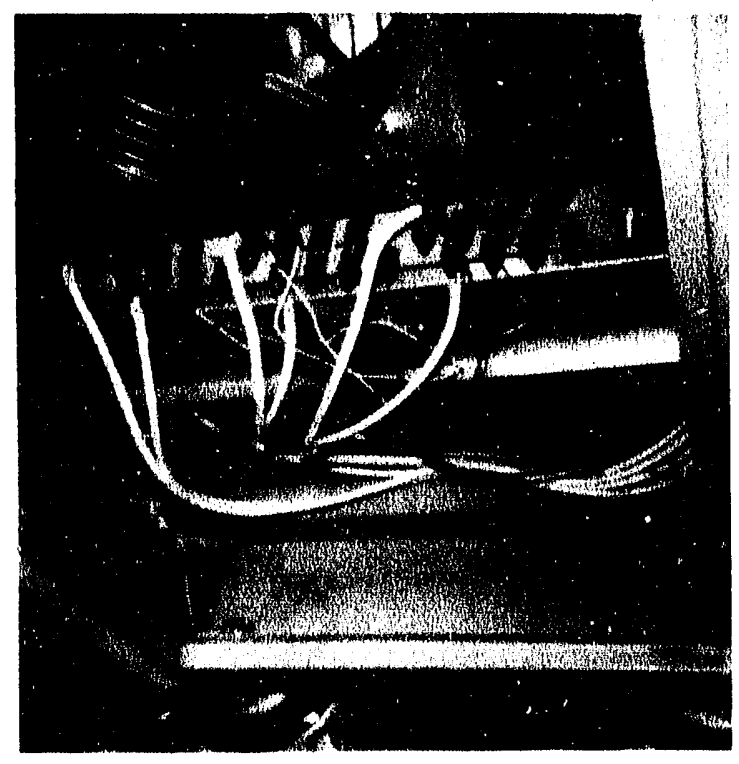

Fig. 41. Transformer terminals for the Harris transmitter racks. The existing MOVs do not provide sufficient protection. Install V130PA20A MOVs from phase to ground and V230LA20A MOVs from phase to phase on the incoming power terminals to the transformer.

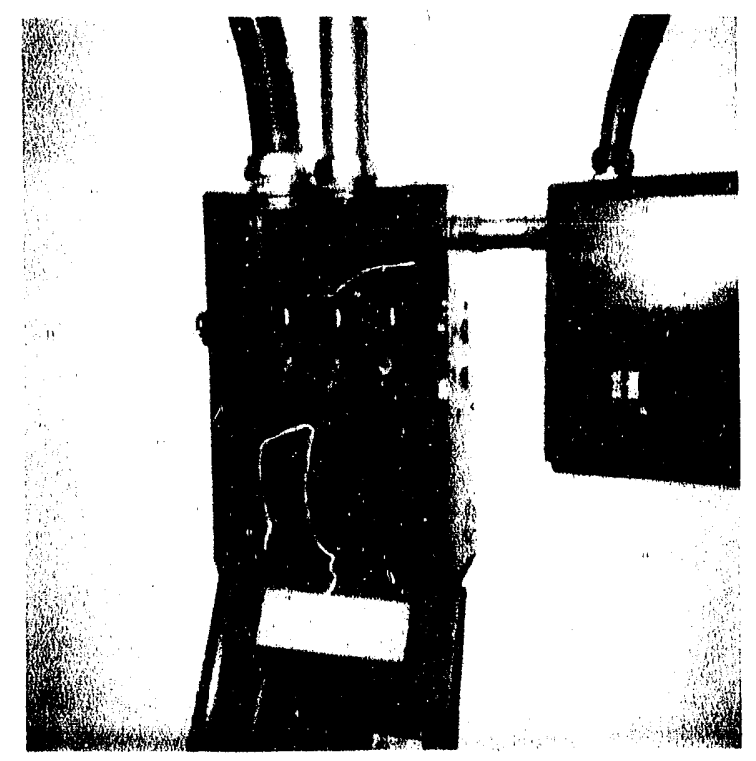

Fig. 42. Control switch for the air makeup heater. Remove the existing series-connected V130LA10A MOVs. Install V275PA40A MOVs from phase to ground and V480LB20A MOVs from phase to phase. 


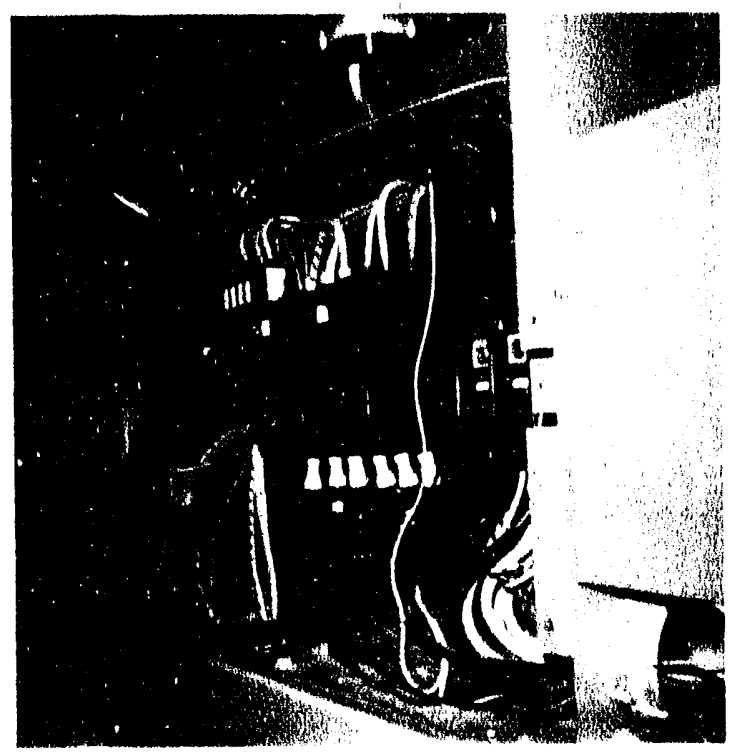

Fig. 43. Chiller control panel. No local protection will be installed in this cabinet; however, the spare conductors in the conduit should be removed.

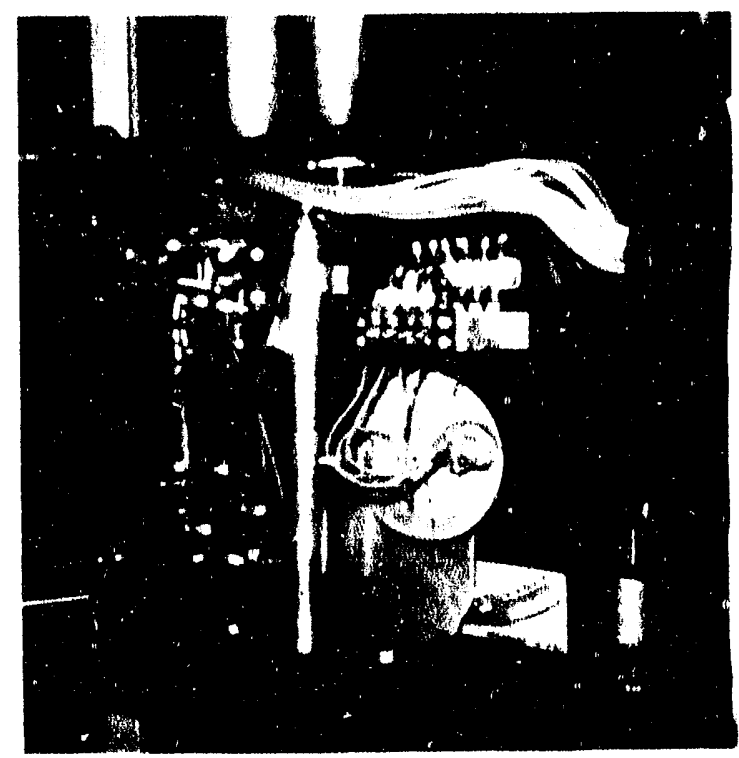

Fig. 44. Contactor for the primary chiller water pump. Install V275PA40A MOVs from phase to ground and V480LB20A MOVs from phase to phase on the line side of the control contactor. The existing V130LA10A MOVs across the contactor coils should remain in place. Protect the backup chiller in a similar manner. 


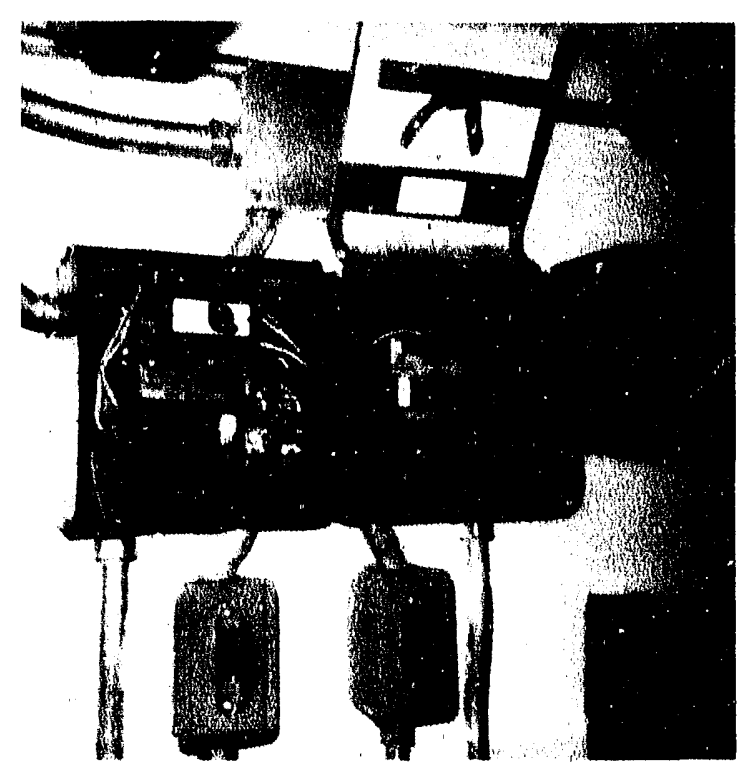

Fig. 45. Contactors for chiller circulating pumps 6 and 7. Install V275PA40A MOVs from phase to ground and V480LB20A MOVs from phase to phase on the line side of each contactor.

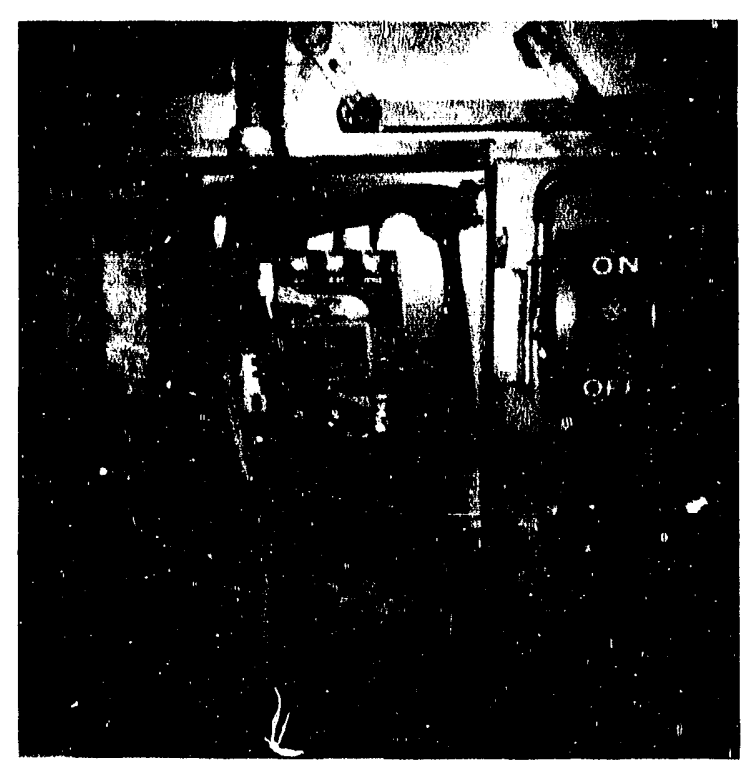

Fig. 46. Contactor for an air duct heater. V130LA10A MOVs are presently installed from each phase to ground and across the contactor coil. This protection is sufficient and should remain installed. 


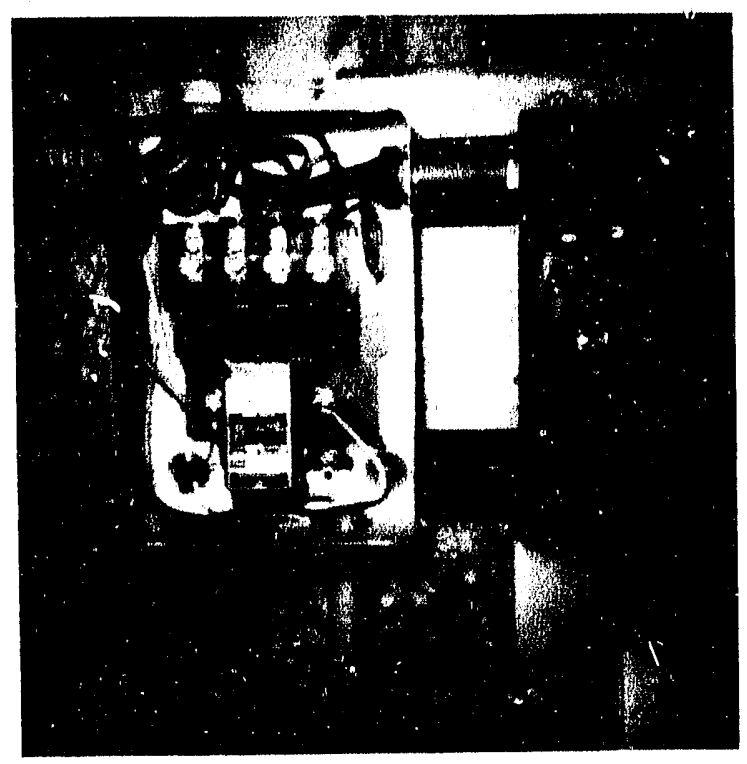

Fig. 47. Contactor for an air duct heater. The coil presently is protected by V130LA10A MOVs, which should be left in place. Add V130LA10A MOVs from each phase to giound.

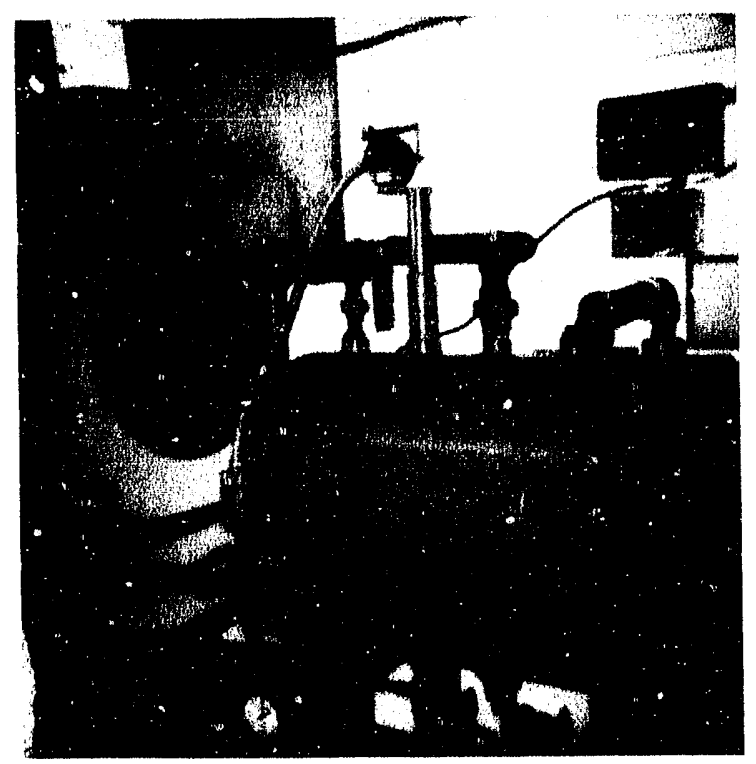

Fig 48. Day tank and pump for the generator fuel supply. The pump leads are routed in conduit from the controller, and no protectors will be installed at the motor. 


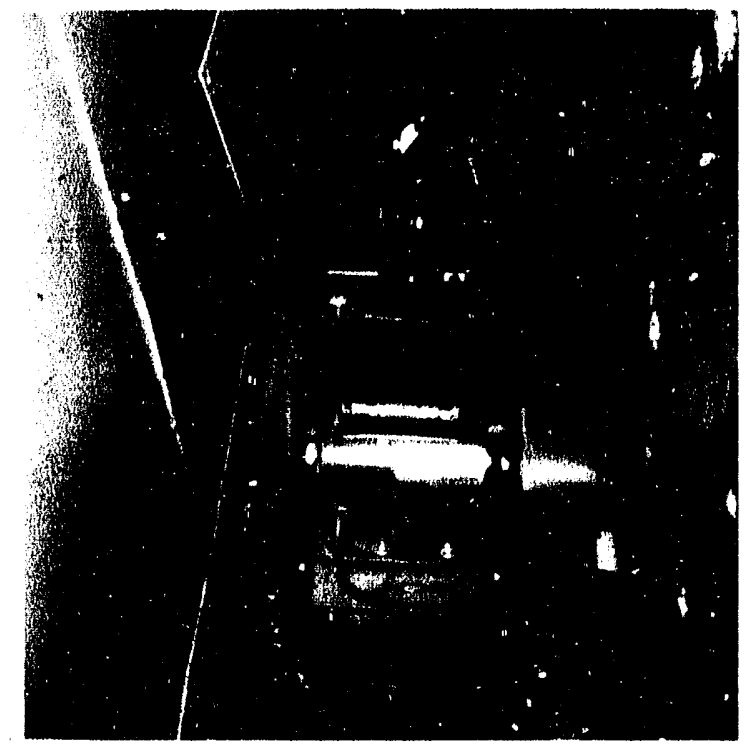

Fig. 49. Air compressor for the door seal bladder to the shielded room.

Protect the power to this compressor by installing a plug-in MOV in the receptacle.

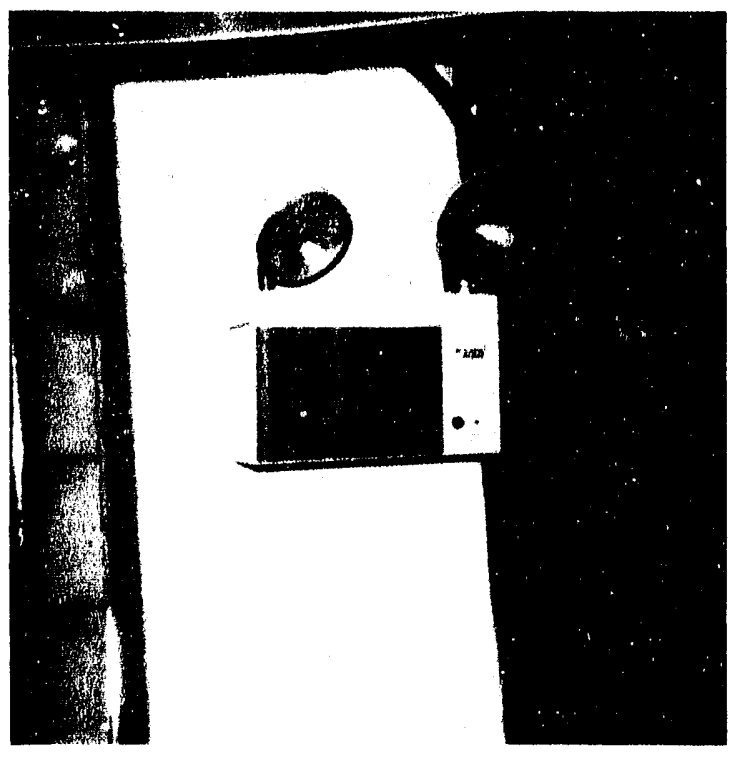

Fig. 50. Battery-powered floodlight used in the Bothell FRC. There are 32 of these lights that should be protected. 


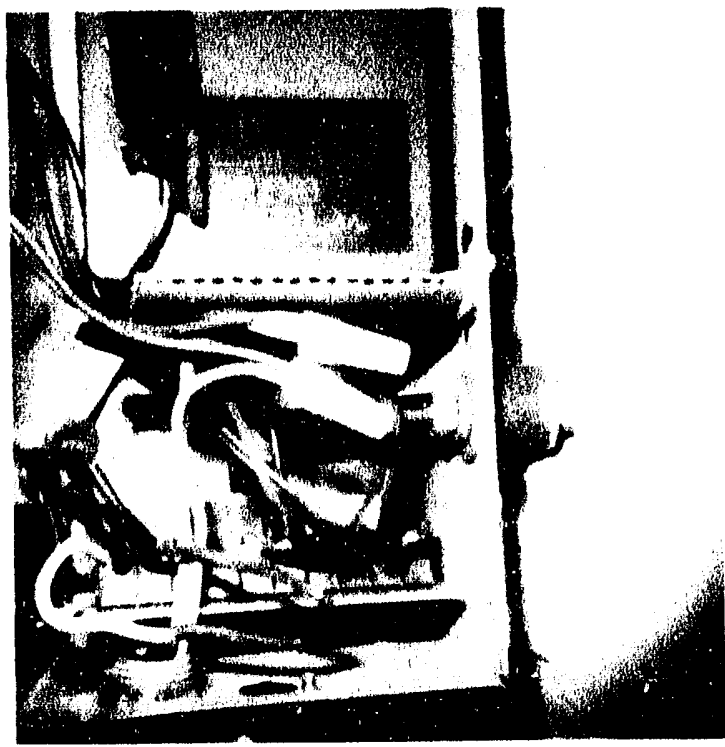

Fig. 51. Inside of the battery-powered floodlight. Install V130I.A10A MOVs from phase to neutral and phase to ground on all units. Check those units with existing MOVs and make wiring changes where necessary to implement the proper protection.

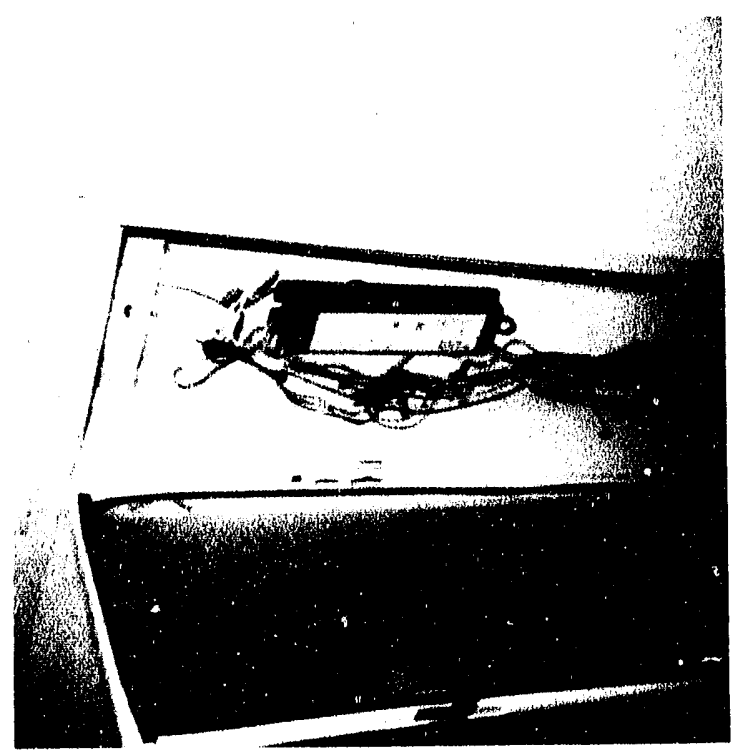

Fig. 52. Typical fluorescent emergency light. Install V275LA20A MOVs frorn phase to neutral and phase to case ground at the wire nut connections. Insulate the MOV leads with heat-shrinkable tubing. 


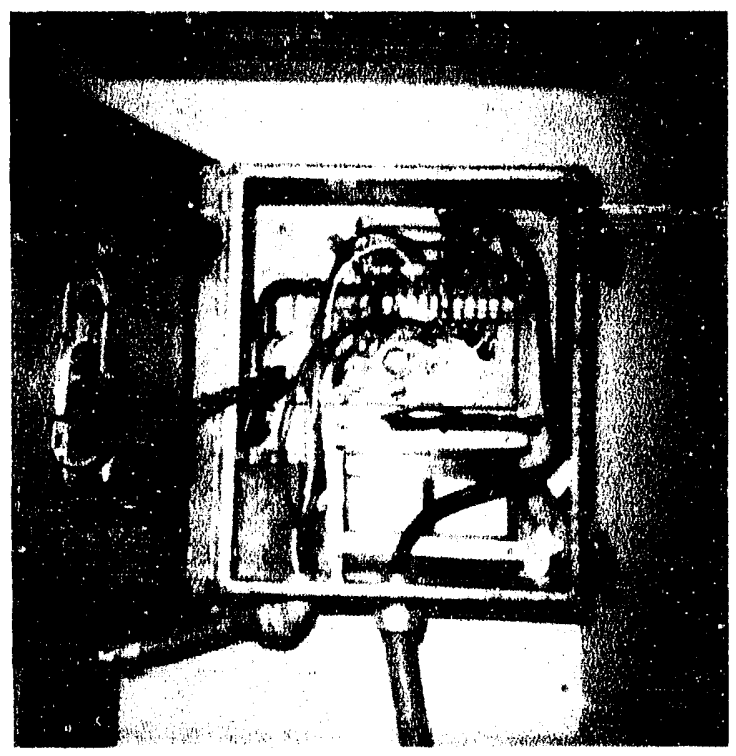

Fig. 53. Control for the automatic blast doors. The incoming power has V130LA10A MOVs installed from phase to neutral and phase to ground. The signal lines have $1.5 \mathrm{KE} 7.5 \mathrm{C}$ and $1.5 \mathrm{KE} 16 \mathrm{C}$ bipolar zeners installed from line to ground.

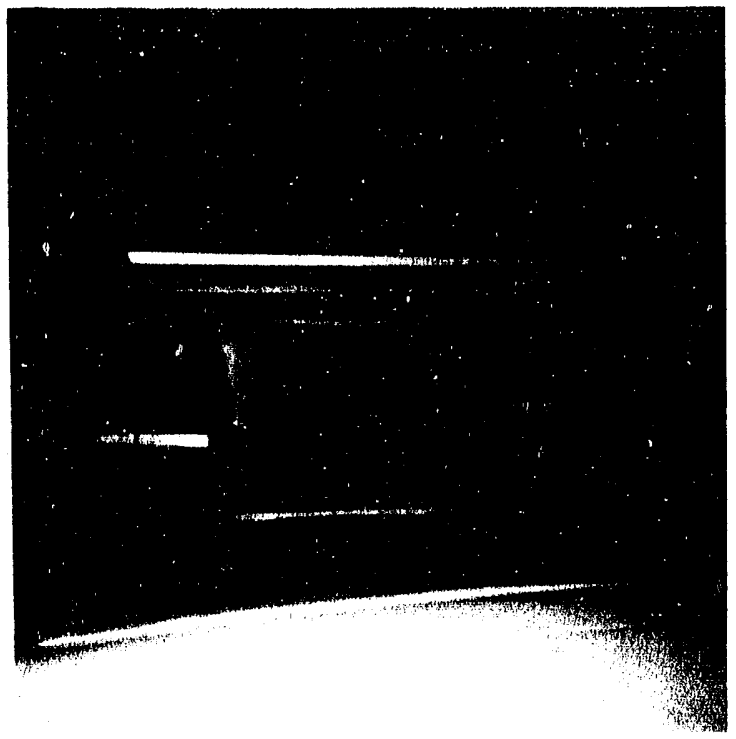

Fig. 54. Inside of the air ventilation duct for the shielded room. The duct has internal metal baffles that reduce the cross section of the duct to act as a waveguide filter for EMP frequencies. 


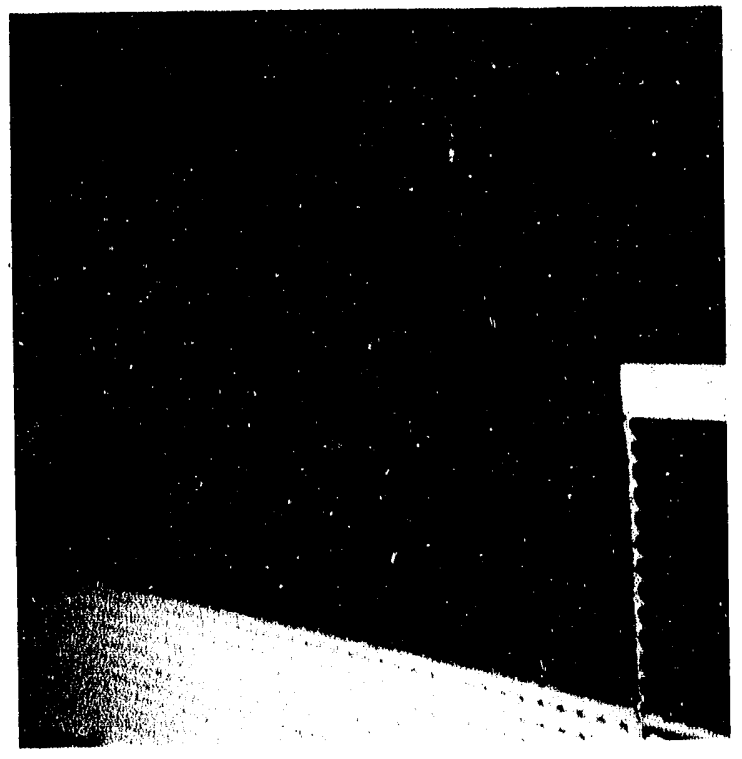

Fig. 55. Honeycomb filter for the return air ventilation duct. The filter is clean, and visual inspection indicates that it is in good condition.

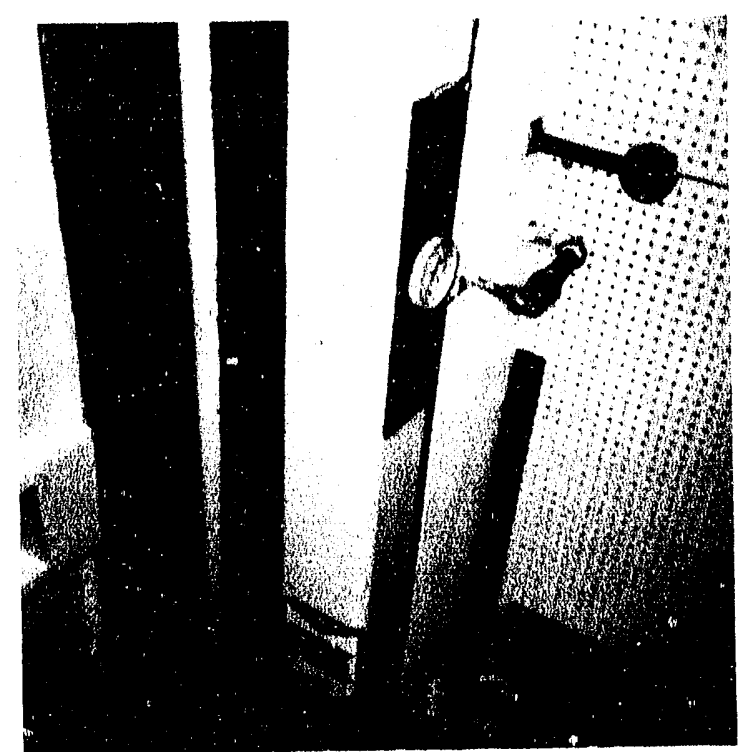

Fig. 56. Personnel door to the shielded radio room. The conductive coating on the door edge is in good condition. The rubber bladder that seals the door has a leak and should either be repaired or replaced. 


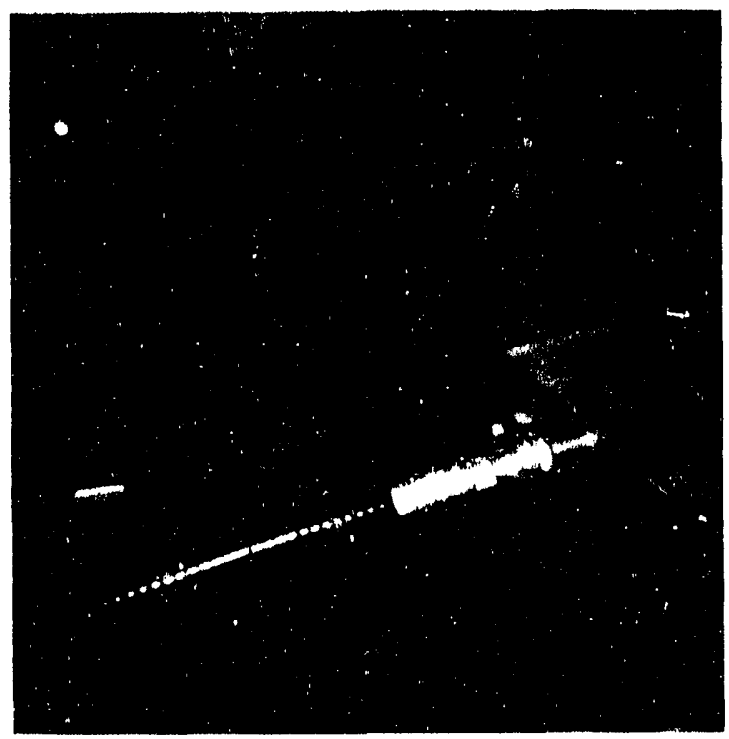

Fig. 57. Inside of the connection vault for the antenna coaxial cables. The junction box lips should be cleaned and coated with conductive cement before replacing the covers. A plug-in MOV should be installed in the receptacle that powers the sump pump.

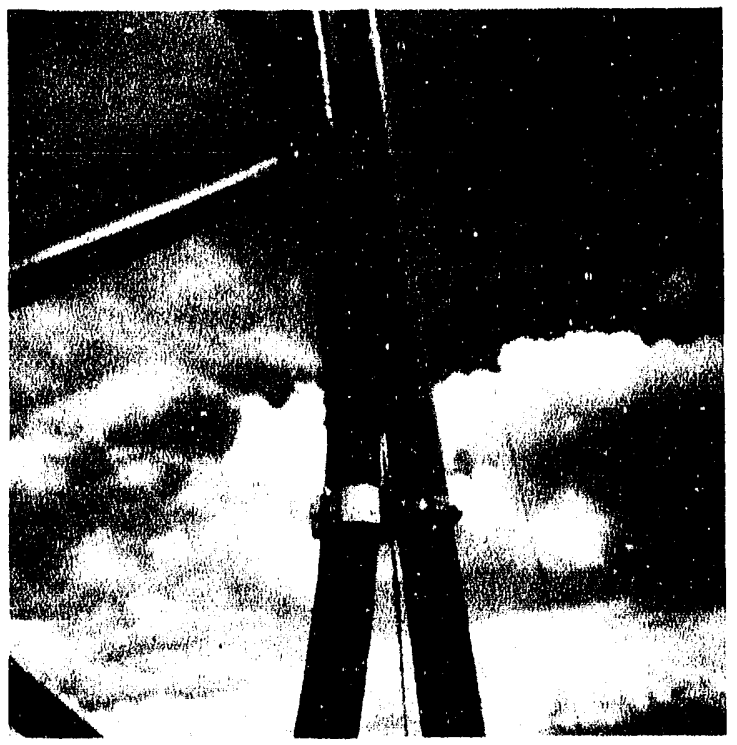

Fig. 58. Shield ground for the Heliax of antenna RLP-2. The shield is grounded with an Andrew grounding kit that ties to a piece of copper tubing. This type of shield grounding should be added to all Heliax cables in the antenna system. 

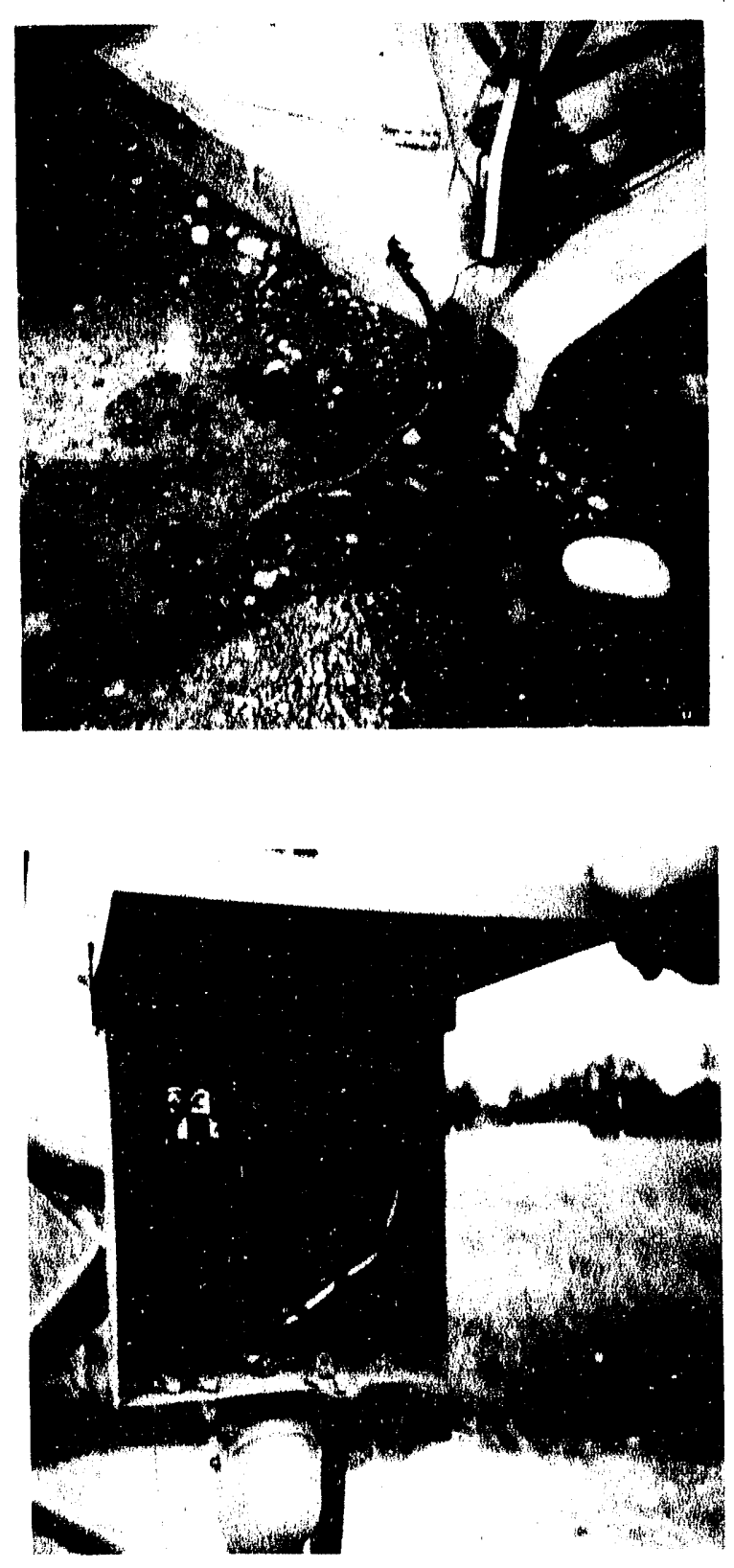

Fig. 59. Base of the tower for antenna RLP-2. The braid connects to a piece of copper tubing that runs into the ground. The grounding should be upgraded with an appropriate counterpoise as discussed in the text.

Fig. 60. Power box for the rotor of antenna RLP-2. The existing MOVs should be removed and reinstalled on the load side of the breakers from line to neutral and from neutral to ground. A V130PA20A MOV should be installed from line to ground. 


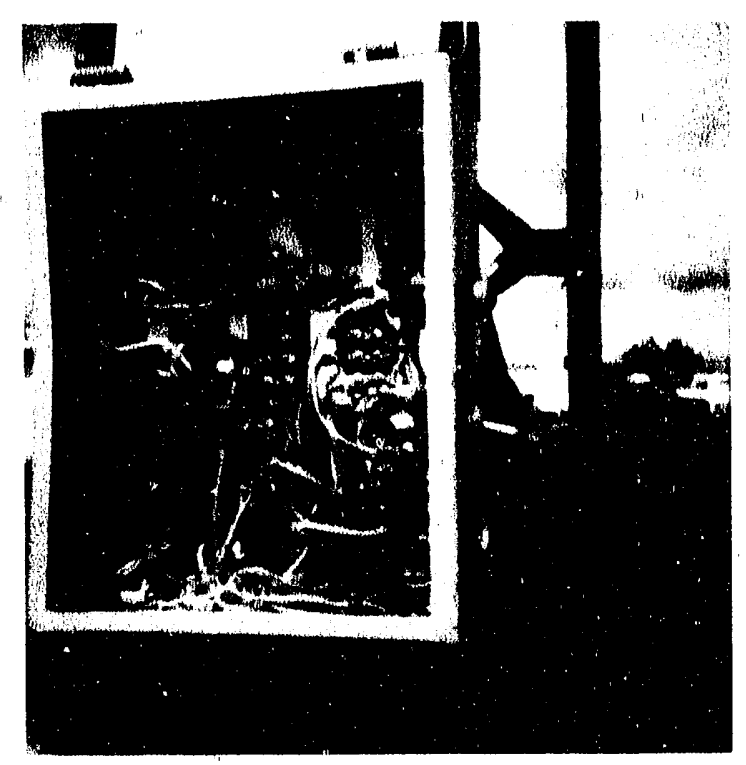

Fig. 61. Wiring and control box for antenna RLP-2. The terminals in this box should have V130LA10A MOVs installed from each conductor to case ground.

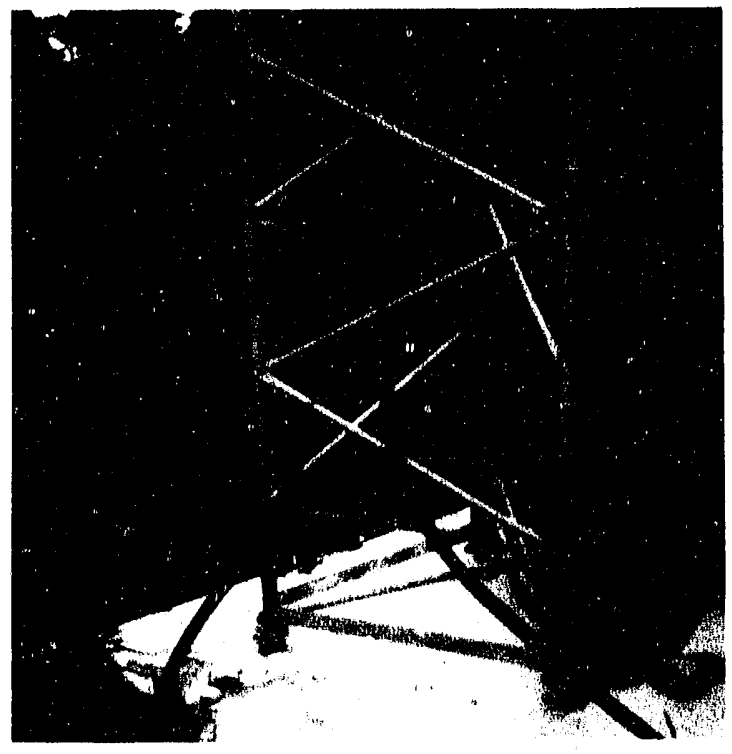

Fig. 62. Base of the support tower for the Spira-cone antenna. Andrew grounding kits should be installed on the shields of the two Heliax cables near the base of the tower. Improve the tower grounding with counterpoise techniques as described in the text. 


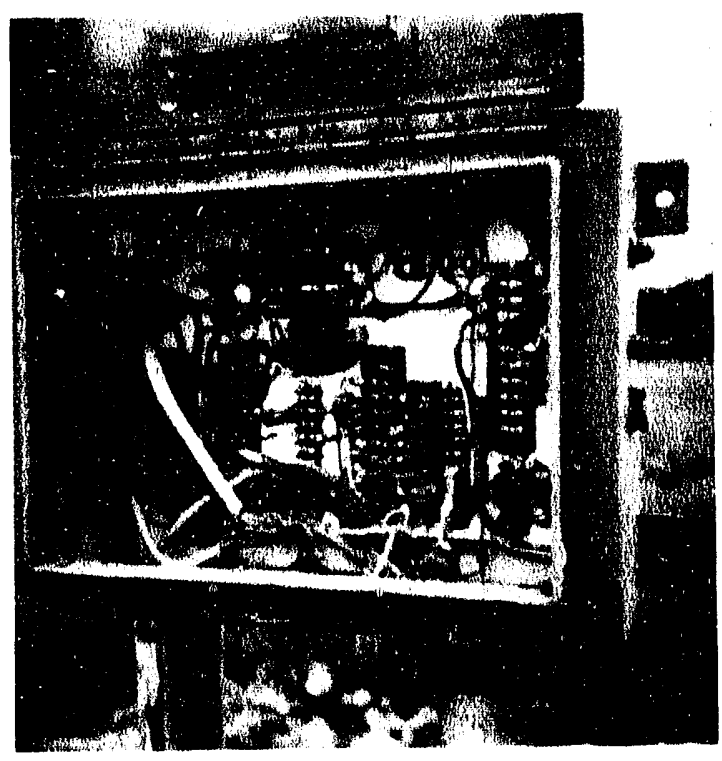

Fig. 63. Control and terminal box for antenna RLP-1. The control lines are presently protected by CG-230 gas gaps with $5-\Omega$ series resistors. These protectors should be removed and replaced by V130LA10A MOVs installed from each terminal to case ground. Rust and corrosion should be removed at the time of the protection upgrade.

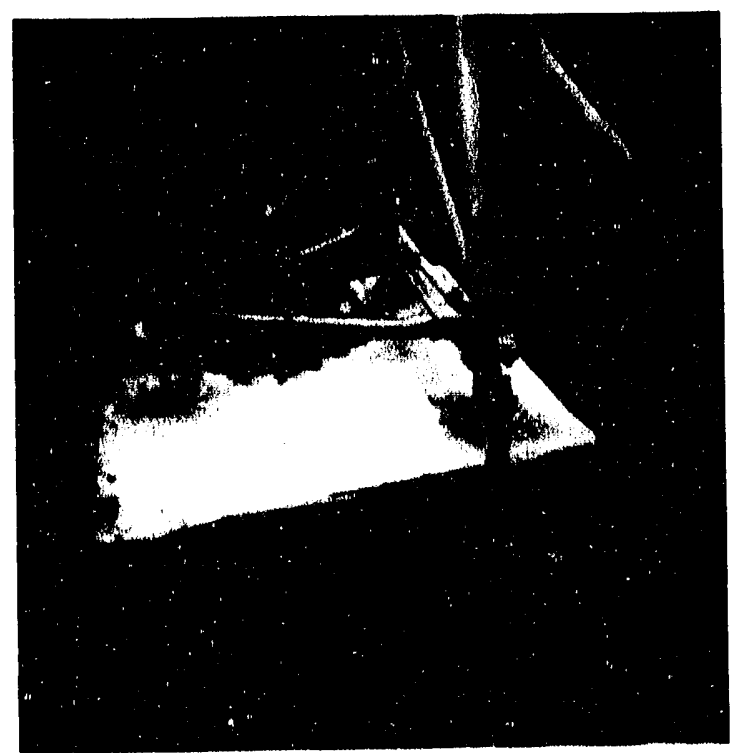

Fig. 64. Base of the tower for antenna RLP-1. The tower is presently grounded with a single ground wire that connects to a grounding network. The grounding should be upgraded by installing a counterpoise that ties back to the tower. 


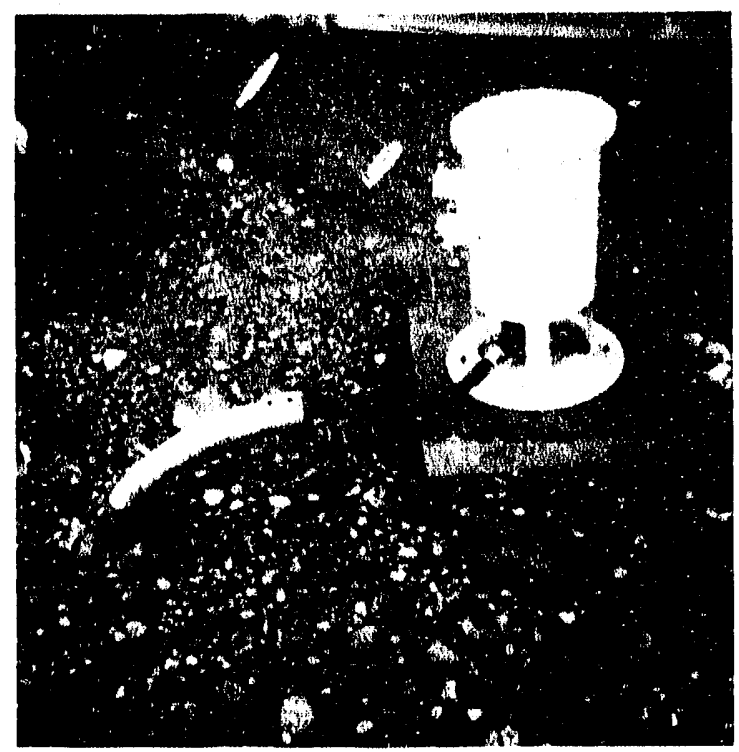

Fig. 65. Balun for antenna FLP-1. The anteina side of the balun should be protected with UGT-7.5 gas tubes and $100-\mathrm{k} \Omega, 100-\mathrm{W}$ resistors as described in the text. The grounding for the balun and the coaxial cable should be upgraded with a counterpoise.

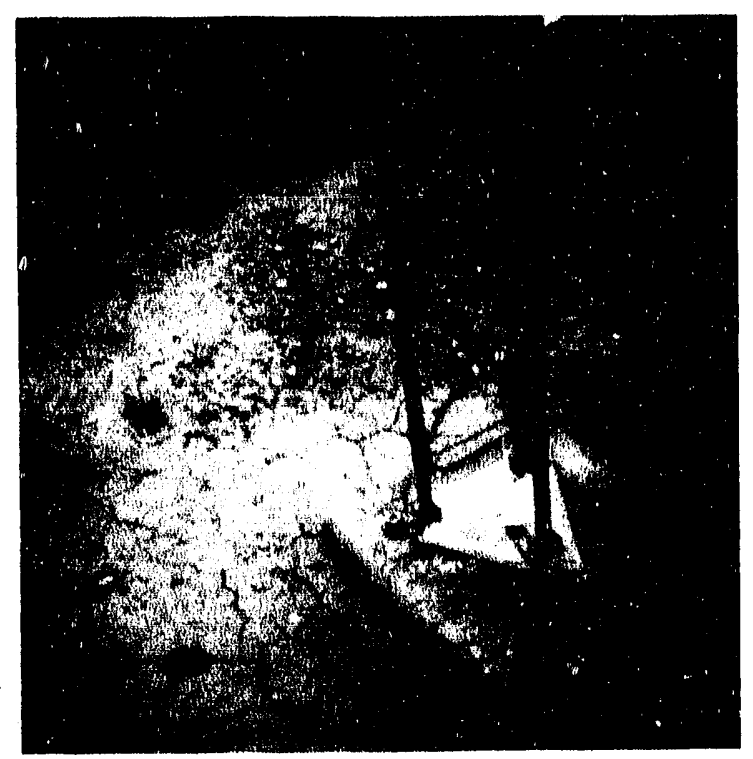

Fig. 66. Base of the support tower for antenna FLP-1. The tower presently has one ground wire that connects to an undetermined grounding network. The grounding should be upgraded to include a counterpoise that ties directly to the antenna. 


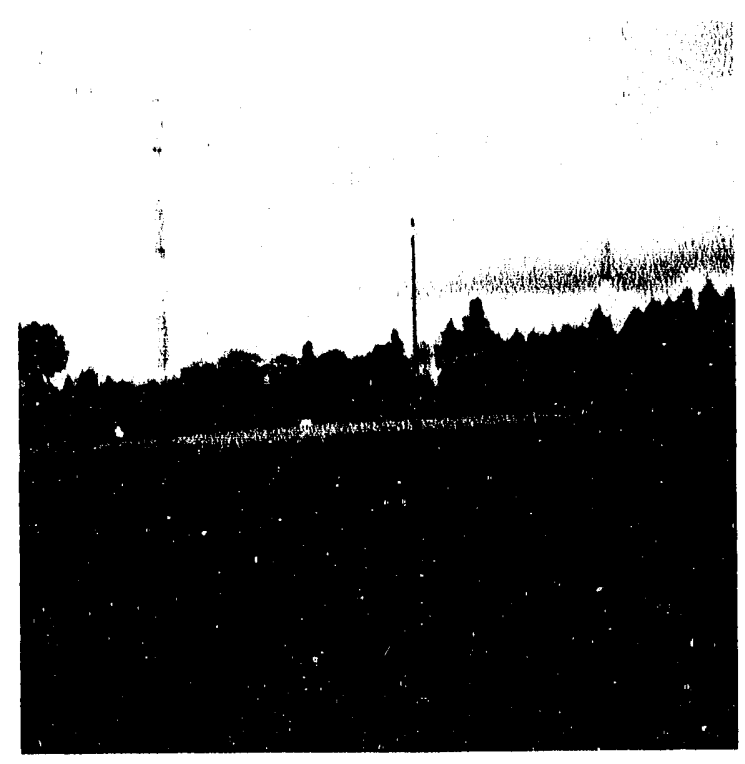

Fig. 67. Fan doublet antenna with a balun on the center post. The balun should be protected with UGT-7.5 gas tubes and resistors as described in the text.

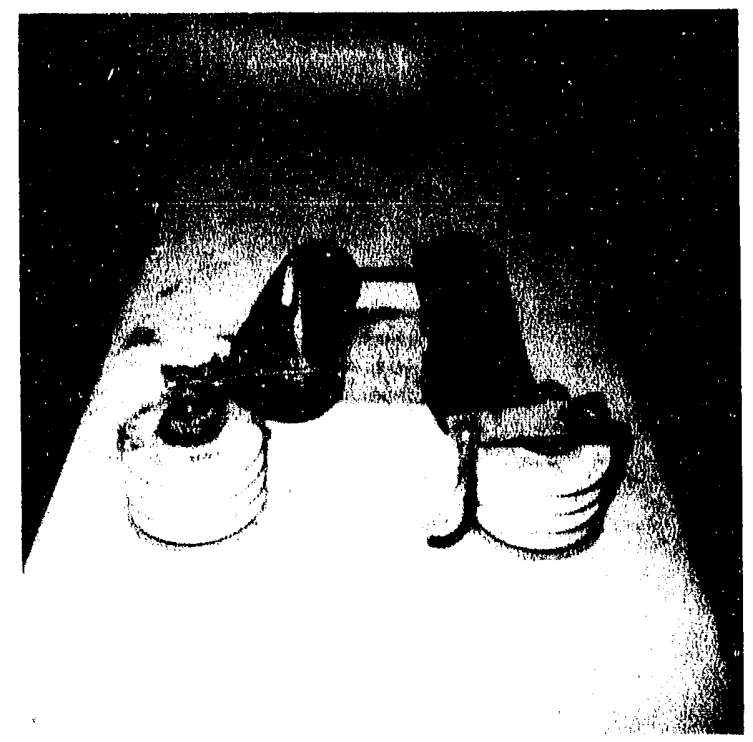

Fig. 68. A 10-kW balun of the type used for the fan doublet antennas. The UGT-7.5 gas tubes and the $100-\mathrm{k} \Omega$, 100 -W resistors should be installed from each terminal to case ground. The text and drawings provide details for the installation. 


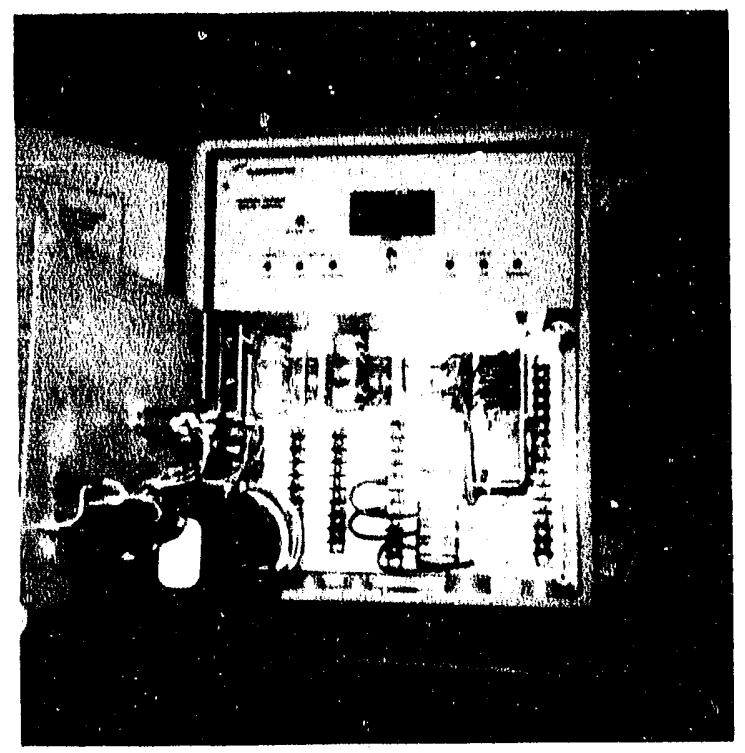

Fig. 69. Rotor box for the new log periodic antennas. The incoming power lines should have V130LA10A MOVs installed from line to neutral and line to ground. The control lines should be protected by installing V130LA10A MOVs from each conductor to case ground.

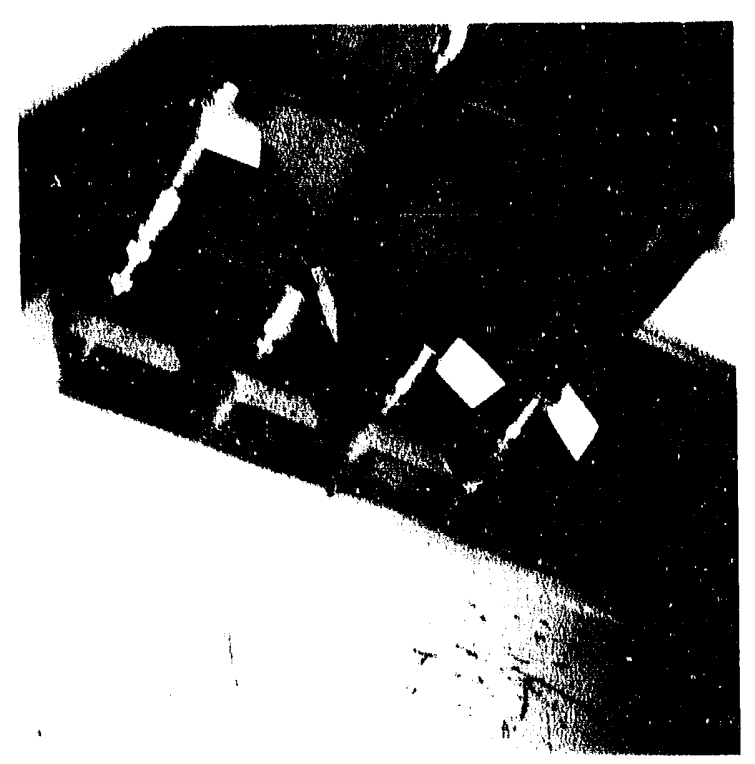

Fig. 70. High-power coaxial penctrations on the outside of the shiclded room. The connectors are type $\mathrm{HN}$ and do not presently have coaxial protectors installed. The penetrations should be upgraded to newer EIA-type flanges and protectors installed at that time. 


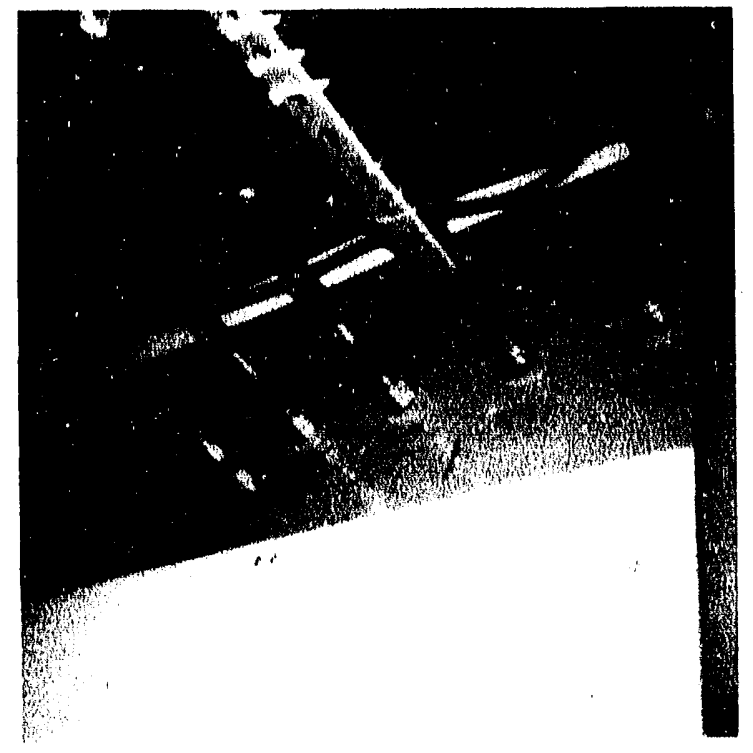

Fig. 71. High-power coaxial penetrations on the inside of the shielded room. The connectors are type LC and are mated to $7 / 8$-in. Heliax. The penetrations should be upgraded. All unused ports should be capped or terminated.

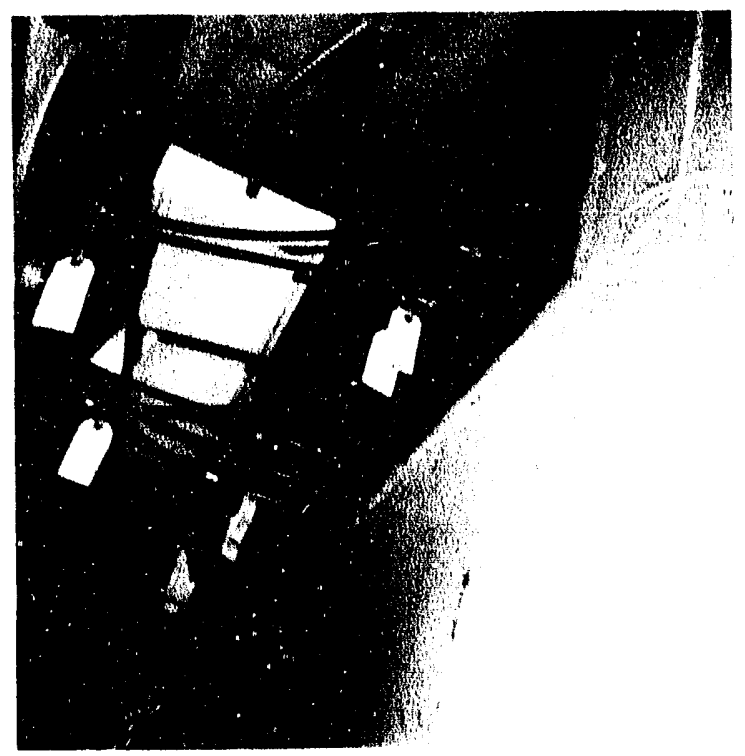

Fig. 72. Low-power coaxial penctrations on the outside of the shiclded room. These are type $\mathrm{N}$ connectors and are considered sufficient for the powers and frequencies on these cables. Note that no protectors are presently installed. 


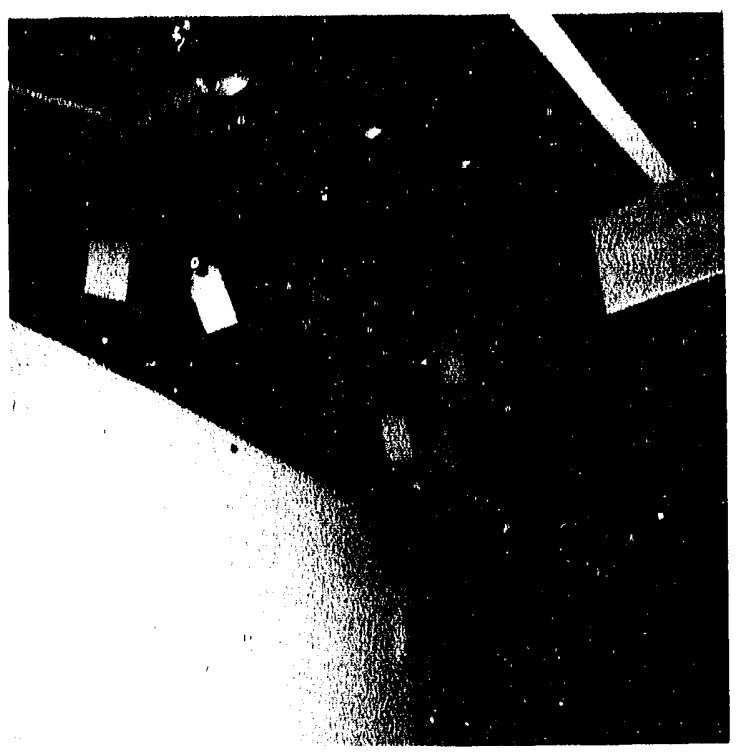

Fig. 73. Low-power coaxial penctrations on the inside of the shielded room. These are type $\mathrm{N}$ connectors with no protectors presently installed. Coaxial protectors should be installed on these lines as described in the text and drawings.

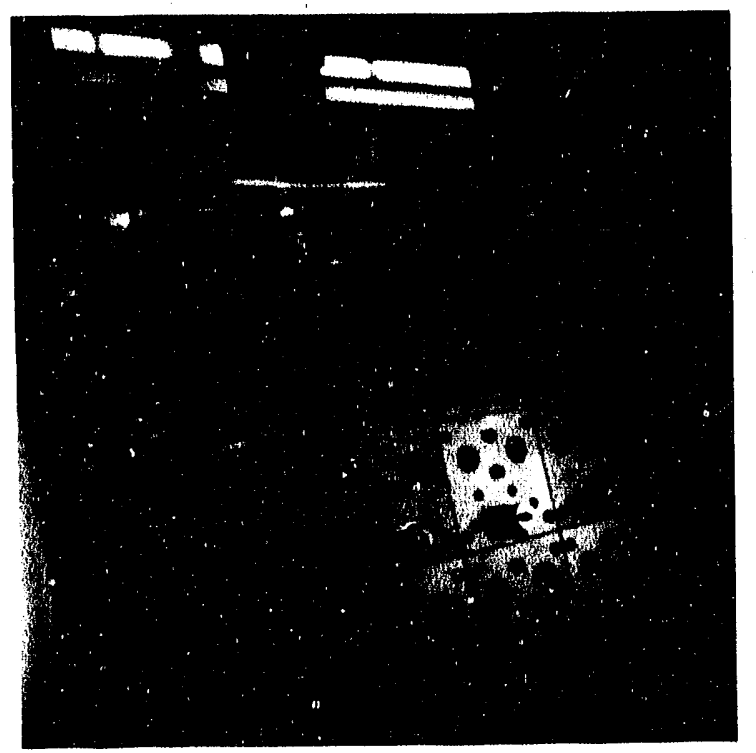

Fig. 74. Rear of the if switching matrix. The existing UGT-4.0 gas tubes should be removed and replaced with UGT-6.0 gas discharge tubes as described in the text. 


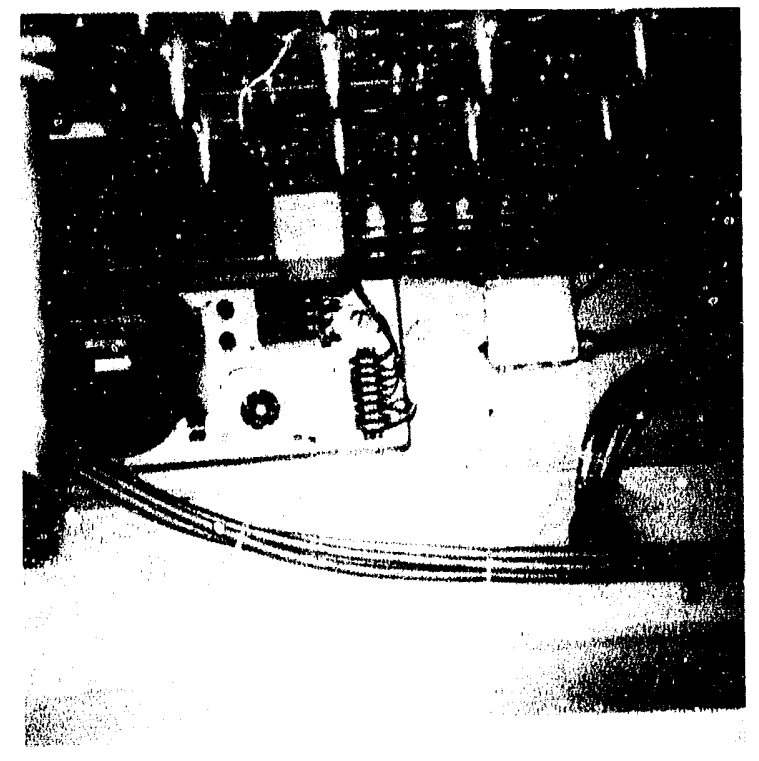

Fig. 75. Control transformer for the if switching matrix. Install V130LA10A MOVs from hot to neutral and hot to ground at the terminal strip.

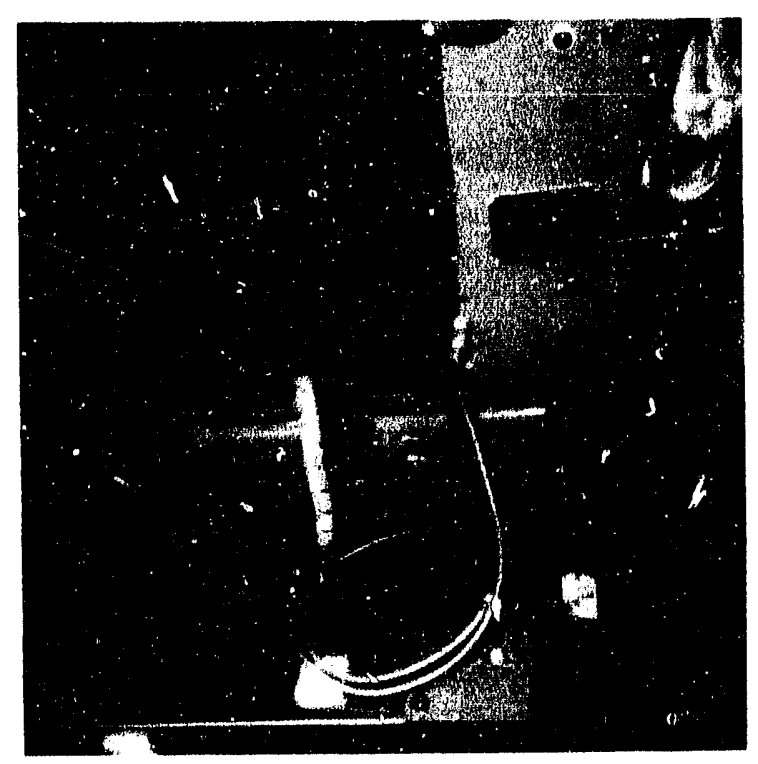

Fig. 76. Rear of the Harris RF-745-02 equipment. An FCC-250-1000-N coaxial protector should be installed on the coaxial line output of the $1-\mathrm{kW}$ driver. The receiver input should be protected with an hf receiver protector on the receiver side of the transmit/receive switch. Protect both the Group 1 and Group 2 equipment in this manner. 

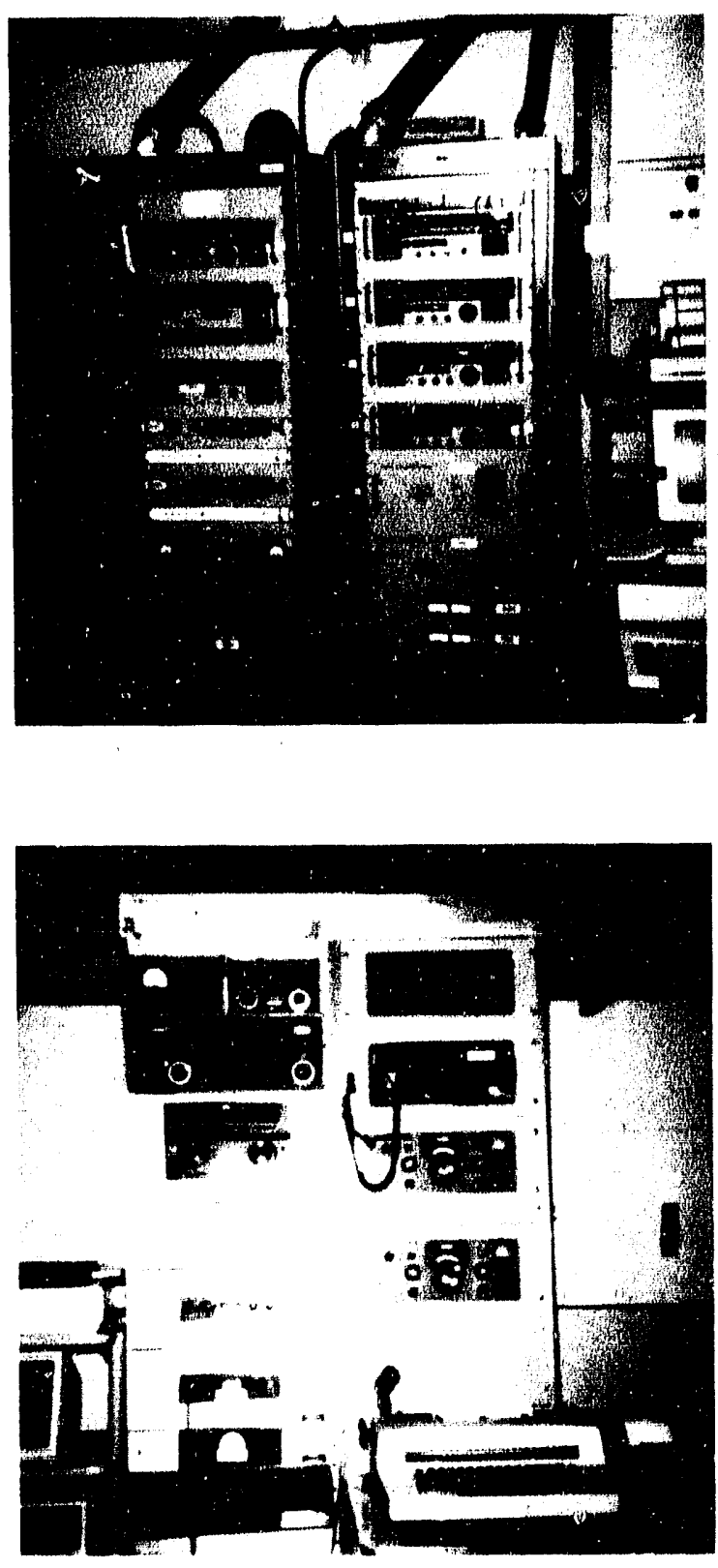

Fig. 77. Harris $A 1$ and $A 2$ equipment racks. The $1-\mathrm{kW}$ driver should have an FCC-250-1000-N coaxial protector installed. Protect all four receivers with the BNC version of the new FRC hf coaxial protector. Both cabinets should have plug-in MOVs installed in the outlet strips.

Fig. 78. KWT-6 No. 1 and auxiliary equipment rack No. 1. Install an FCC-450-3.3-BNC coaxial protector on the frequency generator and an FCC-250-1000-N coaxial protector on the transmitter output. The Collins monitors should have phono versions of the FRC hf protector installed. Install FCC-450-3.3-L protectors in the satellite receivers on the receiver side of the transmit/receive switch. The KWT-6 rack should have V130LA10A MOVs installed on the power terminals from hot to neutral and hot to ground. The auxiliary equipment rack should have a plug-in MOV installed in the power outlet. 


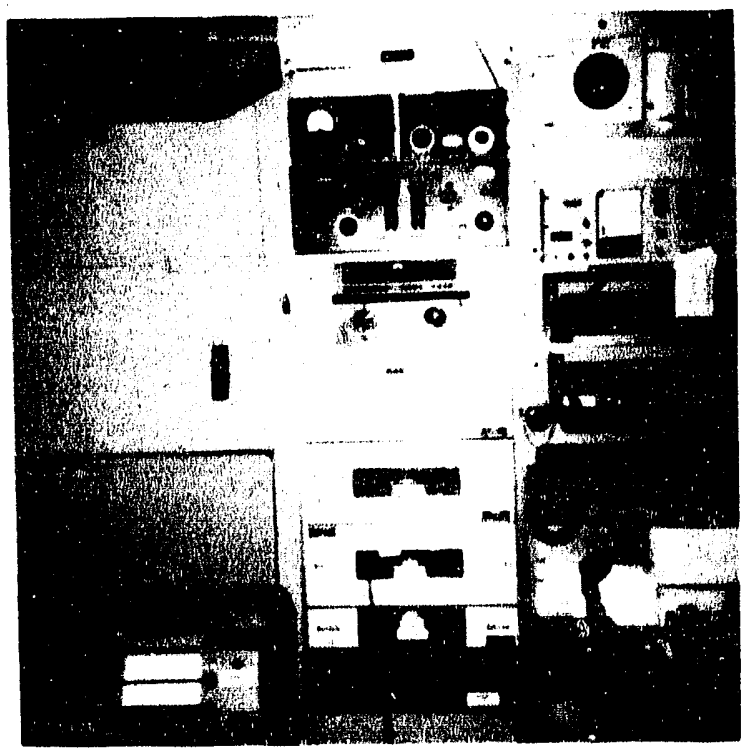

Fig. 79. KWT-6 No. 2. Install a BNC version of the FRC hf coaxial protector on the receiver input and an FCC-250-1000-N coaxial protector on the transmitter output. Install V130LA10A MOVs on the ac power to the rack, from hot to neutral and hot to ground.

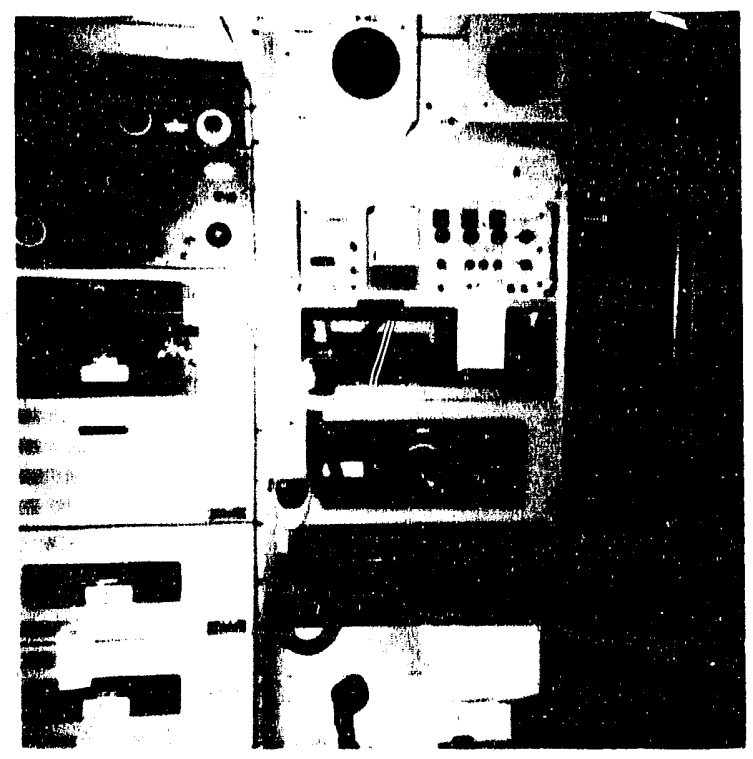

Fig. 80. Auxiliary equipment rack No. 2. The Micom $S$ radio should have an FCC-250-470-UHF protector installed at the rear of the radio. The Collins receiver should have a phono version of the FRC hf protector installed. Other radios will have the coaxial cables protected at the bulkhead penetration. Install a plug-in MOV in the power strip of the rack. 


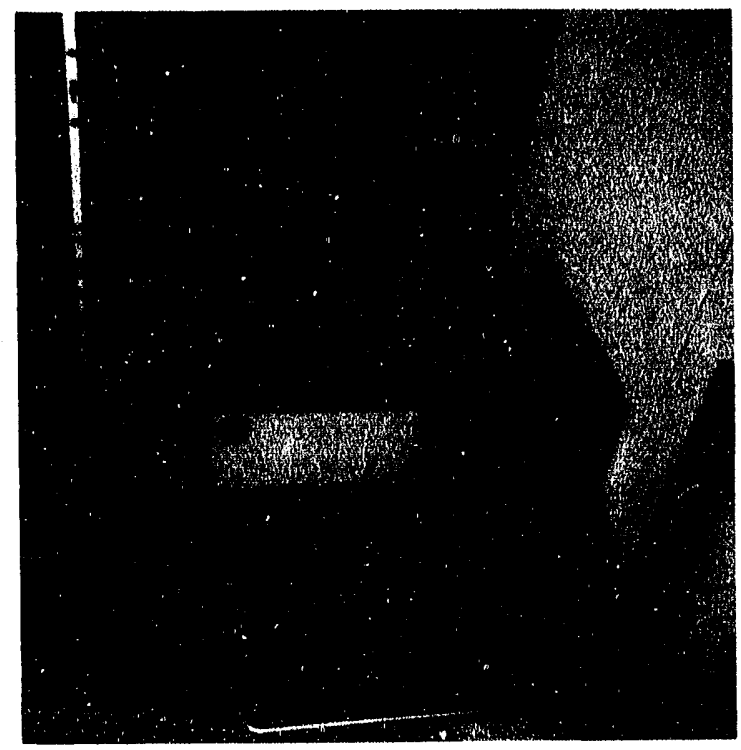

Fig. 81. Public Information Officer radio. The transmitter should be protected by installing an FCC-250-230-N coaxial protector at the bulkhead penetration. An FCC-450-3.3-L bridge should be installed on the receiver side of the transmit/receive switch.

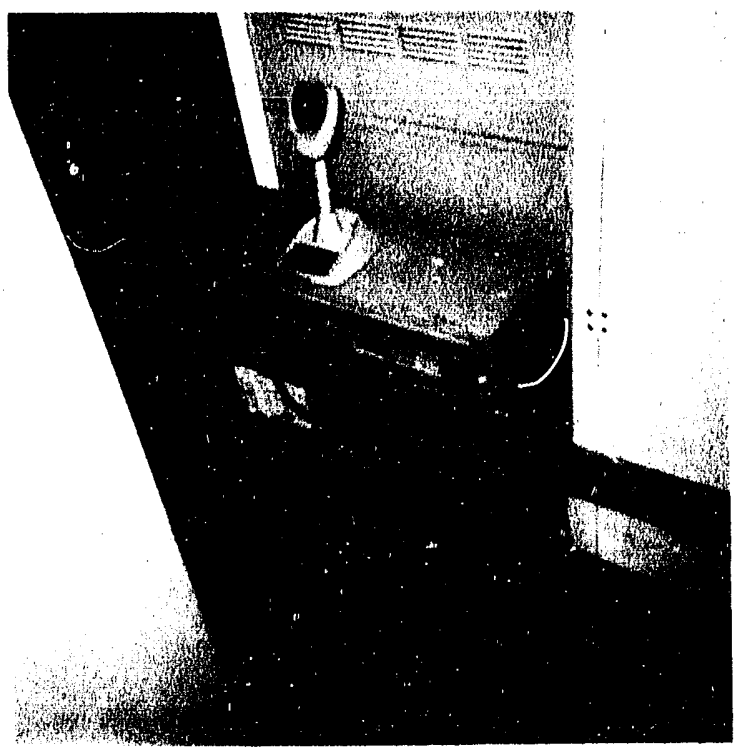

Fig. 82. Corps of Engineers radio. The transmitter should be protected by installing an FCC-250-350- $\mathrm{N}$ coaxial tee at the bulkhead penetration. The receiver should be protected by installing an FCC-450-3.3-Phono protector on the receiver side of the transmit/receive switch. 


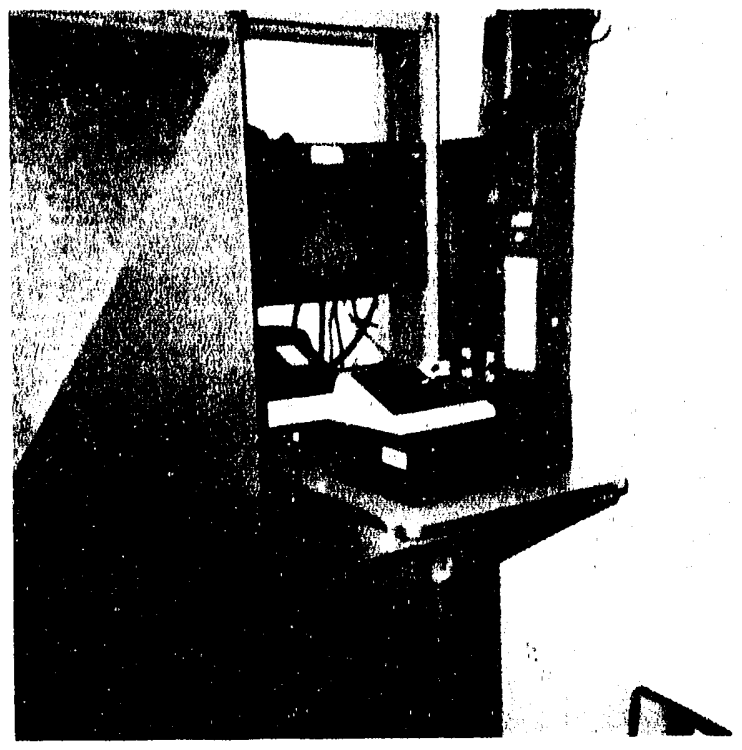

Fig. 83. Duty Officer Radio. The transmitter should be protected by installing an FCC-250-75-N coaxial protector at the bulkhead penetration to the shielded room. The receiver should have an FCC-450-3.3-L diode bridge installed on the receiver side of the transmit/receive switch.

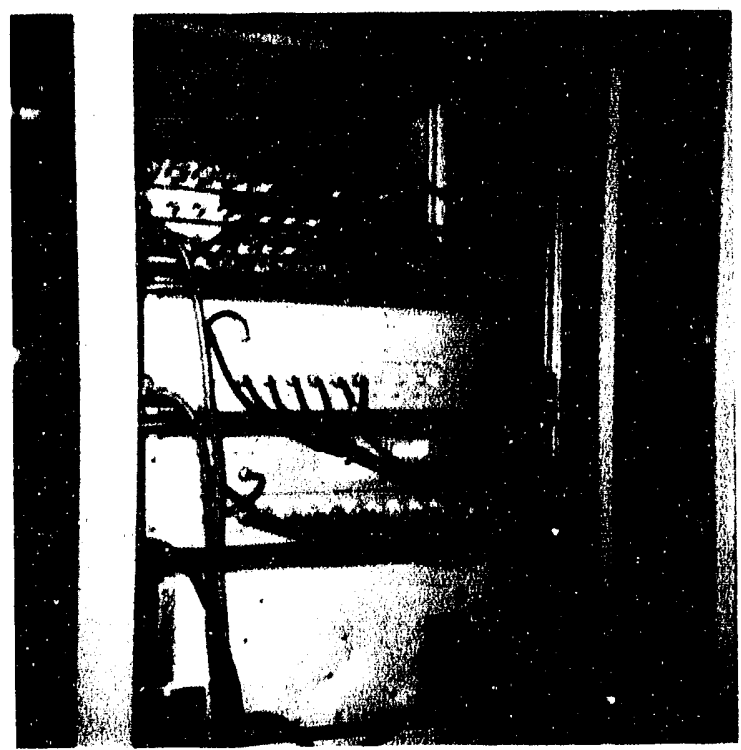

Fig. 84. Receive multicouplers and active preselectors. The multicouplers should be protected with the BNC version of the hf protector being developed for the FRCs. The receive preselectors should be protected with the UHF version of the same protector. A plug-in MOV should be installed in the power strip. 


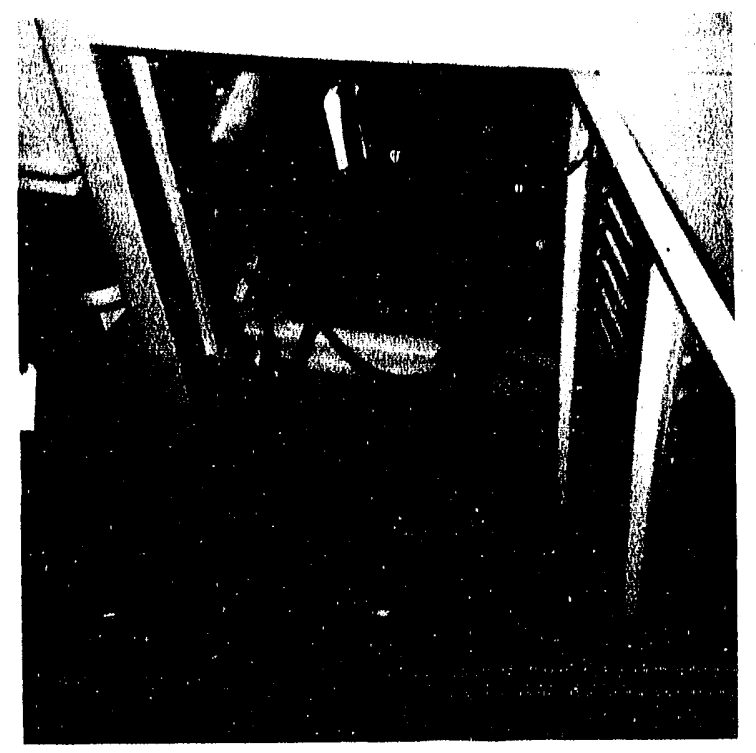

Fig. 85. Rear of the main operating console. The power strips in this console should be protected with a plug-in MOV.

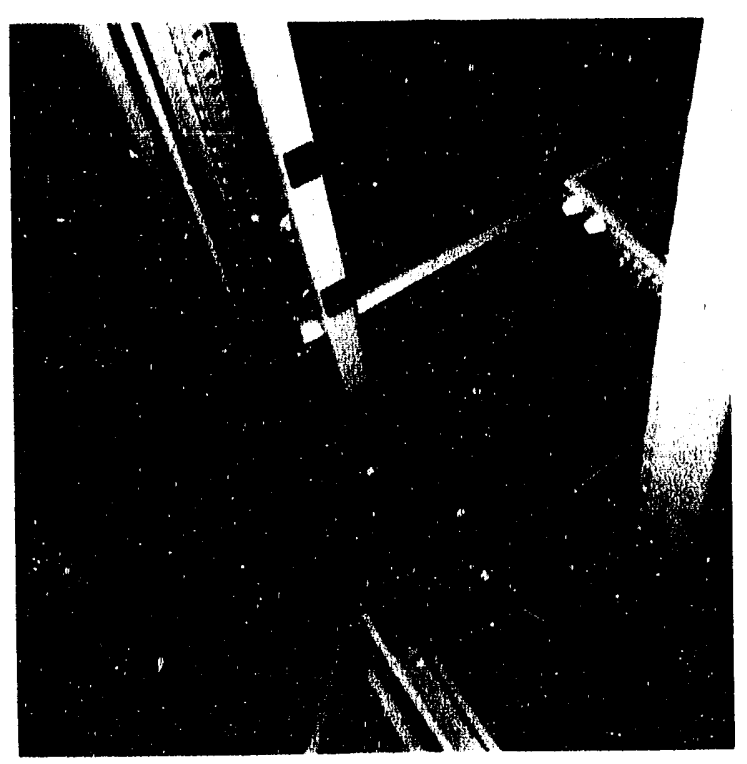

Fig. 86. Rear of the test and teletype equipment rack. The power strip should have a plug-in MOV installed. 


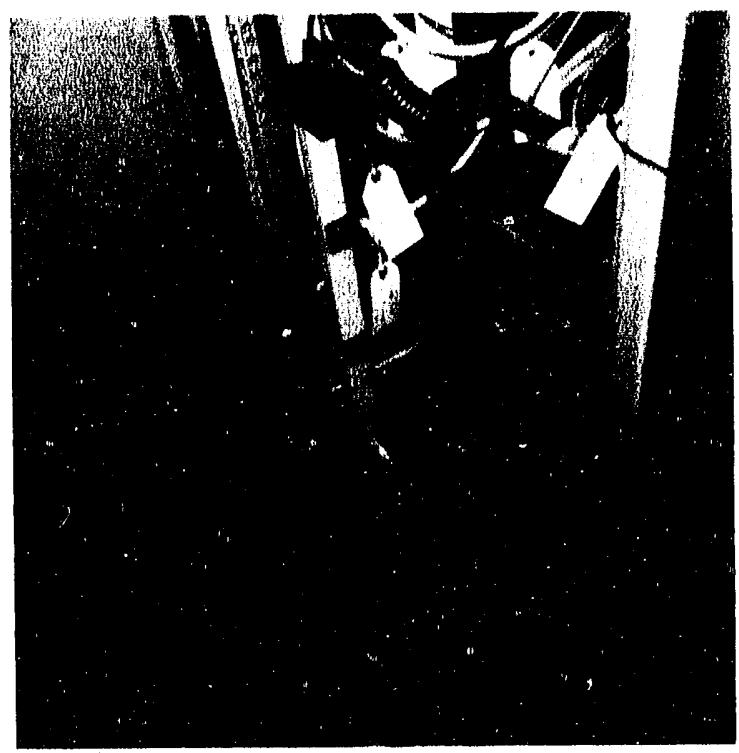

Fig. 87. Rear of the modem bay cabinet. The power strip should have a plug-in MOV installed.

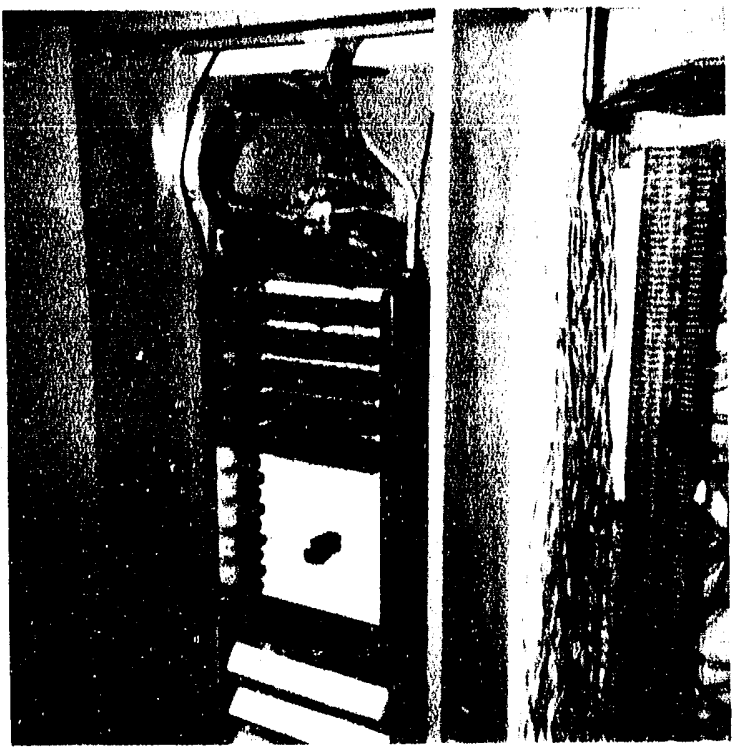

Fig. 88. Punch blocks and heat coils for the telephone room. These heat coils are the only protection presently installed on the incoming telephone lines. 

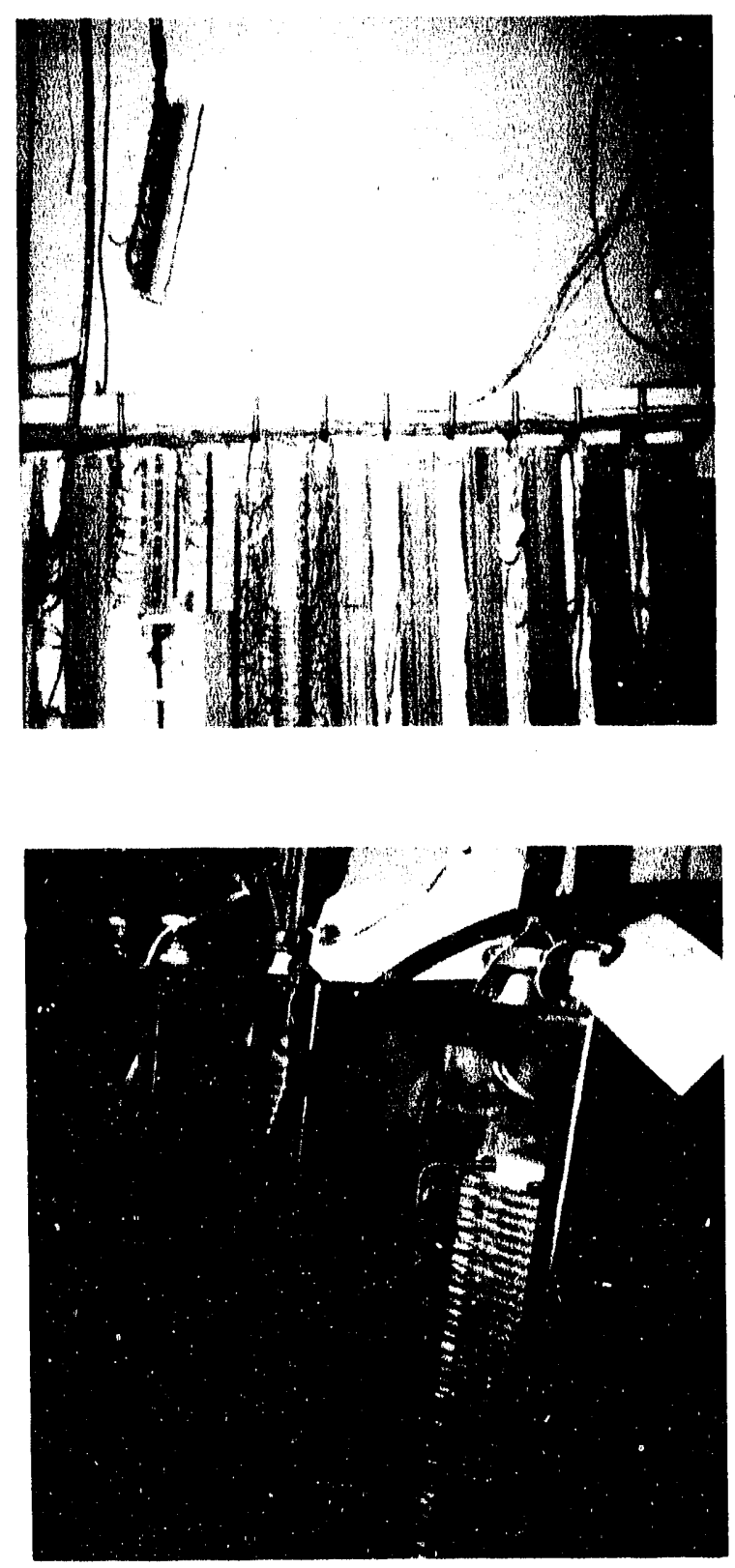

Fig. 89. Telephone terminal blocks. The unterminated cable runs to the shielded enclosure and should either be li:minated or removed.
Fig. 90. Terminal boxes TB2-TB4 at the shiclded room penetration. A portion of these wires have protectors, but some may not be sized properly. Additional punch block space is needed. A general upgrade of the penetrations is recommended, with the protectors resized at the time of the upgrade. 


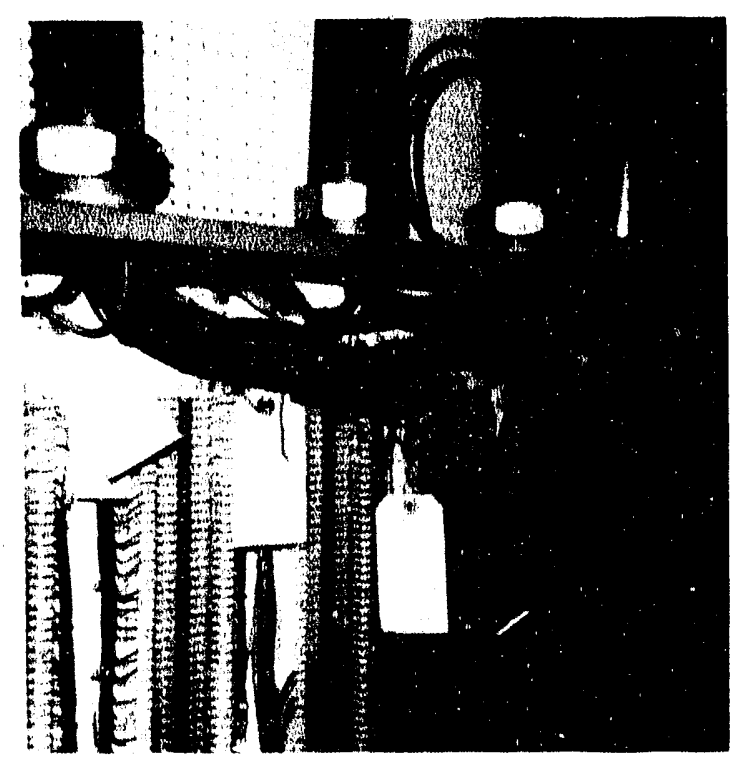

Fig. 91. Terminal box inside the shielded room. No protectors will be installed in this box.

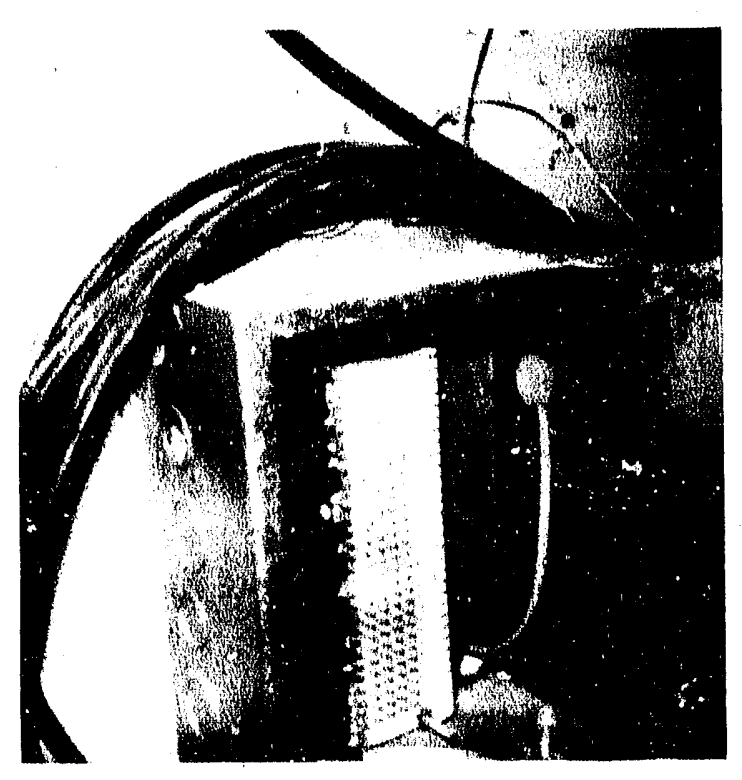

Fig. 92. Spare terminal box with protectors. This terminal box can be used for additional lines. The existing gas gaps may not be sized properly for new cables. The line that runs through the box should be removed. 


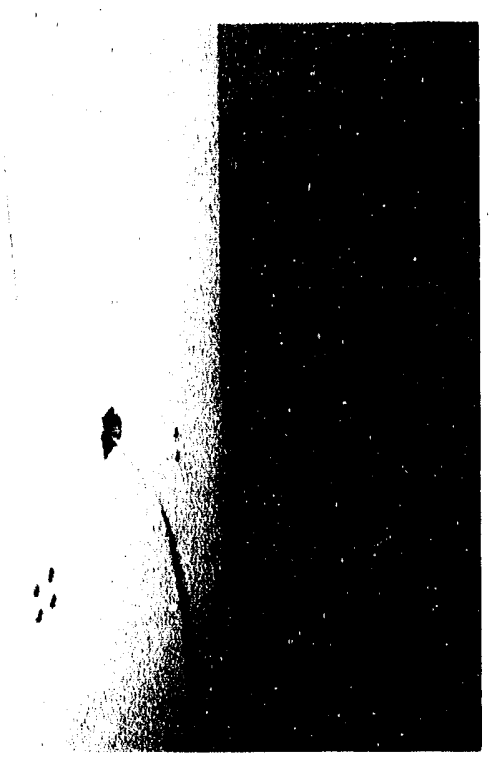

Fig. 93. Inside view of the cable with no penetration protection. This cable is no longer in use and should be removed.

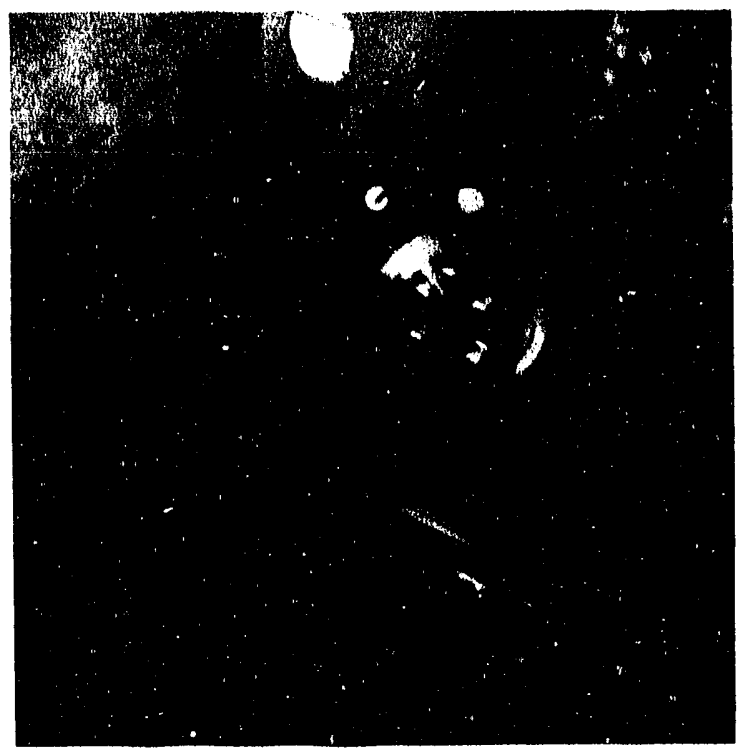

Fig. 94. Ground bus penetration for the telephone lines to the shielded room. The existing V130LA10A MOVs should be removed and replaced with a V130PA20A MOV installed from the bus bar to cabinet ground. 


\section{APPENDIX A-1}

EMP Materials List for FEMA Region X Federal Regional Center, Bothell, Washington

\begin{tabular}{|c|c|c|c|}
\hline $\begin{array}{l}\text { Stock } \\
\text { code }\end{array}$ & Description & Quantity & $\begin{array}{c}\text { FEMA } \\
\text { symbol }\end{array}$ \\
\hline 55003 & FCC-250-470-UHF coaxial tee & 1 ea & 10 \\
\hline 55006 & FCC-250-75-N coaxial tee & 4 ea & $1 \mathrm{j}$ \\
\hline 55007 & FCC-250-1000-N coaxial tee & 4 ea & $1 \mathrm{p}$ \\
\hline 55008 & FCC-450-3.3-UHF coaxial tee & 6 ea & 11 \\
\hline 55013 & FCC-450-3.3-N coaxial tee & 2 ea & $1 \mathrm{~m}$ \\
\hline 55016 & FCC-450-3.3-BNC coaxial tee & 9 ea & $1 \mathrm{i}$ \\
\hline 55018 & FCC-450-3.3-Phono coaxial tee & 4 ea & $1 \mathrm{~b}$ \\
\hline 55019 & FCC-450-3.3-L diode bridge & 3 ea & $3 a$ \\
\hline 55022 & V39ZA6 MOV & 3 ea & $4 \mathrm{e}$ \\
\hline 55025 & V130LA10A MOV & 124 ea & $4 \mathrm{a}$ \\
\hline 55026 & V130PA20A MOV & 94 ca & $4 \mathrm{~b}$ \\
\hline 55030 & V275HE250 MOV & 9 ea & 40 \\
\hline 55031 & V275LA20A MOV & 1355 ea & $4 \mathrm{c}$ \\
\hline 55032 & V275PA40A MOV & 39 ea & $4 \mathrm{~d}$ \\
\hline 55034 & V480HE450 MOV & 9 ea & $4 \mathrm{q}$ \\
\hline 55035 & V480LB20A MOV & 28 ea & $4 \mathrm{~g}$ \\
\hline 55047 & Plug-in protector, req. 1 recept. & 15 ea & $7 d$ \\
\hline 55048 & Cube tap, grounded (pkg of 1) & $2 \mathrm{pkg}$ & $12 \mathrm{~m}$ \\
\hline 55061 & Connector, female tab (pkg of 25 ) & $4 \mathrm{pkg}$ & $10 \mathrm{e}$ \\
\hline
\end{tabular}


APPENDIX A-1 (continued)

\begin{tabular}{|c|c|c|c|}
\hline $\begin{array}{l}\text { Stock } \\
\text { code }\end{array}$ & Description & Quantity & $\begin{array}{l}\text { FEMA } \\
\text { symbol }\end{array}$ \\
\hline 55062 & Connector, male tab (pkg of 10 ) & $1 \mathrm{pkg}$ & $10 \mathrm{~d}$ \\
\hline 55063 & Connector, spade tongue (pkg of 25) & $1 \mathrm{pkg}$ & $10 \mathrm{~b}$ \\
\hline 55064 & Connector, ring tongue (pkg of 25 ) & $1 \mathrm{pkg}$ & $10 \mathrm{a}$ \\
\hline 55065 & Connector, butt splice (pkg of 10 ) & $1 \mathrm{pkg}$ & $10 \mathrm{c}$ \\
\hline 55077 & Machine screw, $10-32 \times 3 / 4(20 / \mathrm{pkg})$ & $2 \mathrm{pkg}$ & $11 \mathrm{e}$ \\
\hline 55079 & Sheet metal screw, No. $8 \times 3 / 8(20 / \mathrm{pkg})$ & $2 \mathrm{pkg}$ & $11 \mathrm{i}$ \\
\hline 55084 & Washer, lock, No. 8 (pkg of 50) & $1 \mathrm{pkg}$ & $11 \mathrm{j}$ \\
\hline 55085 & Washer, flat, No. 10 (pkg of 20) & $2 \mathrm{pkg}$ & $11 \mathrm{~h}$ \\
\hline 55086 & Washer, flat, No. 8 (pkg of 25) & $2 \mathrm{pkg}$ & 111 \\
\hline 55088 & Pop rivet, $1 / 8 \times 3 / 8$ in. $(50 / \mathrm{pkg})$ & $4 \mathrm{pkg}$ & $11 \mathrm{~m}$ \\
\hline 55089 & Tubing, Teflon, 0.034-in. ID & 4 ea & $12 \mathrm{~g}$ \\
\hline 55090 & Shrink tubing, $1 / 4$-in. OD $(2 \mathrm{ft})$ & $1 \mathrm{ea}$ & $12 \mathrm{f}$ \\
\hline 55091 & Shrink tubing, $3 / 8$-in. OD $(2 \mathrm{ft})$ & 1 ea & $12 n$ \\
\hline 55092 & Shrink tubing, $1 / 2$-in. OD $(2 \mathrm{ft})$ & 1 ea & 120 \\
\hline 55093 & Wire, hook-up, Teflon & $20 \mathrm{ft}$ & 121 \\
\hline 55094 & Braid, tinned copper (2 $\mathrm{ft})$ & $10 \mathrm{ea}$ & $6 \mathrm{a}$ \\
\hline 55098 & Copper strip, 3 in. wide & $3 \mathrm{ft}$ & $6 q$ \\
\hline 55099 & Crimping tool & $1 \mathrm{ca}$ & $12 b$ \\
\hline 55100 & Riveting tool & $1 \mathrm{ca}$ & $12 \mathrm{c}$ \\
\hline 55101 & Tap, thread cutting, No. 10-32 & $1 \mathrm{ca}$ & $12 \mathrm{c}$ \\
\hline 55102 & Drill bits, No. 21 and No. 29 (1 cal) & $1 \mathrm{pkg}$ & $12 \mathrm{~d}$ \\
\hline
\end{tabular}


APPENDIX A-1 (continued)

\begin{tabular}{llrr}
\hline $\begin{array}{l}\text { Stock } \\
\text { code }\end{array}$ & \multicolumn{1}{c}{ Description } & Quantity & $\begin{array}{c}\text { FEMA } \\
\text { symbol }\end{array}$ \\
\hline 55104 & Emery cloth, sheet & 2 sh & $6 \mathrm{~g}$ \\
55105 & Label, "EMP SUPPRESSOR" (pkg of 25) & $1 \mathrm{pkg}$ & $12 \mathrm{a}$ \\
55106 & Wire ties, nylon, 7 in. (pkg of 4) & $1 \mathrm{pkg}$ & $12 \mathrm{j}$ \\
55107 & Tape, electrical, 3/4 in. & 1 ro & $6 \mathrm{~d}$ \\
55108 & Adhesive, RTV (3-oz tube) & 1 tu & $6 \mathrm{c}$ \\
55109 & Conductive epoxy (1/2-lb jar) & 1 set & $6 \mathrm{~b}$ \\
TBP & Nut, 10-32, hex & $40 \mathrm{ea}$ & \\
TBP & Gasket strip, rf conductive mesh & $20 \mathrm{ft}$ & \\
TBP & Grounding strap kit, Andrew 204989-4 & 10 ea & \\
TBP & FCC-250-230-N coaxial tee & 1 ea & \\
TBP & FCC-250-350-N coaxial tee & 1 ea & \\
TBP & FCC-350A-8000-EIAEC2 coaxial tee & 10 ea & \\
TBP & V230LA20A MOV & 69 ea & \\
\hline
\end{tabular}

\section{NOTES:}

1. The large quantity of V275LA20A MOVs results from FRC personnel's wanting protection for every fluorescent fixture.

2. Zener diodes and gas gaps for the signal line penetrations have not been included (awaiting an upgrade of the penetrations by FRC personnel).

3. The EIA flange-type coaxial protectors have been included in the parts list; however, the other associated hardware cannot be estimated until an installation design is agreed upon. 


\section{APPENDIX A-2}

Recommended EMP Materials Spare Parts List for FEMA Region X Federal Regional Center, Bothell, Washington

\begin{tabular}{|c|c|c|c|c|}
\hline $\begin{array}{l}\text { Stock } \\
\text { code }\end{array}$ & Description & Quantity & & $\begin{array}{l}\text { FEMA } \\
\text { symbol }\end{array}$ \\
\hline 55003 & FCC-250-470-UHF coaxial tee & 1 & ea & 10 \\
\hline 55006 & FCC-250-75-N coaxial tee & 1 & Ea & $1 \mathrm{j}$ \\
\hline 55007 & FCC-250-1000-N coaxial tee & 1 & ea & $1 \mathrm{p}$ \\
\hline 55008 & FCC-450-3.3-UHF coaxial tee & 1 & ea & 11 \\
\hline 55013 & FCC-450-3.3-N coaxial tee & 1 & ea & $1 \mathrm{~m}$ \\
\hline 55016 & FCC-450-3.3-BNC coaxial tce & 3 & ea & $1 \mathrm{i}$ \\
\hline 55018 & FCC-450-3.3-Phono coaxial tee & 1 & ea & $1 \mathrm{~b}$ \\
\hline 55019 & FCC-450-3.3-L diode bridge & 1 & ea & $3 a$ \\
\hline 55022 & V39ZA6 MOV & 3 & ea & $4 \mathrm{e}$ \\
\hline 55025 & V130LA10A MOV & 10 & ea & $4 a$ \\
\hline 55026 & V130PA20A MOV & 9 & ea & $4 \mathrm{~b}$ \\
\hline 5503() & V275HE250 MOV & 3 & ea & 40 \\
\hline 55031 & V275LA20A MOV & 20 & ea & $4 \mathrm{c}$ \\
\hline 55032 & V275PA40A MOV & 6 & ea & $4 d$ \\
\hline 55034 & V480HE450 MOV & 3 & ea & $4 \mathrm{q}$ \\
\hline 55035 & V480LB20A MOV & 6 & ea & $4 \mathrm{~g}$ \\
\hline 55111 & 3-A pico-fuse (plug-in protector) & 3 & ea & $7 b$ \\
\hline TBP & FCC-250-230-N coaxial tee & 1 & ea & \\
\hline TBP & FCC-25C $350-\mathrm{N}$ coaxial tec & 1 & ea & \\
\hline
\end{tabular}


APPENDIX A-2 (continued)

\begin{tabular}{|c|c|c|c|}
\hline $\begin{array}{l}\text { Stock } \\
\text { code }\end{array}$ & Description & Quantity & $\begin{array}{l}\text { FEMA } \\
\text { symbol }\end{array}$ \\
\hline TBP & FCC-350A-8000-EIAEC2 coaxial tee & $1 \mathrm{ca}$ & \\
\hline TBP & V230LA20A MOV & $6 \mathrm{ca}$ & \\
\hline
\end{tabular}


APPENDIX A-3

EMP Matcrials Cust Estimate to Harden

FEMA Region X Foderal Regional Center, Bothell, Washington

\begin{tabular}{|c|c|c|c|c|}
\hline $\begin{array}{l}\text { Siock } \\
\text { conde }\end{array}$ & Description & Quantity & $\begin{array}{l}\text { Cost } \\
\text { each } \\
\text { (5) }\end{array}$ & $\begin{array}{l}\text { Total } \\
\text { cost } \\
\text { (S) }\end{array}$ \\
\hline $55(x) 3$ & FCC.250.470.LHF coavial lee & 1 ea & 80.00 & $80 .(0)$ \\
\hline $550 \times 6$ & FCC.250.75.N coavial tec & 4 cal & $80 .(x)$ & 320.00 \\
\hline $55(x) 7$ & FCC 25()$-1(x)()-N$ coaxial tee & + ca & 80.00 & 320.00 \\
\hline $55(x) 8$ & FCC $450-3.3-$ UHF coaxial lee & 6 cal & $80 .(x)$ & 480.00 \\
\hline 55013 & FCC $-450-3.3-N$ co axial tec & 2 ca & $80.0(0)$ & $160 .(0)$ \\
\hline 55016 & FCC -45()$-3.3-\mathrm{BNC}^{\prime}$ coaxial tee & 9 ca & 80.0() & 720.00 \\
\hline 55018 & FCC-450-3.3-Phono coaxial tec & 4 ea & 80.00 & 320.00 \\
\hline 55019 & FCC-45()-3.3-L diode bridge & $3 \mathrm{ea}$ & 80.00 & 240.00 \\
\hline 55022 & V39ZA6 MOV & 3 ca & 1.00 & 3.00 \\
\hline 55025 & V130LA10A MOV & $124 \mathrm{ca}$ & 1.00 & 124.00 \\
\hline 55026 & V130PA20A MOV & $94 \mathrm{ca}$ & 12.60 & 1184.40 \\
\hline 55030 & V275HE250 MOV & 9 ca & 36.00 & 324.00 \\
\hline 55031 & V275LA20A MOV & $1355 \mathrm{ea}$ & 1.00 & 1355.00 \\
\hline 55032 & V275PA40A MOV & 39 ea & 12.60 & 491.40 \\
\hline 55034 & V480HE450 MOV & 9 ea & 36.00 & 324.00 \\
\hline 55035 & V480LB20A MOV & $28 \mathrm{ea}$ & 1.00 & 28.00 \\
\hline 55047 & Plug-in protector, req. 1 reccptacle & 15 ea & 19.95 & 299.25 \\
\hline 55048 & Cube tap, grounded (pkg of 1 ) & $2 \mathrm{pkg}$ & 3.95 & 7.90 \\
\hline 55061 & Connector, female tab (pkg of 25) & $4 \mathrm{pkg}$ & 0.10 & 10.00 \\
\hline
\end{tabular}


APPENDIX A-3 (continued)

\begin{tabular}{|c|c|c|c|c|}
\hline $\begin{array}{l}\text { Stock } \\
\text { code }\end{array}$ & Description & Quantity & $\begin{array}{l}\text { Cost } \\
\text { each } \\
(\$)\end{array}$ & $\begin{array}{l}\text { Total } \\
\text { cost } \\
(\$)\end{array}$ \\
\hline 55062 & Connector, male tab ( $\mathrm{pkg}$ of 10 ) & $1 \mathrm{pkg}$ & 0.10 & 1.00 \\
\hline 55063 & Connector, spade tongue (pkg of 25) & $1 \mathrm{pkg}$ & 0.10 & 2.50 \\
\hline 55064 & Conneclor. ring tongue (pkg of 25 ) & $1 \mathrm{pkg}$ & 0.10 & 2.50 \\
\hline 55065 & Connector, bult splice (pkg of 10 ) & $1 \mathrm{pkg}$ & 0.10 & 1.00 \\
\hline 55077 & Machine screw, $10-32 \times 3 / 4(20 / \mathrm{pkg})$ & $2 \mathrm{pkg}$ & 0.05 & 2.00 \\
\hline 55() 79 & Sheet metal screw, No. $8 \times 3 / 8(20 / \mathrm{pkg})$ & 2 pkg & 0.05 & 2.00 \\
\hline 55084 & Washer, lock, No. 8 (pkg of 50) & $1 \mathrm{pkg}$ & 0.02 & 1.00 \\
\hline 55085 & Washer, flat, No. $10(\mathrm{pkg}$ of 20$)$ & $2 \mathrm{pkg}$ & 0.02 & 0.80 \\
\hline 55086 & Washer, flat, No. 8 (pkg of 25) & $2 \mathrm{pkg}$ & 0.02 & 1.00 \\
\hline 55088 & Pop rivet, $1 / 8 \times 3 / 8$ in. $(50 / \mathrm{pkg})$ & $4 \mathrm{pkg}$ & 0.02 & 4.00 \\
\hline 55089 & Tubing, Teflon, 0.034-in. ID & 4 ea & 1.00 & 4.00 \\
\hline 55090 & Shrink tubing, $1 / 4$ in.-OD ( $2 \mathrm{ft})$ & 1 ea & 0.25 & 0.50 \\
\hline 55091 & Shrink tubing, $3 / 8$ in.-OD $(2 \mathrm{ft})$ & 1 ea & 0.50 & 1.00 \\
\hline 55092 & Shrink tubing, $1 / 2$ in.-OD (2 ft) & 1 ea & 0.75 & 1.50 \\
\hline 55093 & Wire, hook-up, Teflon & $20 \mathrm{ft}$ & 0.15 & 3.00 \\
\hline 55094 & Braid, tinned copper & $10 \mathrm{ft}$ & 0.85 & 8.50 \\
\hline 55098 & Copper strip, 3 in. wide & $3 \mathrm{ft}$ & 1.50 & 4.50 \\
\hline 55099 & Crimping tool & 1 ea & 12.00 & 12.00 \\
\hline 55100 & Riveting tool & 1 ea & 10.00 & 10.00 \\
\hline 55101 & Tap, thread cutting, No. $10-32$ & 1 ea & 0.50 & 0.50 \\
\hline 55102 & Drill bits, No. 21 and No. 29 (1 ea) & $1 \mathrm{pkg}$ & 0.50 & 1.00 \\
\hline
\end{tabular}


APPENDIX A-3 (continued)

\begin{tabular}{|c|c|c|c|c|}
\hline $\begin{array}{l}\text { Stock } \\
\text { code }\end{array}$ & Description & $\begin{array}{c}\text { Cost } \\
\text { Quantity } \\
(\$)\end{array}$ & $\begin{array}{l}\text { Total } \\
\text { each } \\
\text { (\$) }\end{array}$ & $\operatorname{cost}$ \\
\hline 55104 & Emery cloth, sheet & $2 \mathrm{sh}$ & 0.50 & 1.00 \\
\hline 55105 & Label, "EMP SUPPRESSOR" (pkg of 25) & $1 \mathrm{pkg}$ & 0.04 & 1.00 \\
\hline 55106 & Wire ties, nylon, 7 in. (pkg of 4) & $1 \mathrm{pkg}$ & 0.10 & 0.40 \\
\hline 55107 & Tape, electrical, $3 / 4$ in. & 1 ro & 2.69 & 2.69 \\
\hline 55108 & Adhesive, RTV (3-oz tubc) & $1 \mathrm{tu}$ & 3.25 & 3.25 \\
\hline 55109 & Conductive epoxy (1/2-lb jar) & 1 set & 25.00 & 25.00 \\
\hline TBP & Nut, 10-32 hex & 40 ea & 0.05 & 2.00 \\
\hline TBP & Gasket strip, rf conductive mesh & $20 \mathrm{ft}$ & 5.00 & 100.00 \\
\hline TBP & Grounding strap kit, Andrew 204989-4 & $10 \mathrm{ea}$ & 29.00 & 290.00 \\
\hline TBP & FCC-250-230-N coaxial tee & 1 ea & 80.00 & 80.00 \\
\hline TBP & FCC-250-350-N coaxial tee & 1 ea & 80.00 & 80.00 \\
\hline TBY & FCC-350A-8000-EIAEC2 coaxial tee & $10 \mathrm{ea}$ & 700.00 & 7000.00 \\
\hline \multirow[t]{2}{*}{ TBP } & V230LA20A MOV & 69 ea & 1.00 & 69.00 \\
\hline & & & TOTAL & 509.59 \\
\hline
\end{tabular}

\section{NOTES:}

1. The large quantity of V275LA20A MOVs results from FRC personnel's wanting protection for every fluoresient fixture.

2. Zener diodes and gas gaps for the signal line penetrations have not been included (awaiting an upgrade of the penetrations by FRC personnel).

3. The EIA flange-type coaxial protectors have been included in the parts list; however, the other associated hardware cannot be estimated until an installation design is agreed upon. 


\section{APPENDIX B}

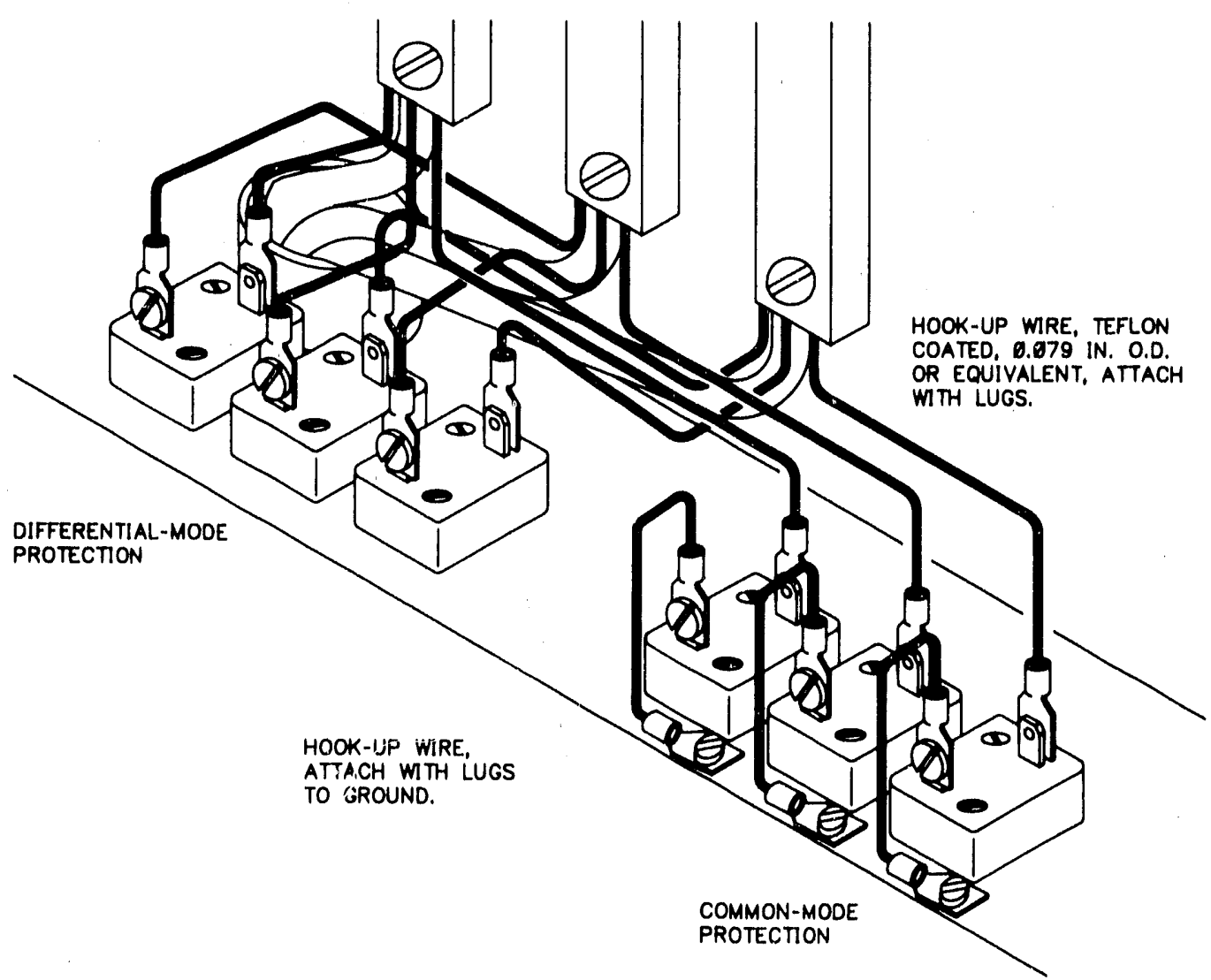

Fig. B.1. Typical installation of DB-Series MOVs in a panel. Keep all lead lengths as short as possible to minimize inductive voltage drops. 


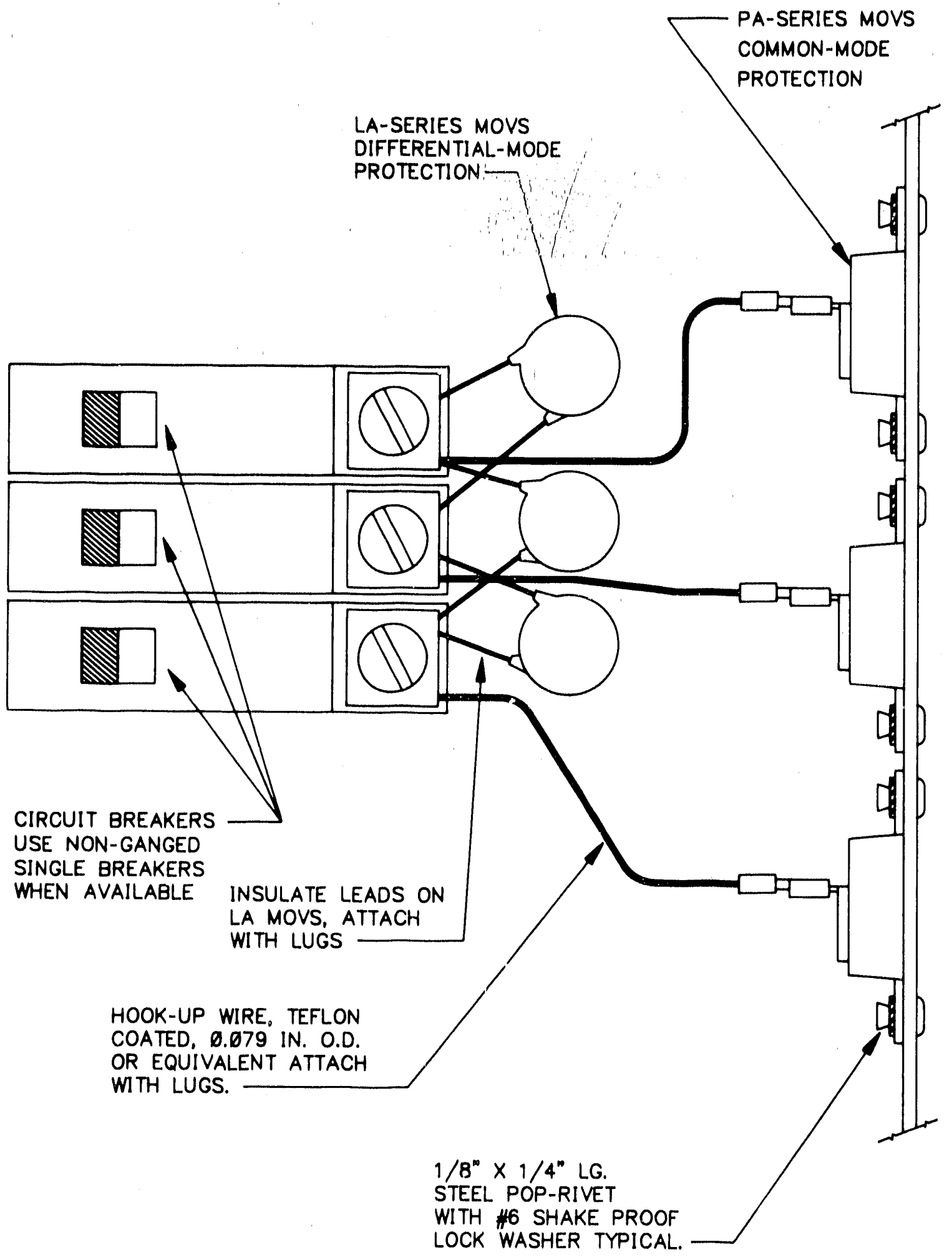

Fig. B.2. Installation of PA-Series and LA-Series MOVs in a panel. Keep all lead lengths as short as possible to minimize inductive voltage drops. 


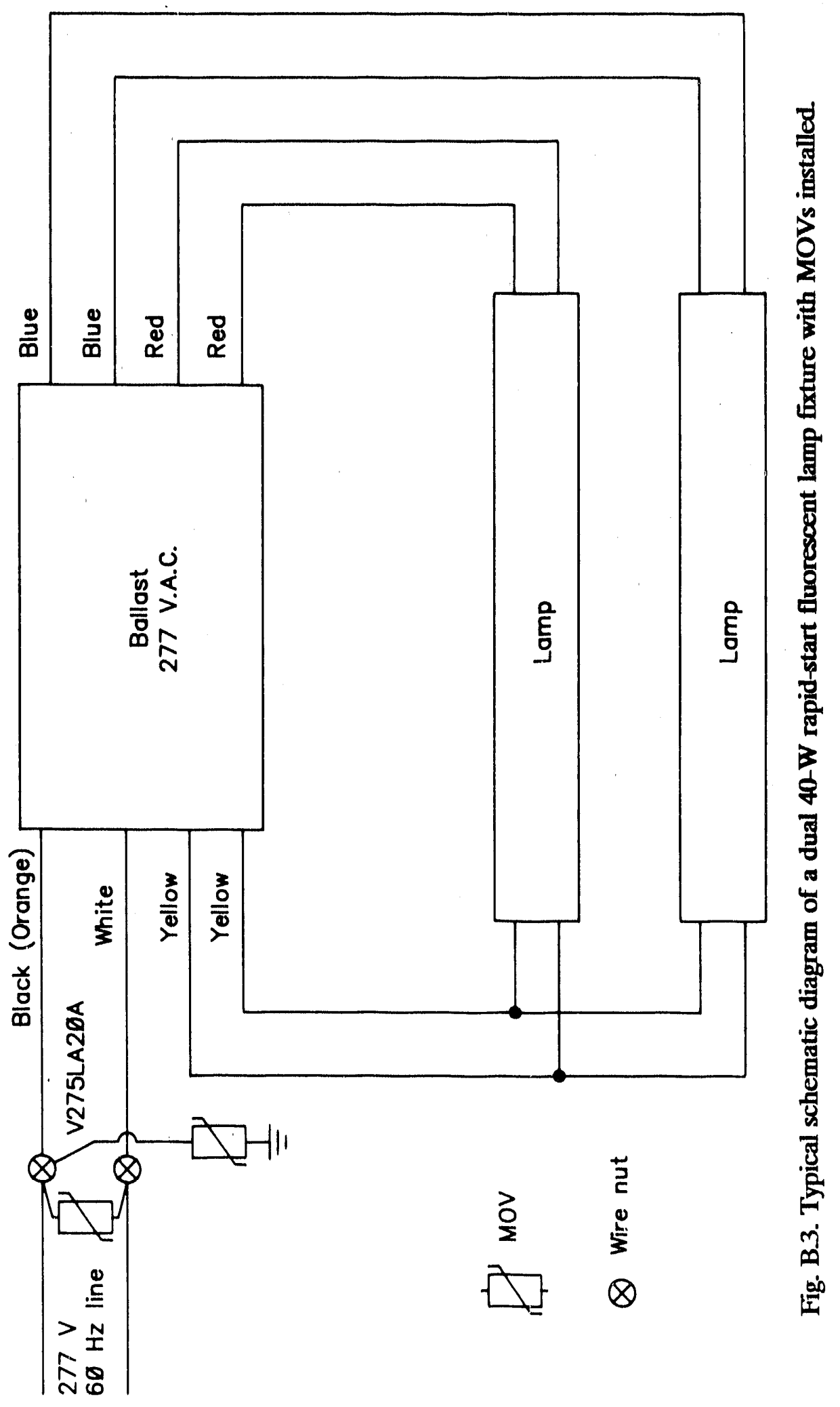




\section{APPENDIX C SIZING OF COAXIAL CABLES}

This appendix contains selected catalog data for the coaxial cables and connectors used for the high-power antenna lines and connectors. An exhaustive discussion will not be given; rather, key points will be presented to direct attention to the important specifications.

Average operating power levels are presented for the 7/8,1-1/4, and $1-5 / 8$ in. Heliax on pages $87,89,91$, and 93 . Note that at $30 \mathrm{MHz}$, the average power is $10.1 \mathrm{~kW}$ for $7 / 8$-in. cable, $17.4 \mathrm{~kW}$ for $1-1 / 4$ in. cable, and $25.3 \mathrm{~kW}$ for $1-5 / 8 \mathrm{in}$. cable. These ratings are based on a voltáge standing wave ratio (VSWR) of 1.0:1 which makes the 7/8-in. Heliax marginal when working into a practical antenna.

However, the real concern and danger is in the peak power (i.e., peak voltage breakdown ratings). Peak power ratings for these cables are given on pages 88,90 , and 92 as $44 \mathrm{~kW}$ for $7 / 8$ in., $90 \mathrm{~kW}$ for $1-1 / 4$ in., and $145 \mathrm{~kW}$ for $1-5 / 8$ in.

Page 84 provides an equation for estimating peak power ratings for either $A M$ or FM cases, but it does not address single sideband (SSB). We will thus need to derive an SSB peak power rating based on peak voltage.

The basic dc relationship for voltage, resistance, and power is

$$
\mathrm{V}=\sqrt{\mathrm{PR}} .
$$

Modifying this equation for ac circuits gives

$$
\mathrm{V}_{\mathrm{rms}}=\sqrt{\mathrm{PZ}},
$$

where $\mathrm{V}_{\text {rms }}$ is the rms value of the voltage, $\mathrm{P}$ is the average power, and $\mathrm{Z}$ is the impedance of the load.

For single sideband transmission, the power output is rated in peak envelope power (PEP). Radio Handbook, Nineteenth Edition defines PEP as the rms power generated at the peak of the modulation envelope. Thus the PEP is the average power present in the radio-frequency signal when the modulating waveform is at an envelope peak. Using the PEP value in the above equation would yield an rms voltage value. A factor of $\sqrt{2}$ must be introduced to represent peak voltage. Substituting into the above equation yields

$$
\mathrm{V}_{\text {peak }}=\sqrt{2 \times \mathrm{PEP} \times \mathrm{Z}_{0}},
$$

where $\mathrm{Z}_{0}$ is the characteristic impedance of the transmission line. A characteristic impedance cannot be maintained in an overall antenna system, however. The mismatches introduced by the transmission line and antenna are typically characterized by VSWR. 
The basic equation for VSWR is given by

$$
\text { VSWR }=\frac{1+|\rho|}{1-|\rho|},
$$

where

$$
\rho=\frac{\mathrm{Z}-\mathrm{Z}_{0}}{\mathrm{Z}+\mathrm{Z}_{0}}
$$

The absolute values can be dropped by analyzing the two cases separately.

Considering the case where $\mathrm{Z}>\mathrm{Z}_{0}$,

$$
\text { VSWR }=\frac{1+\frac{Z-z_{0}}{Z+Z_{0}}}{1-\frac{Z-Z_{0}}{Z+Z_{0}}}
$$

After algebraic reduction,

$$
\mathrm{VSWR}=\frac{\mathrm{Z}}{\mathrm{Z}_{0}} .
$$

Considering the case for $\mathrm{Z}_{0}>\mathrm{Z}$,

$$
\text { VSWR }=\frac{1+\frac{Z_{0}-Z}{Z+Z_{0}}}{1-\frac{Z_{0}-Z}{Z+Z_{0}}} .
$$

After algebraic reduction,

$$
\operatorname{VSWR}=\frac{\mathrm{Z}_{0}}{\mathrm{Z}}
$$

Thus, the VSWR is a dimensionless scaling multiplier that modifies the characteristic impedance $\mathrm{Z}_{0}$ to equal the mismatched impedance. Because the VSWR is an impedance factor, it belongs under the radical with the impedance term.

Adding the VSWR into the above equation for peak voltage yields

$$
\mathrm{V}_{\text {peak }}=\sqrt{2 \times \mathrm{PEP} \times \mathrm{Z}_{0} \times \mathrm{VSWR}} .
$$

Squaring both sides of the equation and dividing both sides by $\mathrm{Z}_{0}$ provides an equation for peak power of an SSB signal as given by

$$
\mathrm{P}_{\text {peak }}=2 \times \mathrm{PEP} \times \mathrm{VSWR} .
$$

Letting PEP $=10 \mathrm{~kW}$ and VSWR $=4$ (max rating for Harris equipment),

$$
\mathrm{P}_{\text {peak }}=2 \times 10 \mathrm{~kW} \times 4=80 \mathrm{~kW} .
$$

Thus, the peak power ratings at full VSWR are low for the 7/8-inch Heliax. 
The recommendations in the text call for coaxial protectors rated at $6 \mathrm{kV}$, which is based on the $80-\mathrm{kW}$ peak power and a gas tube safety factor of 3 . Note that the dc breakdown of $7 / 8$-in. Heliax is given at $6 \mathrm{kV}$ on page 88 . Additionally, page 85 gives the dc test voltage for type HN connectors at $4 \mathrm{kV}$, type $\mathrm{LC}$ at $5 \mathrm{kV}$, and the $7 / 8$-in. EIA flange at $6 \mathrm{kV}$.

Under transient conditions from lightning or electromagnetic pulses, the voltage can easily exceed the peak rating of the present installation. Additionally, high VSWRs will be established when the gas tubes fire and may cause voltage breakdown of the cables, especially at the connectors.

The minimum recommendation for an upgrade is 1-1/4 in. Heliax with 1-5/8 in. EIA flanges. Smaller Heliax and connectors may cause feedline or equipment damage during a transient event. 
Figure 1 - Variation of Attenuation with Ambient Temperature

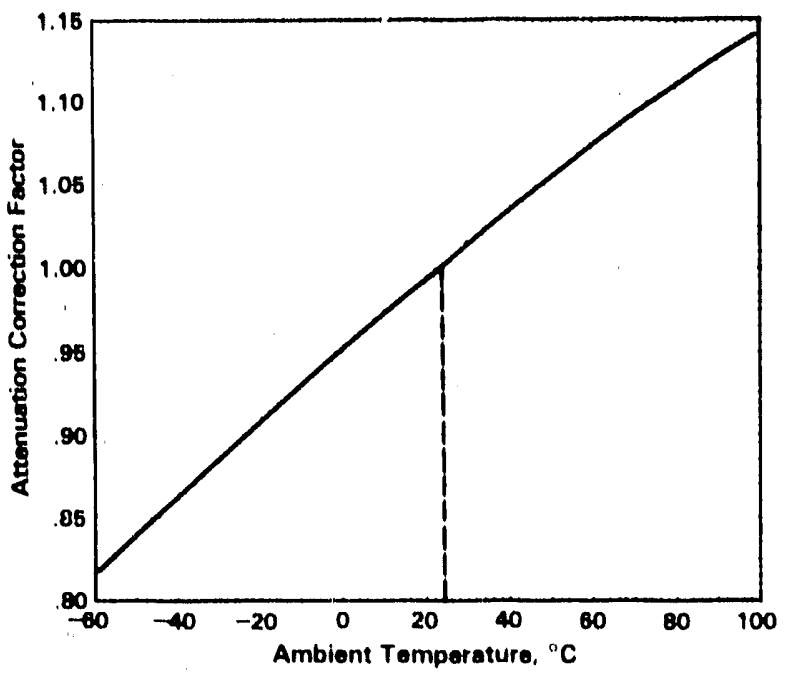

\section{Attenuation}

Pages 346-349 show nominal attenuation versus frequency characteristics of HELIAX coaxial cables. The figures are guaranteed to within $\pm 5 \%$. The values shown are for $24^{\circ} \mathrm{C}$ $\left(75^{\circ} \mathrm{F}\right)$ ambient and increase slightly with higher temperature or applied power, up to approximately $13 \%$ above the curves at $100^{\circ} \mathrm{C}\left(212^{\circ} \mathrm{F}\right)$ ambient temperature.

Figure 1 shows this relationship.

\section{Effect of Connector on Transmission Line Loss}

Connector loss is negligible except for small connectors (SMA, TNC) at frequencies of several $\mathrm{GHz}$ and higher. For these, add $0.1 \mathrm{~dB}$ per connector to approximate connector effect on total transmission line loss.

\section{Load VSWR Effect}

\section{on Total Transmission Loss}

When the transmission line is attached to a load, such as an antenna, the VSWR of the load increases the total transmission loss of the system. This effect is quite small for normal conditions. Figure 2 shows the minimum increase in loss with load VSWR, assuming a VSWR of 1.0 at the input of the transmission line. This requires use of an input matching device.

\section{Power Rating Considerations}

Both peak- and average-power ratings are required to fully describe the capabilities of a given transmission line. Typically, peak-power ratings limit usage with amplitude modulation at medium frequencies $(530-1610 \mathrm{kHz})$ or pulsed usage, while average-power ratings limit the high frequency usage.

\section{Peak-Power Rating}

The peak-power rating of a transmission line is limited by voltage breakdown between the inner and outer conductors.

Voltage breakdown is independent of irequency, but varies with line pressure and type of pressurizing gas. Peak-power ratings are, therefore, generally stated for the following
Figure 2 - Effeot of Load VSWR on Transmission Loss

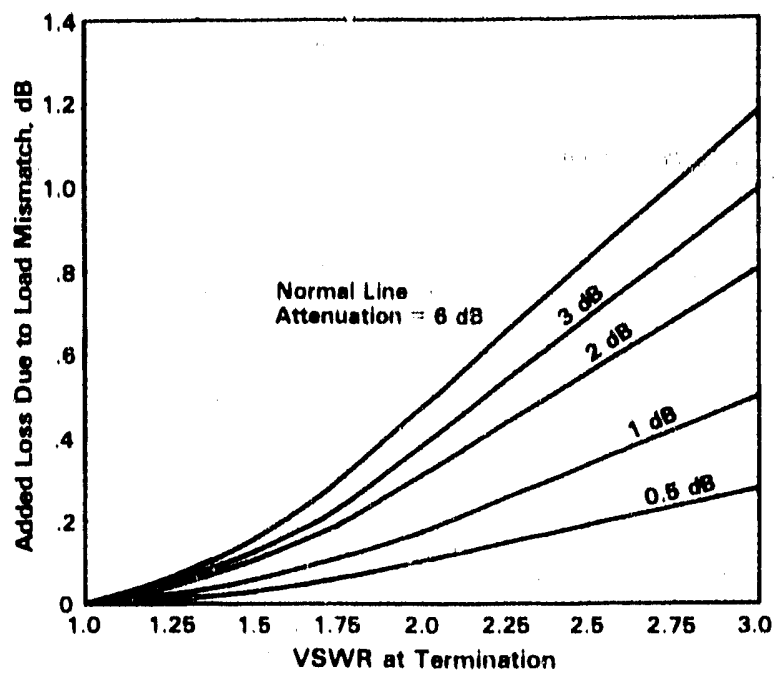

standard conditions: VSWR $=1.6$, zero modulation, and one atmosphere absolute dry air pressure $\left(0 \mathrm{lb} / \mathrm{in}^{2}\right.$ or $0 \mathrm{kPa}$ gauge) at sea level.

The peak-power rating of the selected cable must be greater than the following expression in addition 10 satisfying the average power handling criteria:

$\mathrm{PPK}_{\mathrm{P}}>\mathrm{P} \mathrm{P}(1+\mathrm{M})^{2}$ VSWR

where

Ppk = Cable Peak-Power Rating (kW)

$\mathbf{P r}_{\mathbf{r}}=$ Transmitter Power $(\mathrm{kW})$

$\mathrm{M}=$ Amplitude Modulation percentage expressed decimally $(100 \%=1.0)$

VSWR $=$ Voltage Standing Wave Radio

From this relation it can be seen that $100 \%$ amplitude modulation increases the peak-power in the transmission line by a factor of 4 . Also, the peak power in the transmission line increases directly with VSWR

The transmission line peak-power rating can be significantly increased by pressurization. See page 344 for details.

An adequate safety factor on peak power is necessary to safeguard against voltage breakdown, which can result in permanent damage to the transmission line. All Andrew HELIAX coaxial cables are high-voltage tested to the equivalent of $400 \%$ of their rated peak power (safety factor of 2 on voltage) before shipment to the customer. This safety factor is intended as a provision for transmitter transients, lightning induced transients, and high voltage excursions due to other unforeseen causes. Andrew's use of a safety factor of 4 on published peak-power ratings has resulted in reliable service in thousands of installations over the past 40 years. 
FIGURE 3 - Pressurization Factors

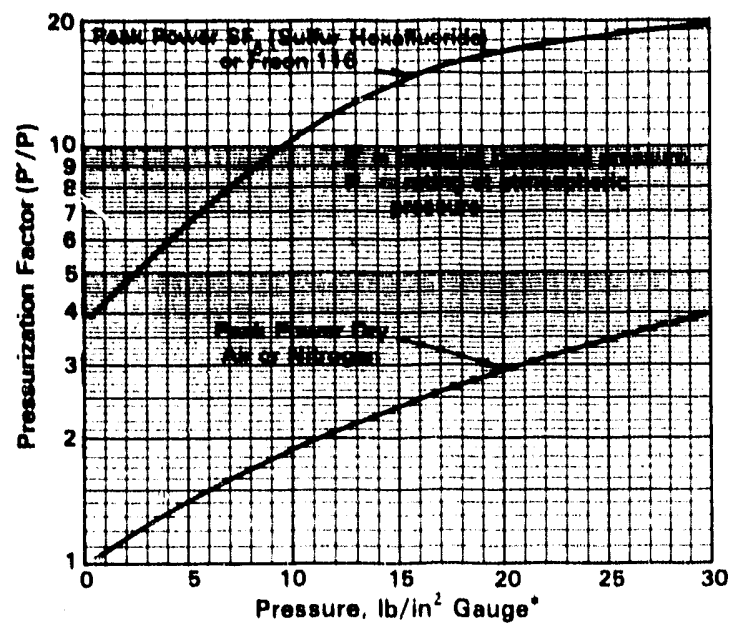

Voltage breakdown will oceur at approximately the same values for similarly sized air-dielectric cables. Therefore, significantly higher peak-power ratings for similarly sized cables advertised by some other cable mamufacturers are clearly the result of operating will a lower safety factor. 7he transmission line specifier is cautioned accordingly.

HELIAX peak-power ratings are decermined according to the relation:

$$
P_{P K}=\frac{\left(\frac{E_{p} \times 0.707 \times 0.7}{2}\right)^{2}}{Z_{0}}
$$

Where

PPK = Cable Peak Power Rating, Standard Concitions

$E_{P}=D C$ production Test Vollagc:

$0.707=$ RMS factor

$0.7=$ DC: 1o RF faclor (empirically verificd)

2 = Safely Factor on Voltage

$\mathrm{Z}_{\mathrm{O}}=$ Characteristic Impedance

Typical DC production test voltages for common sizes of air-diel cetric cables are shown below:

\begin{tabular}{|c|c|c|c|c|c|c|c|}
\hline Nominal & & & & & & & \\
\hline Size & $7 / 8^{\prime \prime}$ & $1.5 / 8^{\prime \prime}$ & $2-1 / 4^{\prime \prime}$ & $3^{\prime \prime}$ & $3.1 / 8^{\prime \prime}$ & $4^{\prime \prime}$ & 5" \\
\hline $\mathrm{kV}$ & 6 & 11 & 13 & 16 & 19 & 20 & 25 \\
\hline
\end{tabular}

Foam-dielectric cables have a greater dielectric strength than air-diclectric cables of similar size and for this reason might be expected to have higher peak-power ratings than air cables. Higher peak-power ratings usually can not be realized, however, because the commonly used connectors for foam cables have air spaces at the cable/connector interface which limit the allowable RF voltage to "air cable" values. Andrew rates similar size foam-and air-dielectric cables alike for this reason.

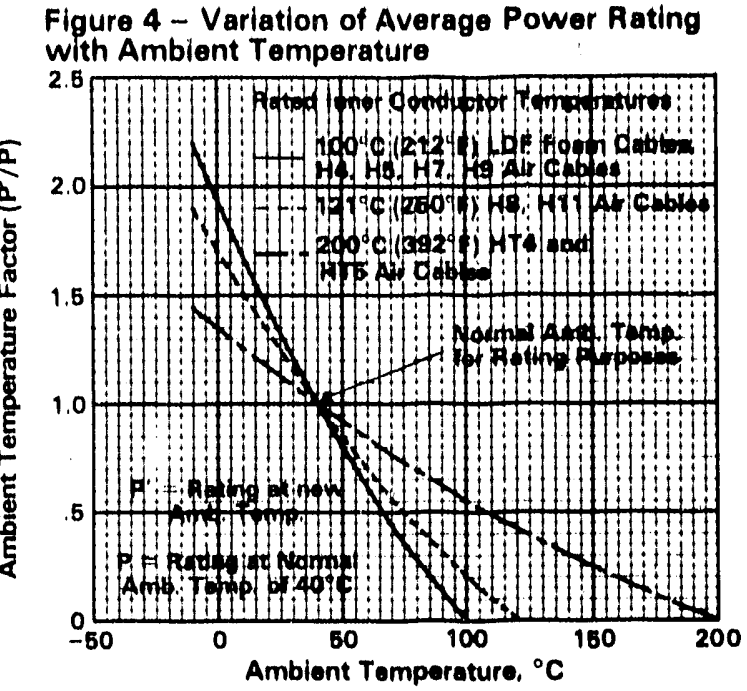

\section{Effect of Connector on Peak Power Rating}

The peak power handling capability of a cable assembly is the smaller of the values for the cable and the connectors. The following table shows peak power ratings for common connectors al standard conditions of VSWR $=1.0$, zero, modulation and one atmosphere dry air pressure $(0) \mathrm{lb} / \mathrm{in}^{2}$ or 0 kPa gauge) at sca level.

\begin{tabular}{lcc}
\hline $\begin{array}{c}\text { Connector } \\
\text { Type }\end{array}$ & $\begin{array}{c}\text { DC Test Volage } \\
\text { kV }\end{array}$ & $\begin{array}{c}\text { Peak Power } \\
\text { kW }\end{array}$ \\
\hline SMA & 1.0 & 1.2 \\
BNC, TNC & 1.5 & 2.8 \\
N, UHF & 2.0 & 4.9 \\
GR & 3.0 & 11 \\
HN, 7/16 DIN & 4.0 & 20 \\
LC & 5.0 & 31 \\
7/8" EIA, "F" Flange & 6.0 & 44 \\
1-5/8" EIA & 11.0 & 150 \\
3-1/8" EIA & 19.0 & 440 \\
\hline
\end{tabular}

\section{Increased Peak Power Ratings}

Pressurization and/or the use of high-density gases with high dielectric strength can be used to increase peak-power ratings. These effects are shown in Figure 3.

For a given transmission line pressure, the increase in peak-power rating is significant. For example, a line pressure of $10 \mathrm{lh} / \mathrm{in}^{2}(70 \mathrm{kPa})$ dry air increases the peak-power rating by a factor of 1,9. Pressurization above $30 \mathrm{lb} / \mathrm{in}^{2}(207 \mathrm{kPa})$ is not recommended.

"For $\mathrm{kPa}$, multiply by 6.895 
Figure 5 - Derating Factor for Average Power Due to VSWR

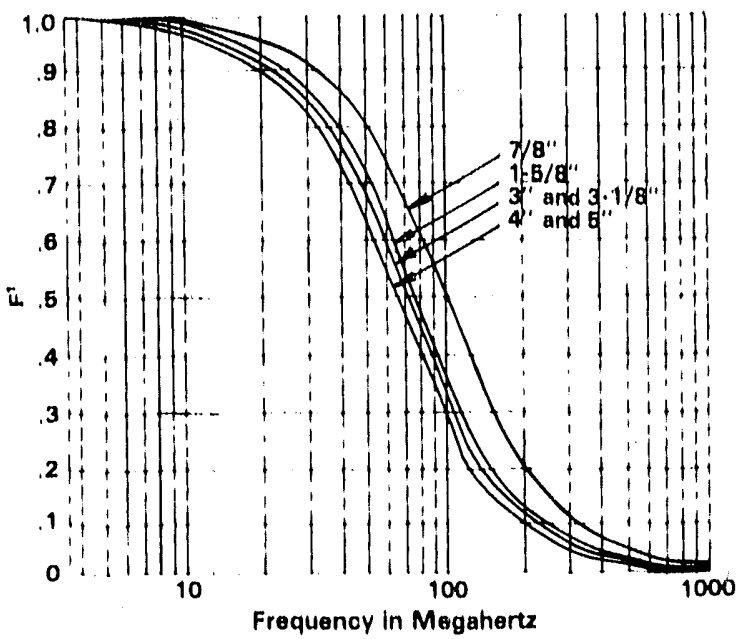

\section{Average Power Rating}

Average-power ratings of transmission lines are governed by the safe long-lerm operating lemperature of the dielectric. The maximum permissible inner conductor temperature varies with the type of dielectric and is based upon consideration of the long term life of the diclectric.

Andrew average power ratings are based on a VSWR of 1.0, atmospheric pressure and ambient lemperalure of 4$)^{\circ} \mathrm{C}$. $\left(104^{\circ} \mathrm{F}\right)$. The ratings include an allowance for full solar radiation. In shady conditions, add $1.5 \%$ to the stated values.

\section{Derating Average Power for \\ Modulation Candition}

To convert rated transmitter power to average power for television transmission, multiply by (2).83. For FM radio, the factor is 1.(0. Transmission lines for $A M$ radio at MF frecpencies (530)-1610 kHz) are usually peak power limited. At higher (HF) frequencies, the limitation is average power capability and the required derating factor is

D.F $=1+\frac{M^{2}}{2}$

where $M$ is the modulation depth $(1(x) \%=1,(1)$, expressed decimally.

\section{Average Power Rating Adjustment for Ambient Temperature}

The baseline power rating can be adjusted (o) meet the actual usage conditions. Figure 4 show's the variation of average power rating with ambient lemperalure.

\section{Derating Average Power for VSWR}

The derating factor (D.F.) is calculated from the following formula:

$$
\text { D.F. }=\frac{2\left(V S W R^{2}+1\right)+2 F^{\prime}\left(V S W R^{2}-1\right)}{(V S W R+1)^{2}}
$$

where $F^{\prime}$ is a factor that varies with frequency and line size select the factor from the applicable curve in Figure 5 , calculale factor D.F., and divide into the average power read off the appropriate graph.

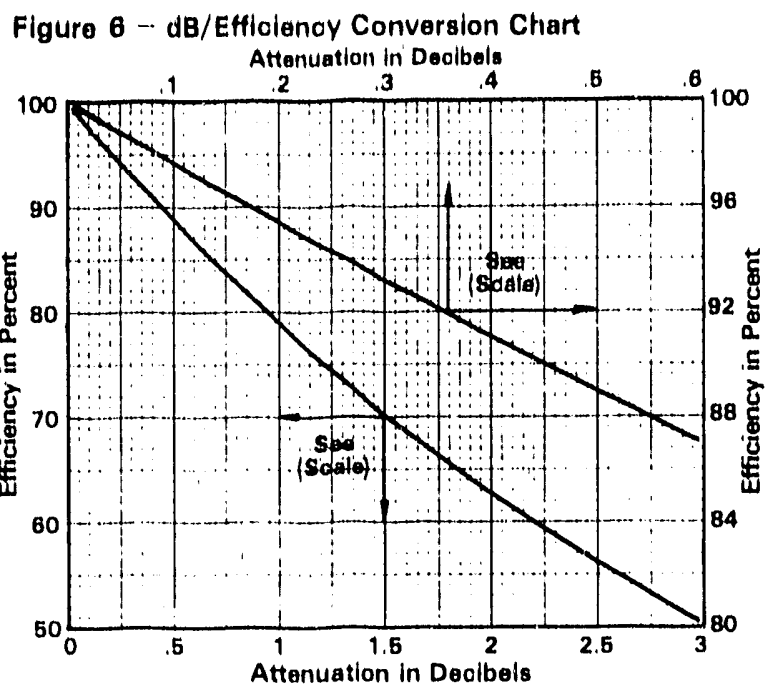

For example: Calculate power rating for 3" HJR-50) cable operating at $1(x) \mathrm{MH} z$ with VSWR $=1,1, \mathrm{~F}$ (from Figure $5)=0.33$ :

D.F. $=\frac{2\left(1.1^{2}+1\right)+2 \times 0.33\left(1.1^{2}-1\right)}{(1.1+1)^{2}}=1.0 .34$

Average Power Raling at $1 .(0)$ VSWR $=37 \mathrm{~kW}$

$$
\text { (from page 214) }
$$

Average Power Rating all 1.1 VSWR :-

$$
37 / 1.03 .4=3.5 .8 \mathrm{~kW}
$$

\section{Effect of Connector on Average Power Rating}

Andruw hrass connectors, with solid TEFLON dic!ectrics, conduct heat efficiently and are the limiting factor for average power rating only when the eonnector is much smaller than the cable. Ela flange econnectors are ideal for cable systems recuiring high power ratings because of their exeellent contact between the spring finger contacts and the cable's inner conductor.

\section{Efficiency}

The efficiency of a transmission line depends on its length and altenuation. The elficiency is delined as the pereent of transmitter power which reaches the antenna. It can be calculated as:

$$
\text { Efficiency }=\frac{10(0) \%}{10\left(\frac{0 \%}{10}\right)}
$$

where dB is the total altenuation of the transmission line at the frecuency of interest.

The remaining power is lost in the transmission line and is dissipated as heal. Figure 6 illustrates a convenient method for delermining transmission line efficiency. 
Foam Dlelectrlo Cable Powrer Rating

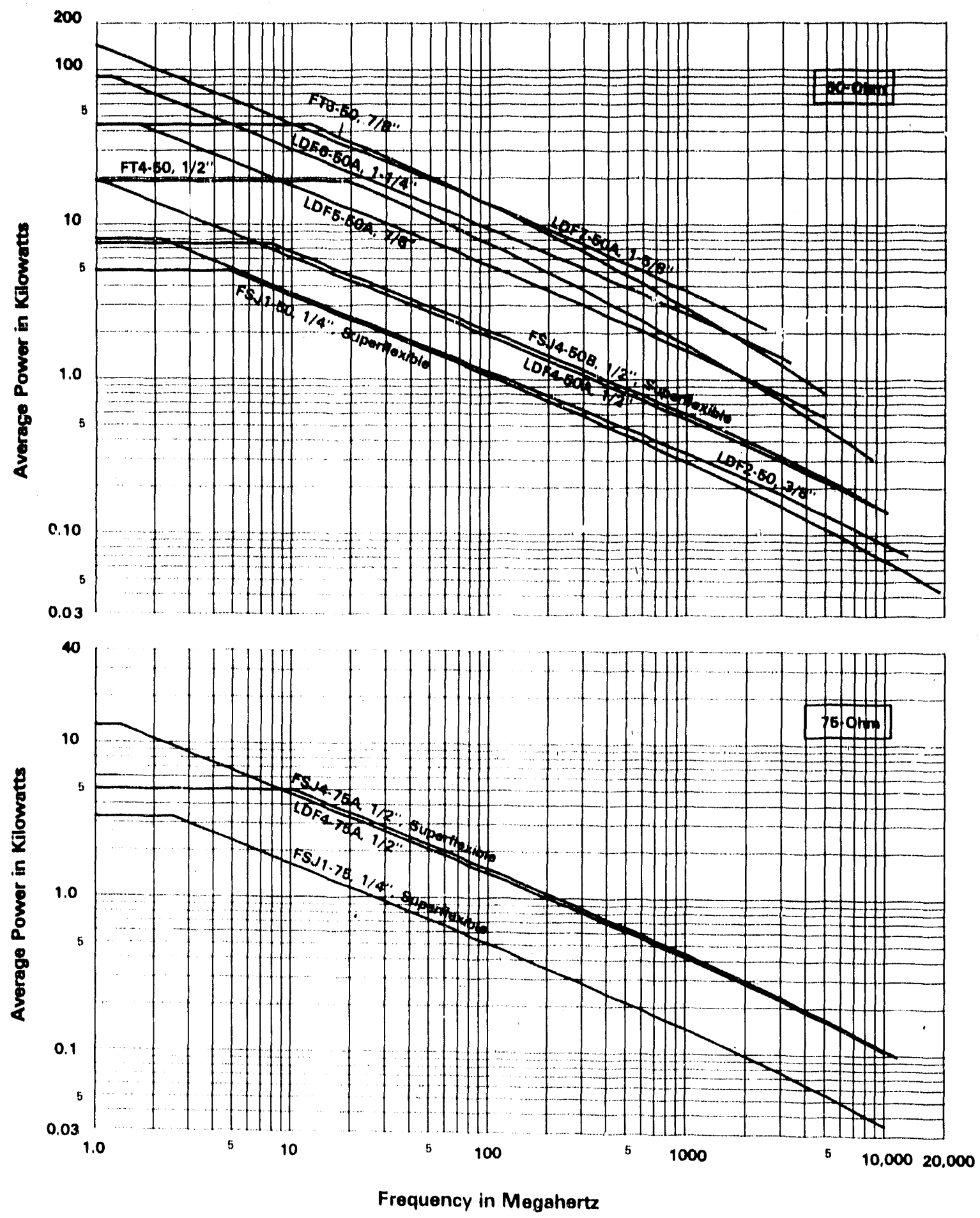

Power Ratings Based On:

VSWR 1.0

Ambient Temperature $40^{\circ} \mathrm{C}\left(104^{\circ} \mathrm{F}\right)$

Inner Conductor Temperature $100^{\circ} \mathrm{C}\left(212^{\circ} \mathrm{F}\right)$

\section{ANDAEW}

Conversion Data:

For other ambient temperatures, sce curve on page 344. 
hellax Coaxial Cable

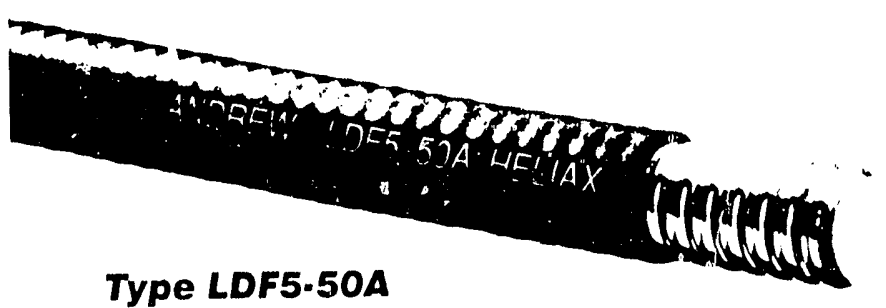

\section{Superior to Braided Cable}

Solid copper corrugated outer conductor results in low loss, higli power handling and continuous RFI/EMI shiclding (o) minimize interference and maximize system security. (able can be formed 10 a 10 in $(2.5) \mathrm{mm}$ ) radius.

\section{Weatherproof}

Annular corrugations prevent water migration. Connector ()-rings seal out moi.ture. Ciosed cell foam prevents water pen tration.

\section{Quick and Easy Connector Attachment}

Patented, self-flaring design.

\section{Low Loss Foam}

Pressurization not required.

\section{Proven performance in applicatiors such as:}

- Industry standard in land mubile radio.

- Cellular radic.

- Phase stabilized versions for phased array radars.

- VLF and HF communicatinns systems; AM and FM radio hroadcast.

- Mil-spec versions available.

\section{Low VSWR Cable}

Type LDF5P-50)A is a low-VSWR version of LDF5-50A. Low VSWR specificatic: 's are tabulated on the right. Achicvable VSWR is a function of maximum operating freyuency, connector interfaces and cable length. The figures are guaranted for factory assemblies and are typical for field cut lengths. If two diferent interfaces are used, the higher VSWR value is the guarantec.

Standard operating frequency bands include those commonly used for terrestrial microwave and satcilite communication carth station applications:

Terrestrial Microwave Low VSWR specifications for trequency bands (Specity bands):

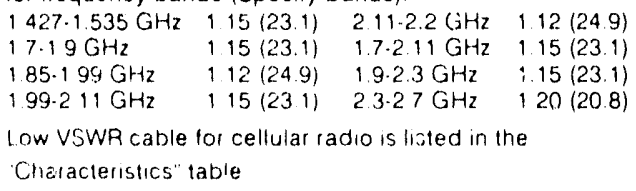

Earth Station $3625.42 \mathrm{GHz}$

\section{7/8" Foam Dielectric} 50.0hm

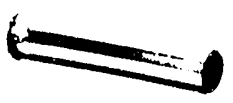

\section{Characteristics}

\begin{tabular}{|c|c|}
\hline $\begin{array}{l}\text { Nominal Size } \\
\text { Impedance, ohms }\end{array}$ & $\begin{array}{r}7 / 8^{4} \\
50^{* * *} \\
\end{array}$ \\
\hline \multicolumn{2}{|l|}{ Cable Type Numbers } \\
\hline $\begin{array}{l}\text { Standard Cable, Standard Jacket } \\
\text { Standard Cable, Fire-Retardant, } \\
\text { Non-Halogenated Jacket } \\
\text { Specially Tested and Selected Cable } \\
\text { Low.VSWR Cable } \\
\text { (Specify Operating Band, see table below) } \\
\text { Cellular Radio } \\
824-894 \mathrm{MHz}, 1.20 \text { max. VSWR } \\
880-960 \mathrm{MHz}, 1.20 \text { max. VSWR } \\
\text { Qualified to MIL.C-28830/4 } \\
\end{array}$ & $\begin{array}{r}42150 B-48 \\
42150 B-54 \\
202071-2 \\
\end{array}$ \\
\hline \multicolumn{2}{|l|}{ Electrical Characteristics } \\
\hline $\begin{array}{l}\text { Maximum Frequency, } \mathrm{GHz} \\
\text { Velocity, percent } \\
\text { Peak Power Rating, } \mathrm{kW} \\
\text { DC Resistance, ohms } / 1000 \mathrm{ft}(1000 \mathrm{~m}) \\
\text { Inner } \\
\text { Outer } \\
\text { DC Breakdown, volts } \\
\text { Jacket Spark, volts RMS } \\
\text { Capacitance, } \mathrm{pF} / \mathrm{tt}(\mathrm{m}) \\
\text { Inductance, } \mu \mathrm{H} / \mathrm{ft}(\mathrm{m}) \\
\end{array}$ & $\begin{array}{r}5.0 \\
89 \\
44 \\
\\
0.35(1.15) \\
0.36(1.18) \\
6000 \\
8000 \\
22.8(75.0) \\
0.057(0.187) \\
\end{array}$ \\
\hline \multicolumn{2}{|l|}{ Mechanical Characteristics } \\
\hline $\begin{array}{l}\text { Outer Conductor } \\
\text { Inner Conductor } \\
\text { Diameter nver Jacket, in (mm) } \\
\text { Diameter over Copper Outer Conductor, in (mm) } \\
\text { Minimum Bending Radius, in (mm) } \\
\text { Number of Bends, minimum (typical) } \\
\text { Bending Moment, } \mathrm{tt} \cdot \mathrm{lb}(\mathrm{N} \cdot \mathrm{m}) \\
\text { Cable Weight, Ib/ft }(\mathrm{kg} / \mathrm{m}) \\
\text { Tensile Strength, } \mathrm{lb}(\mathrm{kg}) \\
\text { Flat Plate Crush Strength, } \mathrm{lb} / \mathrm{in}(\mathrm{kg} / \mathrm{mm})\end{array}$ & $\begin{array}{r}\text { Copner } \\
\text { Copper } \\
1.09(28) \\
0.98(24.9) \\
10(250) \\
15(50) \\
12(16.3) \\
0.33(0.49) \\
325(147) \\
80(1.4)\end{array}$ \\
\hline
\end{tabular}

* For broadcast applications, specify TV channel or frequency.

" "A 75.ohm 7/8" diameter cable is available. Contact Andrew for further information.

\begin{tabular}{|c|c|c|c|c|}
\hline $\begin{array}{l}\text { Up to } \\
\text { Freq. } \\
\text { GHz }\end{array}$ & $\begin{array}{l}\text { Using Connector } \\
\text { Type No. }\end{array}$ & $\begin{array}{l}\text { Assembly } \\
\text { lo } 25 \mathrm{ft} \\
(8 \mathrm{~m})\end{array}$ & $\begin{array}{l}\text { ISWA, Maxim } \\
25-100 \mathrm{tt} \\
(8-30 \mathrm{~m})\end{array}$ & $\begin{array}{l}\text { um (R.L., dB) } \\
100 \cdot 200 \mathrm{t1} \\
(30 \cdot 60 \mathrm{~m})\end{array}$ \\
\hline $1.7 \dagger$ & $\begin{array}{l}\text { L45W (N Plug) } \\
\text { L45N (N Jack) } \\
\text { L45F or L45R }\end{array}$ & $\begin{array}{l}1.10(26.4) \\
1.12(24.9) \\
1.10(26.4)\end{array}$ & $\begin{array}{l}1.20(20.8) \\
1.22(201) \\
1.20(208)\end{array}$ & $\begin{array}{l}130(17.7) \\
1.33(17.0) \\
1.30(17.7)\end{array}$ \\
\hline $2.7 \dagger$ & $\begin{array}{l}\text { L45W (N Plug) } \\
\text { L45N (N Jack) } \\
\text { L45F or L45R }\end{array}$ & $\begin{array}{l}1.10(26.4) \\
1.15(23.1) \\
1.15(23.1)\end{array}$ & $\begin{array}{l}1.20(20.8) \\
1.25(191) \\
1.25(191)\end{array}$ & $\begin{array}{l}130(177) \\
135(166) \\
135(166)\end{array}$ \\
\hline 42 & L.45W (N Plug) & $110(264)$ & $120(208)$ & $135(166)$ \\
\hline 50 & l.45W (N Plug) & $115(23)$ & $120(208)$ & $135(166)$ \\
\hline
\end{tabular}


Attenuation and Average Power

\begin{tabular}{|c|c|c|c|c|c|c|c|}
\hline $\begin{array}{l}\text { Frequency } \\
\mathrm{MHz}\end{array}$ & $\begin{array}{l}\text { Attenuation } \\
\text { dB/100 } \mathrm{t}\end{array}$ & $\begin{array}{l}\text { Attenuation } \\
\text { dB/100m }\end{array}$ & $\begin{array}{c}\text { Avorage Power } \\
\text { kW }\end{array}$ & $\begin{array}{l}\text { Frequency } \\
\mathrm{MHz}\end{array}$ & $\begin{array}{c}\text { Attenuation } \\
\mathrm{dB} / 100 \mathrm{ft}\end{array}$ & $\begin{array}{c}\text { Attenualion } \\
\mathrm{dB} / 100 \mathrm{~m}\end{array}$ & $\begin{array}{c}\text { Average Power } \\
\mathrm{kW}\end{array}$ \\
\hline $\begin{array}{c}0.5 \\
1 \\
1.5 \\
2 \\
10 \\
20 \\
30 \\
50 \\
88 \\
100 \\
108 \\
150 \\
174 \\
200 \\
300 \\
400 \\
450\end{array}$ & $\begin{array}{l}0.0245 \\
0.0350 \\
0.0431 \\
0.0500 \\
0.112 \\
0.160 \\
0.197 \\
0.257 \\
0.345 \\
0.369 \\
0.384 \\
0.458 \\
0.4 \prime 3 \\
0.535 \\
0.668 \\
0.781 \\
0.834\end{array}$ & $\begin{array}{l}0.080 .4 \\
0.115 \\
0.141 \\
0.164 \\
0.367 \\
0.525 \\
0.646 \\
0.843 \\
1.13 \\
1.21 \\
1.26 \\
1.50 \\
1.63 \\
1.76 \\
2.19 \\
2.56 \\
2.74\end{array}$ & $\begin{array}{c}44.0 \\
44.0 \\
44.0 \\
40.0 \\
17.7 \\
12.4 \\
10.1 \\
7.74 \\
5.75 \\
5.38 \\
5.17 \\
4.34 \\
4.01 \\
3.72 \\
2.98 \\
2.55 \\
2.39\end{array}$ & $\begin{array}{r}500 \\
512 \\
600 \\
700 \\
800 \\
824 \\
894 \\
960 \\
1000 \\
1250 \\
1500 \\
1700 \\
2000 \\
2300 \\
3000 \\
4000 \\
5000\end{array}$ & $\begin{array}{l}0.885 \\
0.896 \\
0.979 \\
1.07 \\
1.15 \\
1.17 \\
1.23 \\
1.28 \\
1.31 \\
1.49 \\
1.66 \\
1.79 \\
1.97 \\
2.15 \\
2.53 \\
3.03 \\
3.50\end{array}$ & $\begin{array}{r}2.90 \\
2.94 \\
3.21 \\
3.50 \\
3.78 \\
3.85 \\
4.03 \\
4.20 \\
4.30 \\
4.90 \\
5.45 \\
5.87 \\
6.46 \\
7.05 \\
8.31 \\
9.94 \\
11.5\end{array}$ & $\begin{array}{l}2.25 \\
2.22 \\
2.03 \\
1.86 \\
1.73 \\
1.70 \\
1.62 \\
1.56 \\
1.52 \\
1.33 \\
1.20 \\
1.11 \\
1.01 \\
0.926 \\
0.785 \\
0.656 \\
0.568\end{array}$ \\
\hline
\end{tabular}

\section{Connectors}

\begin{tabular}{|c|c|c|c|c|c|}
\hline Interface - See photos on pages 332 and 333 & Type No. & $\begin{array}{l}\text { Length } \\
\text { In ( } \mathrm{mm})\end{array}$ & $\begin{array}{l}\text { Body Dim. } \\
\text { In (mm) }\end{array}$ & $\begin{array}{l}\text { Flsinge Dia. } \\
\text { In }(\mathrm{mm})\end{array}$ & $\begin{array}{l}\text { Welght } \\
\text { lb (kg) }\end{array}$ \\
\hline $\begin{array}{l}\text { "F" (male) connects with "F"-Series antennas } \\
\text { "F" Flange (iemale) for connection to jumper cable } \\
7 / 8 \text { ElA flang , no gas barrier at intertace, } \\
\text { includes inner connector }\end{array}$ & $\begin{array}{l}\text { L45F } \\
48041 \\
\text { L45R }\end{array}$ & $\begin{array}{l}1.76(44.7) \\
1.76(44.7 \\
3.32(84.3)\end{array}$ & $\begin{array}{l}1.40(35.6) \\
1.40(35.6) \\
1.35(34.3)\end{array}$ & $\begin{array}{l}2.25(57.2) \\
2.25(57.2) \\
2.25(57.2)\end{array}$ & $\begin{array}{l}1.5(0.7) \\
1.5(0.7) \\
1.5(0.7)\end{array}$ \\
\hline $\begin{array}{l}\text { 7/8 ElA Flango, ight angle, no gas barrier at } \\
\text { intertace, includes inner connector }\end{array}$ & $124800-1$ & $3.94(100.0)$ & $1.34(34.0)$ & $2.25(57.2)$ & $1.5(0.7)$ \\
\hline $\begin{array}{l}\text { N Plug (male), mates with UG-23 } \\
\text { N Plug (male), low VSWh, mates with UG-23 } \\
\text { N Jack (female), mates with UG-21 } \\
\text { UHF Plug (male), mates with SO-239A } \\
\text { UHF Jack (female), mates with PL-259A } \\
\text { LC Plug (male), mates with UG-352 } \\
\text { LC Jack (female), mates with UG-154 } \\
\text { HN Plug (male), mates with UG-60 } \\
7 / 16 \text { DIN male } \\
7 / 16 \text { DIN female } \\
\text { End Terminal, for strap connection to center conductor } \\
\text { Splice } \\
\text { Connector Pin-Paks, five replacement pins }\end{array}$ & $\begin{array}{l}\text { L45W } \\
\text { L45EW } \\
\text { L45N } \\
\text { L45P } \\
\text { L45U } \\
\text { L45M } \\
\text { L45L } \\
\text { L45J } \\
\text { L45DM } \\
\text { L45DF } \\
\text { L45T } \\
\text { L45Z }\end{array}$ & $\begin{array}{l}2.83(71.9) \\
2.83(71.9) \\
2.80(71.1) \\
2.70(68.5) \\
2.68(68.1) \\
3.69(93.7 \\
3.42(86.8) \\
2.95(74.9) \\
2.63(66.7) \\
2.72(69.1) \\
4.88(123.8) \\
3.34(84.8)\end{array}$ & 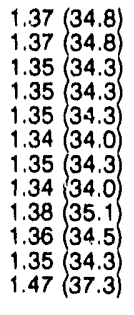 & $\begin{array}{l}\bar{z} \\
\overline{-} \\
\overline{-} \\
\bar{z} \\
\bar{z} \\
\overline{-}\end{array}$ & 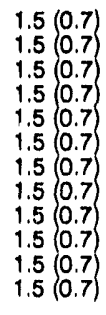 \\
\hline $\begin{array}{l}\text { For } L 45 W \\
\text { For } L 45 N\end{array}$ & $\begin{array}{l}43158-5 \\
43157-2\end{array}$ & - & $\overline{-}$ & - & $\overline{-}$ \\
\hline
\end{tabular}

For RF connector adaptors, see page 334

"Connector for low-VSWR applications. Includes gold-plated inner connector and nickel-plated body.

Accessories - See page 301

\section{To Order}

- A sample order is shown on page 273.

- Specify cable Type Number and length in feet or metres. Sec "Characteristics" table.

- For low-VSWR cable, specify the operating frequency band (see "Low-VSWR Cables" for standard frequency bands and VSWR/Return Loss specifications).
- Specify connector Type Nurnbers and "attached" or "unattached". When attached connectors on an assembly are different, specify which is "first off" the reel.

\section{Further Iriformation}

For general information on HELIAX coaxial cables see pages $268-273$. 


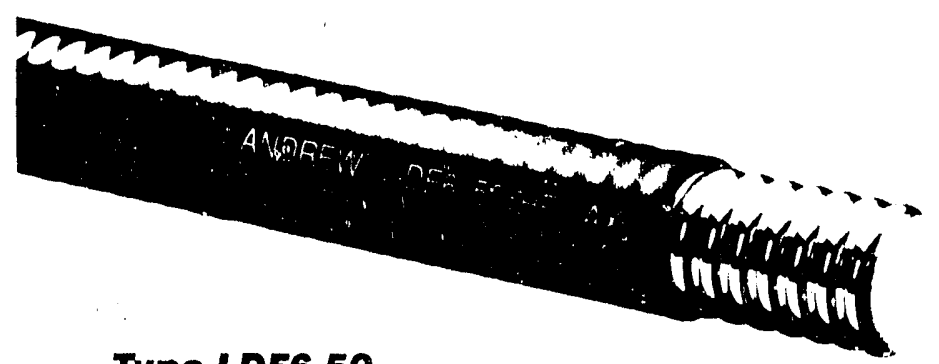

Type LDF6.50

\section{Copper Corrugated}

Solid copper corrugated outer conductor results in low loss, high power handling and continuous RFI/EMI shielding to minimize interference and maximize system security. Cable can be formed to a 15 in $(380 \mathrm{~mm})$ radius.

\section{Weatherproof}

Annular corrugations prevent water migration. Connector O-rings seal out moisture. Closed cell foam prevents water penetration.

\section{Quick and Easy Connector Attachment}

Patented, self-flaring design.

\section{Low Loss Foam}

Pressurization not required.

\section{Proven performance in applications such as:}

- Land mobile radio and cellular radio feeders.

- VLF and HF communications systems; AM and FM radio broadcast.

- Point-t()-point terrestrial microwave

\section{Pressure Path}

Type LDF6-50 cable provides a pressure path through the tubular inner conductor for pressurization of air-diclectric feeds and other pressurizable components. 7/8" and 1-5/8" EIA flange connectors include an internal pressure path All other connectors, exeept LA6F, have a gas barricr at the interface and include a pressure port to complete the pressure path using polyethylene lubing.

\section{1-1/4" Foam Dielectric}

\section{0hm}

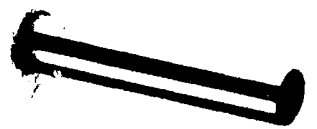

\section{Characteristics}

\begin{tabular}{|c|c|}
\hline $\begin{array}{l}\text { Nominal Size } \\
\text { Impedance, ohms }\end{array}$ & $\begin{array}{r}1-1 / 4^{\prime \prime} \\
50\end{array}$ \\
\hline \multicolumn{2}{|l|}{ Cable Type Numbers } \\
\hline $\begin{array}{l}\text { Standard Cable, Standard Jacket } \\
\text { Standard Cable, Fire-Retardant } \\
\text { Non-Halogenated Jacket } \\
\text { Specially Tested and Selected Cable } \\
\text { Low-VSWR Cable } \\
\text { (Specity Operating Band, see table on page 43) } \\
\text { Cellular Radio } \\
824-894 \mathrm{MHz}, 1.20 \text { max. VSWR } \\
880-960 \mathrm{MHz}, 1.20 \text { max. VSWR } \\
\end{array}$ & $\begin{array}{l}\text { LDF6-50* } \\
\text { LDF6RN-50 }\end{array}$ \\
\hline \multicolumn{2}{|l|}{ Electrical Characteristics } \\
\hline $\begin{array}{l}\text { Maximum Frequency, } \mathrm{GHz} \\
\text { Velocity, percent } \\
\text { Peak Power Rating, } \mathrm{kW} \\
\text { DC Resistance, ohms/1000 } \mathrm{ft}(10 \mathrm{n} 0 \mathrm{~m}) \\
\text { Inner } \\
\text { Outer } \\
\text { DC Breakdown, volts } \\
\text { Jacket Spark, volts RMS } \\
\text { Capacitance, pF/ft }(\mathrm{m}) \\
\text { Inductance, } \mu \mathrm{H} / \mathrm{tt}(\mathrm{m})\end{array}$ & $\begin{array}{r}3.3 \\
89 \\
90 \\
\\
0.24(0.79) \\
0.17(0.56) \\
9000 \\
10000 \\
22.9(75.1) \\
0.056(0.184) \\
\end{array}$ \\
\hline \multicolumn{2}{|l|}{ Mechanical Characteristics } \\
\hline $\begin{array}{l}\text { Outer Conductor } \\
\text { Inner Conductor } \\
\text { Diameter Over Jacket, in (mm) } \\
\text { Diameter Over Copper Outer Conductor, in (mm) } \\
\text { Minimum Bending Radius, in (mm) } \\
\text { Number of Bends, minimum (typical) } \\
\text { Bending Moment, } \mathrm{ft}-\mathrm{lb}(\mathrm{N} \cdot \mathrm{m}) \\
\text { Cable Weight, } \mathrm{lb} / \mathrm{ft}(\mathrm{kg} / \mathrm{m}) \\
\text { Tensile Strength, Ib }(\mathrm{kg}) \\
\text { Flat Plate Crush Strength, lb/in }(\mathrm{kg} / \mathrm{mm}) \\
\end{array}$ & $\begin{array}{r}\text { Copper } \\
\text { Copper } \\
1.55(39.4) \\
1.41(35.8) \\
15(380) \\
15(50) \\
39(53) \\
0.66(0.98) \\
1500(678) \\
138(2.4)\end{array}$ \\
\hline
\end{tabular}

312

ANDREW 


\section{Low VSWR Cable}

Type LDF6P-50 is a low-VSWR version of LDF6-50. Low VSWR specifications are tabulated on the right. Achievable VSWR is a function of maximum operating frequency, connector interfaces and cable length. The figures are guaranteed for factory assemblies and are typical for field cut lengths. If two different interfaces are used, the higher VSWR value is the guarantee.

Standard operating frequency bands include those commonly used for terrestrial microwave applications: Low VSWR Specifications for frequency bands (Specify band):

$\begin{array}{llll}1.427-1.535 \mathrm{GHz} & 1.15(23.1) & 2.11-2.2 \mathrm{GHz} & 1.15(23.1) \\ 1.7-1.9 \mathrm{GHz} & 1.15(23.1) & 1.7-2.11 \mathrm{GHz} & 1.15(23.1) \\ 1.85-1.99 \mathrm{GHz} & 1.15(23.1) & 1.9-2.3 \mathrm{GHz} & 1.15(23.1) \\ 1.99-2.11 \mathrm{GHz} & 1.15(23.1) & 2.3-2.7 \mathrm{GHz} & 1.20(20.8)\end{array}$

Low VSWR cable for cellular radio is listed in the "Characteristics" table.
Low VSWR Specifications, Type LDF6P-50

\begin{tabular}{|c|c|c|c|c|}
\hline $\begin{array}{l}\text { Up to } \\
\text { Freq. } \\
\text { OHz }\end{array}$ & $\begin{array}{l}\text { Ueing Connector } \\
\text { Type No. }\end{array}$ & $\begin{array}{l}\text { Assembly } \\
\text { to } 25 \mathrm{ft} \\
(8 \mathrm{~m})\end{array}$ & $\begin{array}{c}\text { ISWR, Maxin } \\
25-100 \mathrm{ft} \\
(\mathrm{B}-30 \mathrm{~m})\end{array}$ & $\begin{array}{c}\operatorname{um}(R . L, d B) \\
100-200 \mathrm{H} \\
(30.60 \mathrm{~m})\end{array}$ \\
\hline $2.7 t$ & $\begin{array}{l}\text { L46W (N Plug) } \\
\text { L46N (N Jack) } \\
\text { L46F or L46S }\end{array}$ & $1.10(28.4)$ & $1.20(20.8)$ & $1.35(16.6)$ \\
\hline 3.3 & $\begin{array}{l}\text { L46W (N Plug) } \\
\text { L46N (N Jack) }\end{array}$ & $1.10(26.4)$ & $1.20(20.8)$ & $1.35(16.6)$ \\
\hline
\end{tabular}

tSee specifications on the left for data on specific narrow terrestrial microwave bands.

Attenuation and Average Power

\begin{tabular}{|c|c|c|c|c|c|c|c|}
\hline $\begin{array}{l}\text { Frequency } \\
\mathrm{MHz}\end{array}$ & $\begin{array}{l}\text { Attenuation } \\
\text { dB/100 } n\end{array}$ & $\begin{array}{l}\text { Attenuation } \\
\mathrm{dB} / 100 \mathrm{~m}\end{array}$ & $\begin{array}{c}\text { Average Power } \\
\text { KW }\end{array}$ & $\begin{array}{l}\text { Frequency } \\
\text { MHz }\end{array}$ & $\begin{array}{l}\text { Attenuation } \\
\text { dB/100 } n\end{array}$ & $\begin{array}{l}\text { Atilenuation } \\
\mathrm{dB} / 100 \mathrm{~m}\end{array}$ & $\begin{array}{c}\text { Average Power } \\
\text { kW }\end{array}$ \\
\hline $\begin{array}{c}0.5 \\
1 \\
1.5 \\
2 \\
10 \\
20 \\
30 \\
50 \\
88 \\
100 \\
108 \\
150 \\
174 \\
200 \\
300 \\
400 \\
450\end{array}$ & $\begin{array}{l}0.0183 \\
0.0260 \\
0.0320 \\
0.0370 \\
0.0840 \\
0.120 \\
0.147 \\
0.191 \\
0.257 \\
0.275 \\
0.286 \\
0.340 \\
0.368 \\
0.397 \\
0.495 \\
0.578 \\
0.617\end{array}$ & $\begin{array}{l}\text { C. } 0599 \\
0.0853 \\
0.105 \\
0.121 \\
0.276 \\
0.392 \\
0.482 \\
0.627 \\
0.844 \\
0.902 \\
0.939 \\
1.12 \\
1.21 \\
1.30 \\
1.62 \\
1.90 \\
2.02\end{array}$ & $\begin{array}{l}90.0 \\
90.0 \\
79.7 \\
68.9 \\
30.5 \\
21.4 \\
17.4 \\
13.4 \\
9.95 \\
9.30 \\
8.93 \\
7.50 \\
6.93 \\
6.43 \\
5.16 \\
4.41 \\
4.13\end{array}$ & $\begin{array}{l}500 \\
512 \\
600 \\
700 \\
800 \\
824 \\
894 \\
960 \\
1000 \\
1250 \\
1500 \\
1700 \\
2000 \\
2300 \\
3000 \\
3300\end{array}$ & $\begin{array}{l}0.654 \\
0.663 \\
0.724 \\
0.789 \\
0.851 \\
0.866 \\
0.907 \\
0.945 \\
0.967 \\
1.10 \\
1.22 \\
1.32 \\
1.45 \\
1.58 \\
1.86 \\
1.97\end{array}$ & $\begin{array}{l}2.15 \\
2.18 \\
2.38 \\
2.59 \\
2.79 \\
2.84 \\
2.98 \\
3.10 \\
3.17 \\
3.61 \\
4.00 \\
4.31 \\
4.76 \\
5.18 \\
6.10 \\
6.46\end{array}$ & $\begin{array}{l}3.90 \\
3.84 \\
3.52 \\
3.23 \\
3.00 \\
2.95 \\
2.81 \\
2.70 \\
2.64 \\
2.32 \\
2.08 \\
1.93 \\
1.76 \\
1.61 \\
1.37 \\
1.29\end{array}$ \\
\hline
\end{tabular}

Standard Conditions:

For Attenuation. VSWR 1.0 , ambient temperature $24^{\circ} \mathrm{C}\left(75^{\circ} \mathrm{F}\right)$.

For Average Power. VSWR 1.0, ambient temperature $40^{\circ} \mathrm{C}\left(104^{\circ} \mathrm{F}\right)$, inner conductor temperature $100^{\circ} \mathrm{C}\left(212^{\circ} \mathrm{F}\right)$.

\section{Connectors}

\begin{tabular}{|c|c|c|c|c|c|c|c|}
\hline Interface - See photos on pages 332 and 333 & $\begin{array}{c}\text { Gas } \\
\text { Barrier }\end{array}$ & $\begin{array}{c}\text { Pressure } \\
\text { Port }\end{array}$ & Type No. & $\begin{array}{l}\text { Length } \\
\text { in ( } \mathrm{mm})\end{array}$ & $\begin{array}{l}\text { Body Dla. } \\
\text { In }(\mathrm{mm})\end{array}$ & $\begin{array}{c}\text { Flange Dia. } \\
\text { In }(\mathrm{mm})\end{array}$ & $\begin{array}{l}\text { Woight } \\
\text { lb (kg) }\end{array}$ \\
\hline $\begin{array}{l}\text { "F" Flange (male) connects with } \\
\text { "F" Series antennas }\end{array}$ & - & - & L46F & $4.00(101.6)$ & $2.03(51.6)$ & $2.25(57.2)$ & $1.5(0.7)$ \\
\hline $\begin{array}{l}\text { 1.5/8" EIA Flange, includes inner connector } \\
7 / 8^{\prime \prime} \text { EIA Flange, includes inner connector } \\
\text { N Plug (male), males with UG-23 } \\
\text { N Jack (fermale), mates with UG-21 } \\
\text { LC Plug (male), mates with UG-352 } \\
\text { LC Jack (female), mates with UG-154 } \\
7 / 16 \text { DIN male } \\
\text { 7/16 DIN fermale } \\
\text { Splice }\end{array}$ & $\begin{array}{l}- \\
\vdots \\
* \\
* \\
-\end{array}$ & 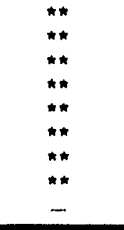 & $\begin{array}{l}\text { L46R } \\
\text { L46S } \\
\text { L46W } \\
\text { L46N } \\
\text { L46M } \\
\text { L46L } \\
\text { L46DM } \\
\text { L46DF } \\
\text { L46Z }\end{array}$ & $\begin{array}{l}5.08(129.0) \\
4.64(117.9) \\
3.81(96.8) \\
3.7 C(94.0) \\
4.86(123.4) \\
4.70(119.4) \\
3.91(99.3) \\
4.08(103.6) \\
3.00(76.2)\end{array}$ & 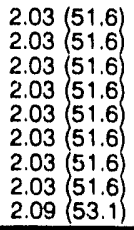 & $\begin{aligned} 3.50 & (88.9) \\
2.25 & (57.2) \\
& = \\
& = \\
& = \\
& = \\
& =\end{aligned}$ & 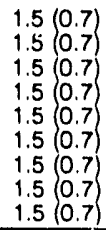 \\
\hline
\end{tabular}

For RF connector adaptors, see page 334.

" Gas barrier at intertace. A pressure path through these connectors can be created by connecting the pressure port on the connector and the antenna feed with polyethylene tubing listed on page 442

" "Includes pressure port for pressurization of antenna feed. 


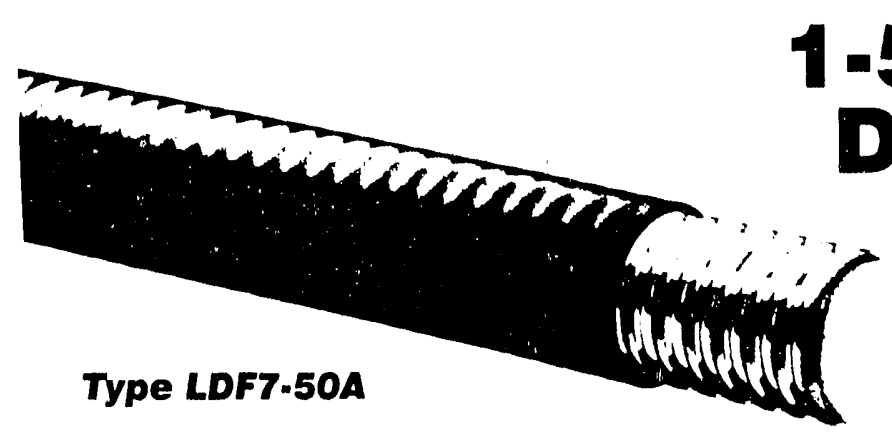

\section{Copper Corrugated}

Solid copper corrugated outer conductor results in low loss, high power handling and continuous RFI/EMI shielding to minimize interference and maximize system security. Cable can be formed to a 20 in $(510 \mathrm{~mm})$ radius.

\section{Weatherproof}

Annular corrugations prevent water migration. Connector O-rings seal out moisture. Closed cell foam prevents water penetration.

\section{Quick and Easy Connector Attachment}

Patented, self-flaring design.

\section{Low Loss Foam}

Pressurization not required.

\section{Proven performance}

\section{in applications such as:}

- Land moble radio and cellular radio.

- VLF and AM and FM radio broadcast.

- Point-to-point terrestrial microwave.

- Mil-spec versions available.

\section{Characteristics}

\begin{tabular}{|c|c|}
\hline $\begin{array}{l}\text { Nominal Size } \\
\text { Impedance, ohms }\end{array}$ & $\begin{array}{r}1.5 / 8^{\prime \prime} \\
50\end{array}$ \\
\hline \multicolumn{2}{|l|}{ Cable Type Numbers } \\
\hline $\begin{array}{l}\text { Standard Cable, Standard Jacket } \\
\text { Standard Cable, Fire-Retardant } \\
\text { Non-Halogenated Jacket } \\
\text { Specially Tested and Selected Cable } \\
\text { Low-VSW/R Cable } \\
\text { (Specify Operating Band, see table on page 306) } \\
\text { Cellular Radio } \\
824-894 \mathrm{MHz}, 1.20 \text { max. VSWR } \\
880-960 \mathrm{MHz}, 1.20 \text { max. VSWR } \\
\text { Qualified to MLL-C-28830/5 }\end{array}$ & $\begin{array}{r}42151 A-18 \\
42151 A-19 \\
202071-3\end{array}$ \\
\hline \multicolumn{2}{|l|}{ Electrical Characteristics } \\
\hline $\begin{array}{l}\text { Maximum Frequency, } \mathrm{GHz} \\
\text { Velocity, percent } \\
\text { Peak Power Rating, } \mathrm{kW} \\
\text { DC Resistance, ohms/1000 } \mathrm{H}(1000 \mathrm{~m}) \\
\text { Inner } \\
\text { Outer } \\
\text { DC Breakdown, volts } \\
\text { Jacket Spark, volts RMS } \\
\text { Capacitance, pF/tt (m) } \\
\text { Inductance, } \mu \mathrm{H} / \mathrm{tt}(\mathrm{m})\end{array}$ & $\begin{array}{r}2.5 \\
88 \\
145 \\
\\
0.23(0.75) \\
0.12(0.39) \\
11000 \\
10000 \\
23.1(75.8) \\
0.058(0.190)\end{array}$ \\
\hline \multicolumn{2}{|l|}{ Mechanical Characteristics } \\
\hline $\begin{array}{l}\text { Outer Conductor } \\
\text { Inner Conductor } \\
\text { Diameter over Jacket, in (mm) } \\
\text { Diameter over Copper Outer Conductor, in }(\mathrm{mm}) \\
\text { Minimum Bending Radius, in (mm) } \\
\text { Number of Bends, minimum (typical) } \\
\text { Bending Moment, } \mathrm{ft}-\mathrm{lb}(\mathrm{N} \cdot \mathrm{m}) \\
\text { Cable Weight, Ib/t }(\mathrm{kg} / \mathrm{m}) \\
\text { Tensile Strength, } 1 \mathrm{~b}(\mathrm{~kg}) \\
\text { Flat Plate Crush Strength, lb/ln }(\mathrm{kg} / \mathrm{mm}) \\
\end{array}$ & $\begin{array}{r}\text { Copper } \\
\text { Coppor } \\
1.98(50) \\
1.83(46.5) \\
20(510) \\
15(50) \\
50(68) \\
0.92(1.36) \\
1000(455) \\
150(2.7)\end{array}$ \\
\hline
\end{tabular}

*For broadcast applications, specify TV channel or frequency. 


\section{Low VSWR Cable}

TYpe LDF7P-50A is a low-VSWR version of LDF7-50A Low VSWR specifications are tabulated on the right. Achievahle VSWR is a function of maximum operating frequency, connector interfaces and cable length. The figures are guaranteed for factory assemblies and are typical for field cut lengths. If two different interfaces are used, the higher VSWR value is the guarantee.

Standard operating frequency bands include those commonly used for ferrestrial microwave applications.

Maximum VSWR for the listed bands is 1.15 (Specify band).

$$
\begin{array}{ll}
1.427 .1 .535 \mathrm{GHz} & 2.11 .2 .2 \mathrm{GHz} \\
1.7 .1 .9 \mathrm{GHz} & 1.7 .2 .11 \mathrm{GHz} \\
1.85 .1 .99 \mathrm{GHz} & 1.9 .2 .3 \mathrm{GHz} \\
1.99 .2 .11 \mathrm{GHz} &
\end{array}
$$

\begin{tabular}{|c|c|c|c|c|}
\hline $\begin{array}{l}\text { Up to } \\
\text { Froq. } \\
\mathrm{GHz}\end{array}$ & $\begin{array}{l}\text { Ualng Connector } \\
\text { Typo No. }\end{array}$ & $\begin{array}{l}\text { Assembly } \\
\text { to } 25 \mathrm{H} \\
(8 \mathrm{~m})\end{array}$ & $\begin{array}{l}\text { SWA, Maxtm } \\
25-100 \mathrm{H} \\
(8-30 \mathrm{~m})\end{array}$ & $\begin{array}{l}\text { um (R.L., dB) } \\
100.200 \mathrm{n} \\
(30.60 \mathrm{~m})\end{array}$ \\
\hline $5 t$ & $\begin{array}{l}\text { L47N (N Jack) } \\
\text { L47S (7/8" E|A })\end{array}$ & 1.10 & $(20.8)$ & $177)$ \\
\hline
\end{tabular}

Low VSWR cable for cellular radio is listed in the

"Characteristics" table.
Low VSWR Specifications, Type LDF7P.50A

\begin{tabular}{|c|c|c|c|c|c|c|c|}
\hline $\begin{array}{l}\text { Frequency } \\
\mathrm{MHz}\end{array}$ & $\begin{array}{l}\text { Attenuation } \\
\mathrm{dB} / 100 \mathrm{ft}\end{array}$ & $\begin{array}{l}\text { Attenuation } \\
\mathrm{dB} / 100 \mathrm{~m}\end{array}$ & $\begin{array}{c}\text { Averagg Power } \\
\mathrm{kW}\end{array}$ & $\begin{array}{l}\text { Frequency } \\
\mathrm{MHz}\end{array}$ & $\begin{array}{c}\text { Attenuation } \\
\mathrm{dB} / 100 \mathrm{Ht}\end{array}$ & $\begin{array}{l}\text { Attenuation } \\
\mathrm{dB} / 100 \mathrm{~m}\end{array}$ & $\begin{array}{c}\text { Average Power } \\
\text { KW }\end{array}$ \\
\hline 0.5 & 0.0147 & 0.0482 & 143 & 450 & 0.516 & 1.69 & 5.86 \\
\hline 1 & 0.0210 & 00689 & 143 & 500 & 0.548 & 1.80 & 552 \\
\hline 1.5 & 0.0259 & 0.0849 & 117 & 512 & 0.556 & 1.82 & 544 \\
\hline 2 & 0.0300 & 0.0984 & 101 & 600 & 0.609 & $2 \infty$ & 497 \\
\hline 10 & 0.0680 & 0.223 & 44.5 & 700 & 0.665 & 218 & 455 \\
\hline 20 & 0.0973 & 0.319 & 31.2 & 800 & 0.719 & 2.36 & 4.21 \\
\hline 30 & 0.120 & 0.394 & 25.3 & 824 & 0.731 & 240 & 413 \\
\hline 50 & 0.156 & 0.512 & 19.3 & 894 & 0.767 & 2.52 & 3.94 \\
\hline 88 & 0.210 & 0.690 & 14.3 & 960 & 0.800 & 2.62 & 378 \\
\hline 100 & 0.225 & 0.738 & 13.4 & 1000 & 0.819 & 2.69 & 3.69 \\
\hline 108 & 0235 & 0.769 & 12.9 & 1250 & 0.939 & 3.08 & 3.23 \\
\hline 150 & 0.280 & 0.919 & 10.8 & 1500 & 1.05 & 344 & 2.89 \\
\hline 174 & 0.304 & 0.997 & 9.95 & 1700 & 1.13 & 3.72 & 268 \\
\hline 200 & 0.328 & 1.08 & 9.22 & 2000 & 1.25 & 4.10 & 2.42 \\
\hline 300 & 0411 & 1.35 & 736 & 2300 & 1.37 & 4.48 & 221 \\
\hline 400 & 0.482 & 1.58 & 6.27 & 2500 & 1.44 & 4.72 & 2. 10 \\
\hline
\end{tabular}

tSee specifications on the left for data on specific narrow terrestria microwave bands

\section{Attenuation and Average Power}

Standard Conditions:

For Attenuation VSWR 1.0, ambient temperature $24^{\circ} \mathrm{C}\left(75^{\circ} \mathrm{F}\right.$

\begin{tabular}{|c|c|c|c|c|c|}
\hline Interface - See photos on pages 332 and 333 & Type No. & $\begin{array}{l}\text { Longth } \\
\text { in (mm) }\end{array}$ & $\begin{array}{c}\text { Body Dia. } \\
\text { In (mm) }\end{array}$ & $\begin{array}{c}\text { Flange Dla. } \\
\text { In }(\mathrm{mm})\end{array}$ & $\begin{array}{l}\text { Weight } \\
\text { it (kg) }\end{array}$ \\
\hline $\begin{array}{l}\text { "F" Flange (male) connects with "F". Series antennas } \\
\text { "F" Flange (female) for connection to jumper cable } \\
\text { 1.5/8* Ela Flange, no gas barrier at intertace. } \\
\text { Includes inner connector }\end{array}$ & $\begin{array}{l}\text { L47F } \\
201942 \\
\text { L.47R }\end{array}$ & $\begin{array}{l}5.88(149.4) \\
5.42(137.7) \\
5.10(130.0)\end{array}$ & $\begin{array}{l}2.38(60.5) \\
2.38(60.5) \\
2.38(605)\end{array}$ & $\begin{array}{l}2.25(57.2) \\
2.25(572) \\
3.50(889)\end{array}$ & $\begin{array}{l}45(20) \\
45(20) \\
45(20)\end{array}$ \\
\hline $\begin{array}{l}\text { 7/8 ElA Flange, no gas barrier at intertace, } \\
\text { includes inner connector }\end{array}$ & L.47S & $5.10(130.0)$ & $2.38(60.5)$ & $225(572)$ & $45(20)$ \\
\hline $\begin{array}{l}\text { N Jack (temale), mates with UG-21 } \\
\text { N Jack (fermale), bulkhead, mates with UG.21 } \\
\text { LC Plug (male), mates with UG-352 } \\
\text { LC Jack (female), mates with UG-154 } \\
\text { 7/16 DIN male } \\
\text { T/16 DIN (emale } \\
\text { Splice }\end{array}$ & $\begin{array}{l}\text { L47N } \\
200220 \\
\text { L47M } \\
\text { L47L } \\
\text { L.47DM } \\
\text { L47DF } \\
\text { L.47Z }\end{array}$ & 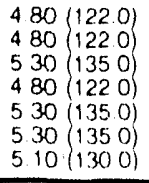 & 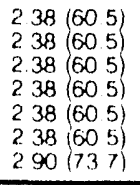 & & $\begin{array}{l}45(20) \\
45(20) \\
45(20) \\
45(20) \\
45(20) \\
45(20) \\
45(20)\end{array}$ \\
\hline
\end{tabular}

For Average Power. VSWR 1.0, ambient temperature 40" $\mathrm{C}\left(104^{\prime \prime} \mathrm{F}\right)$. inner conductor temperature $100^{\prime \prime} \mathrm{C}\left(212^{\prime \prime} \mathrm{F}\right.$

\section{Connectors}

For FAF connector adaptors, see page 334 


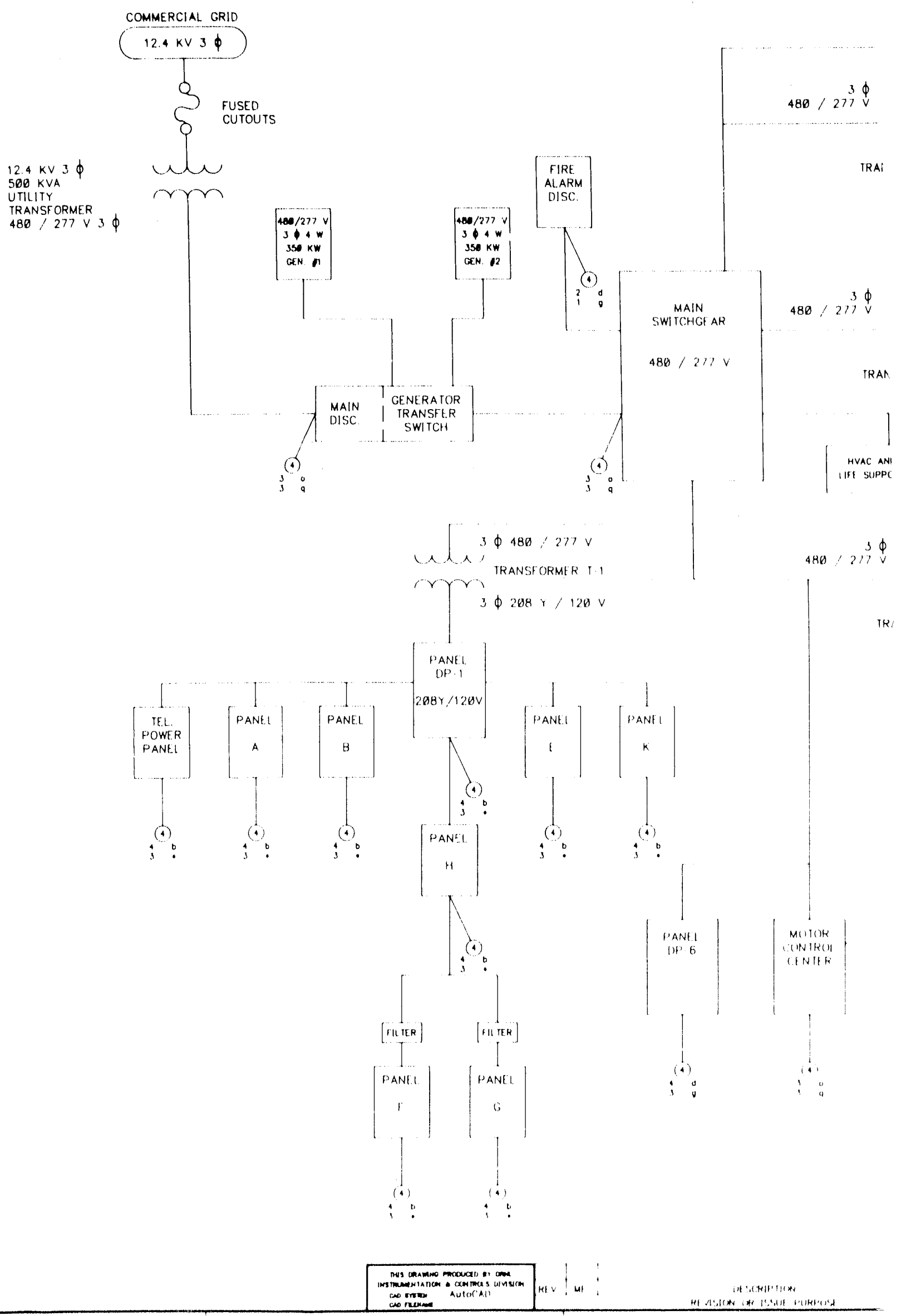



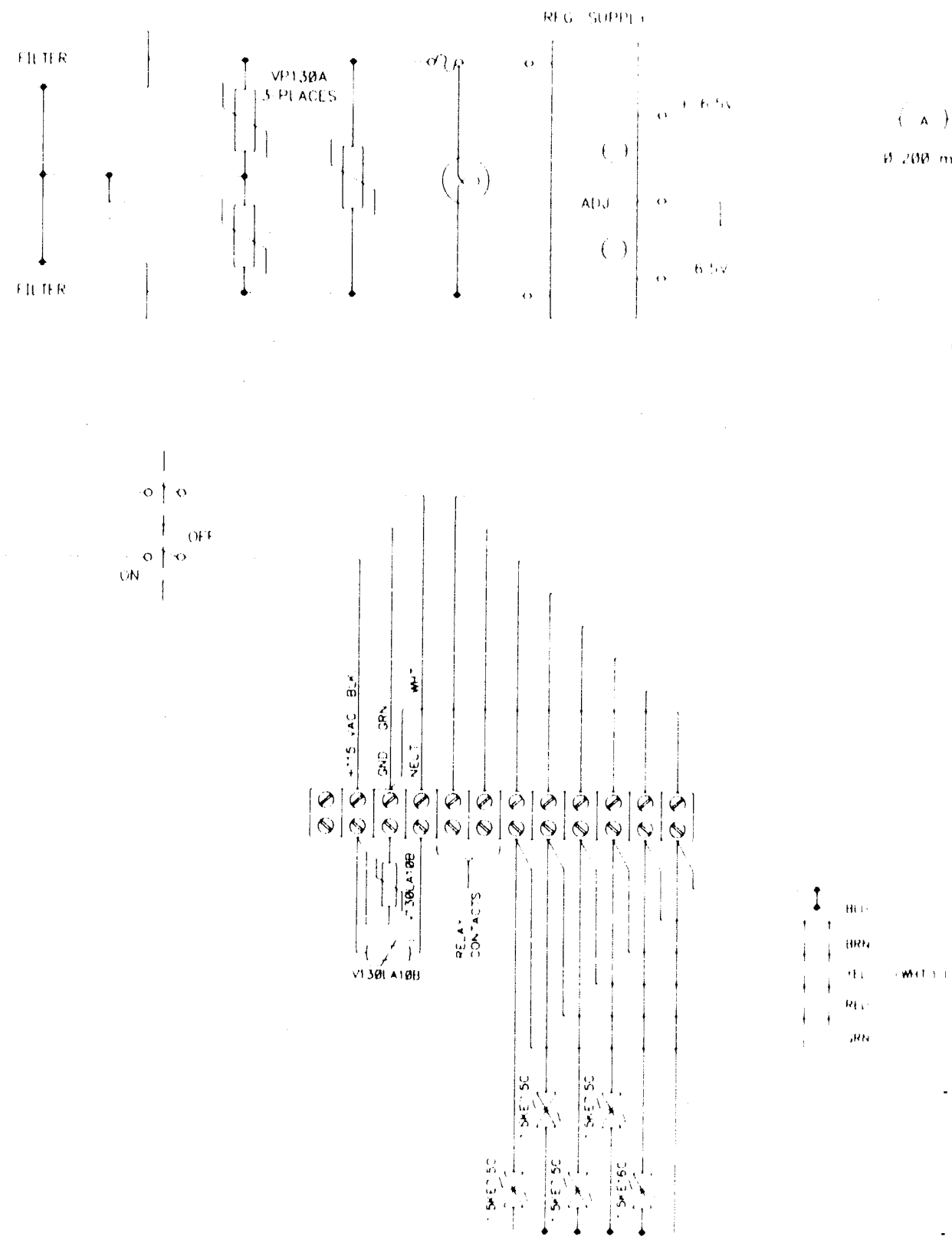


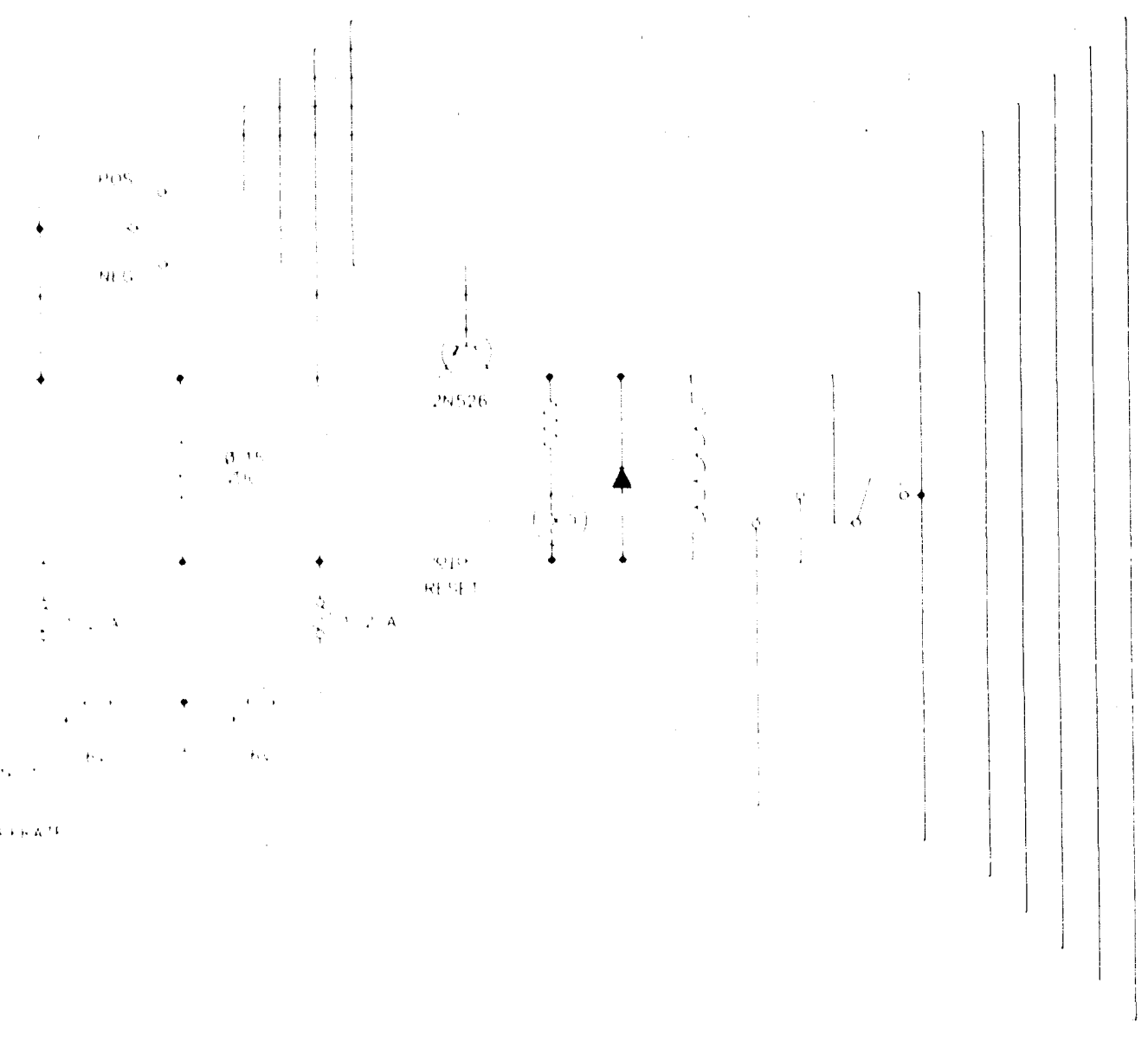

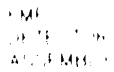

$\begin{array}{ccccc}5 & \ddots & \vdots & \ddots & \vdots \\ \vdots & \vdots & \vdots & \vdots & \vdots \\ & \ddots & \ddots & \ddots & \ddots\end{array}$

$\therefore$

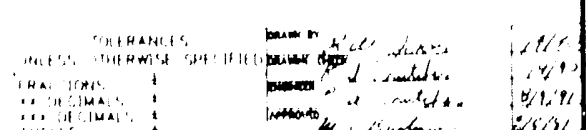

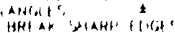

$\because$ as H ind

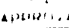

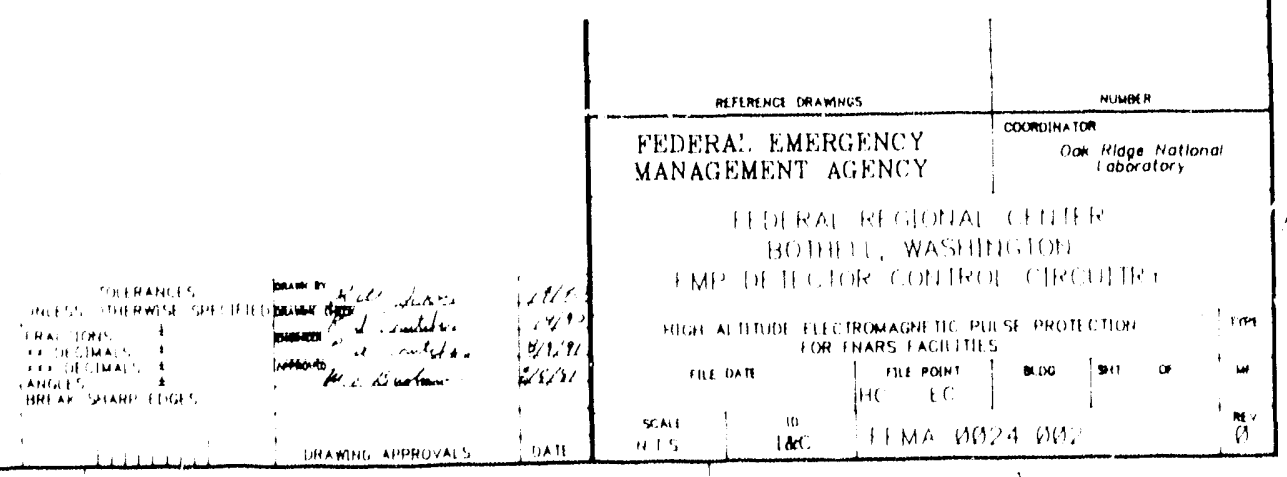




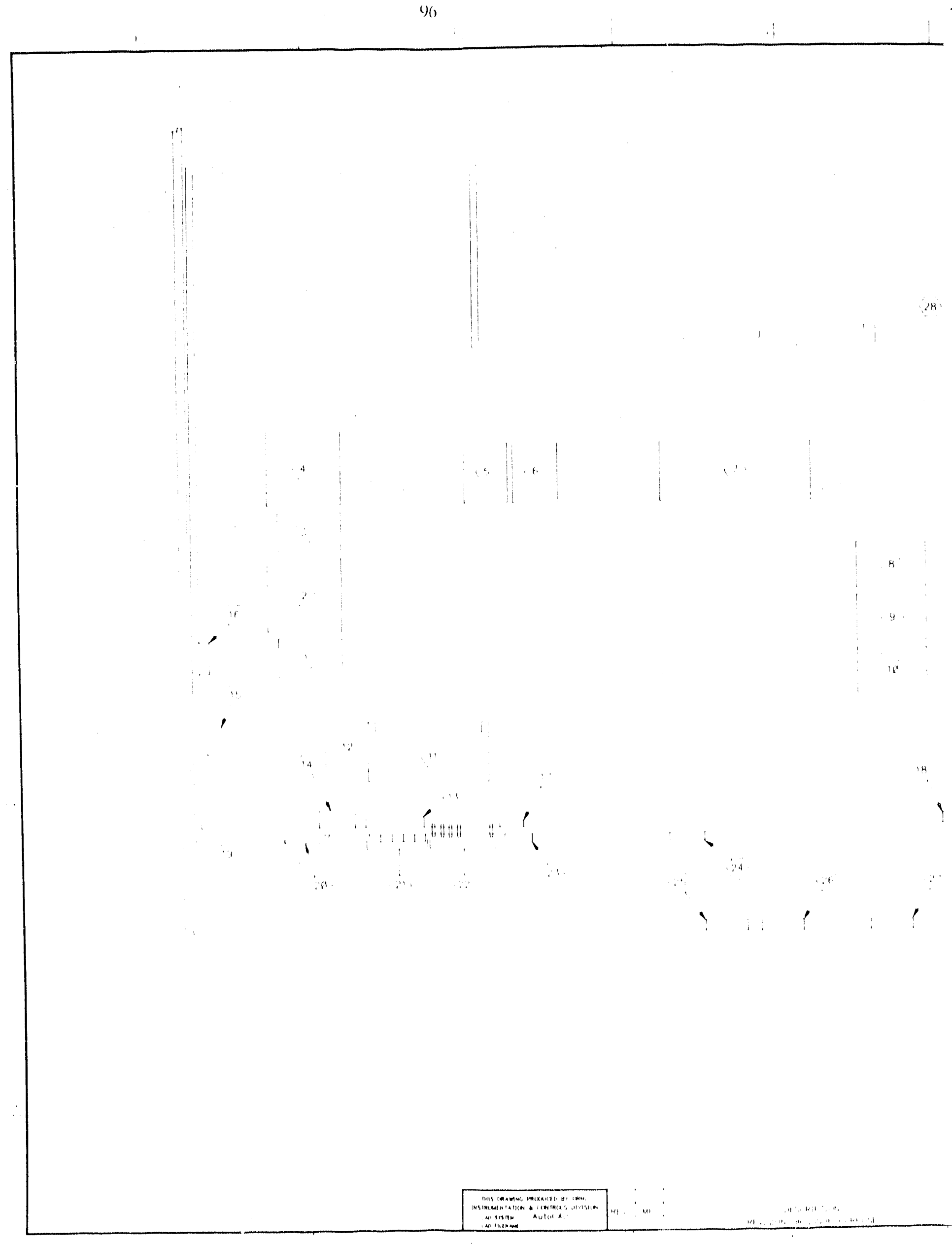



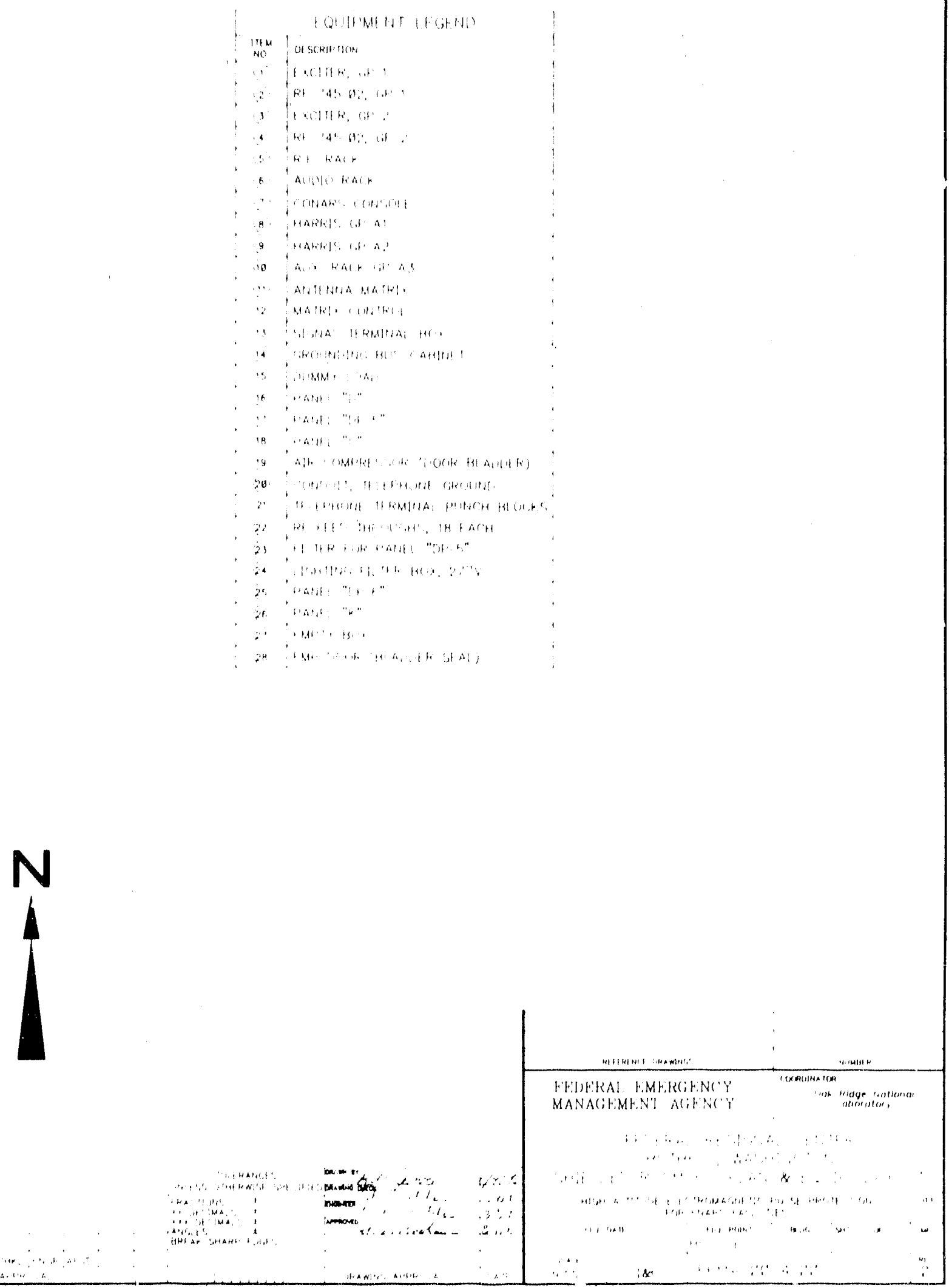


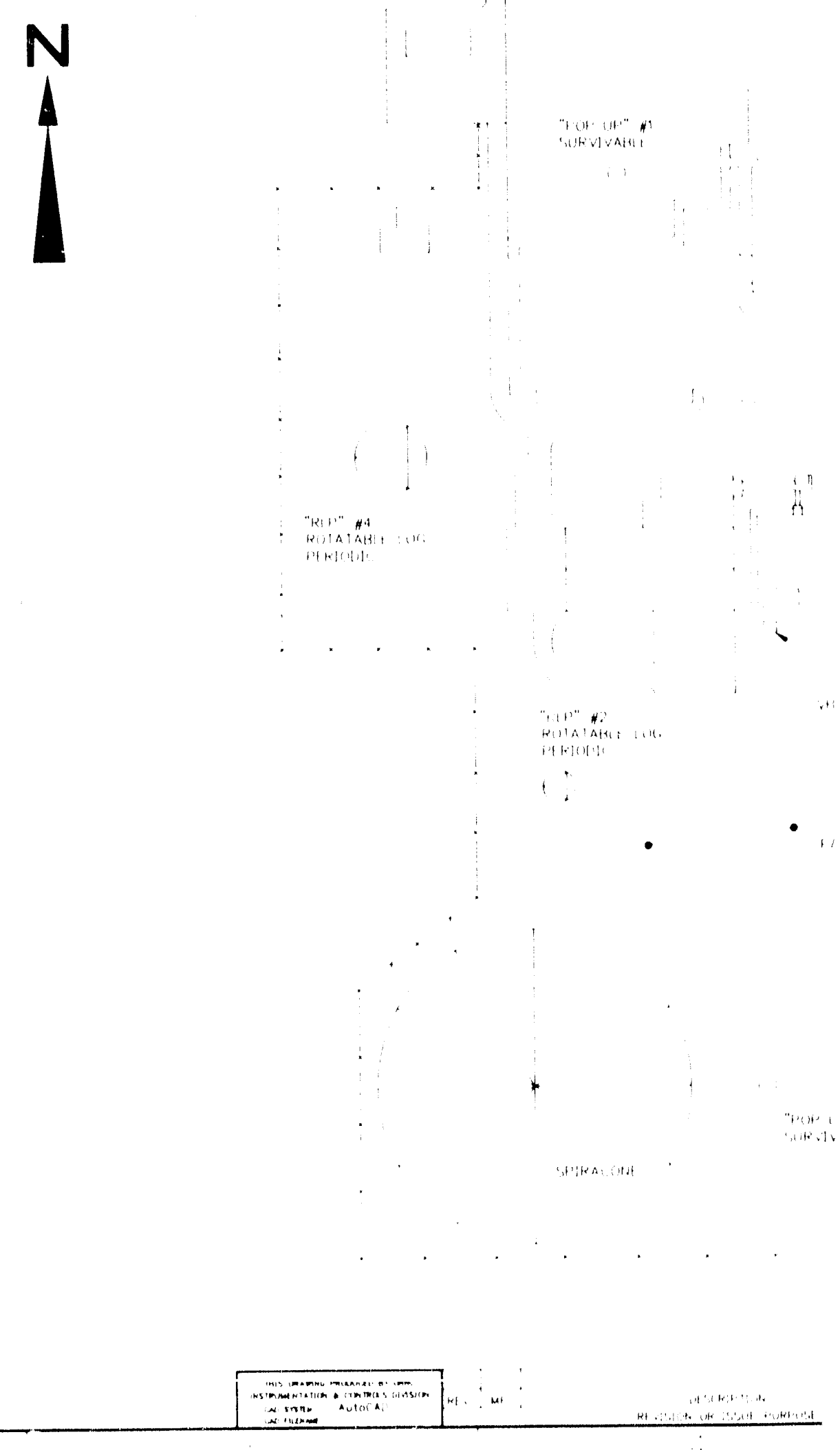



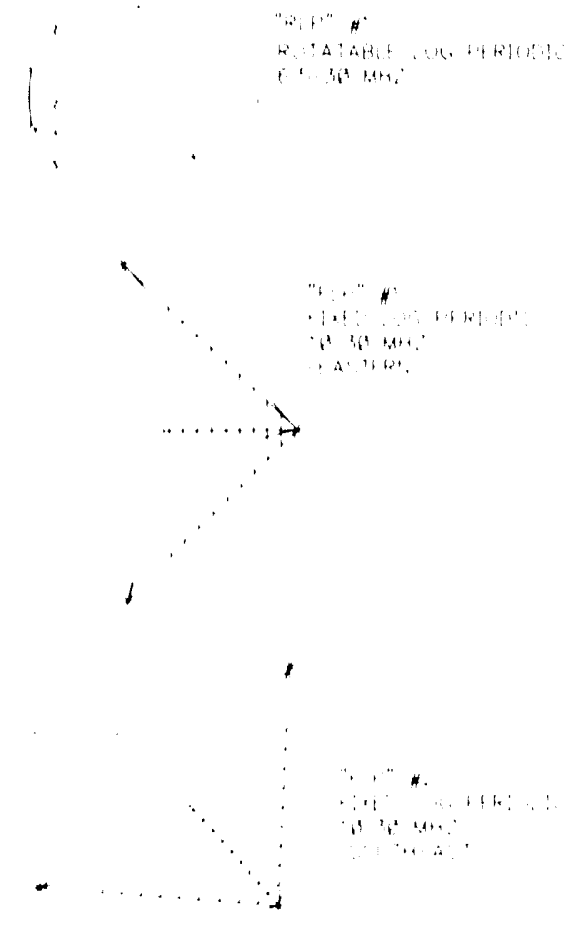

$\bullet$

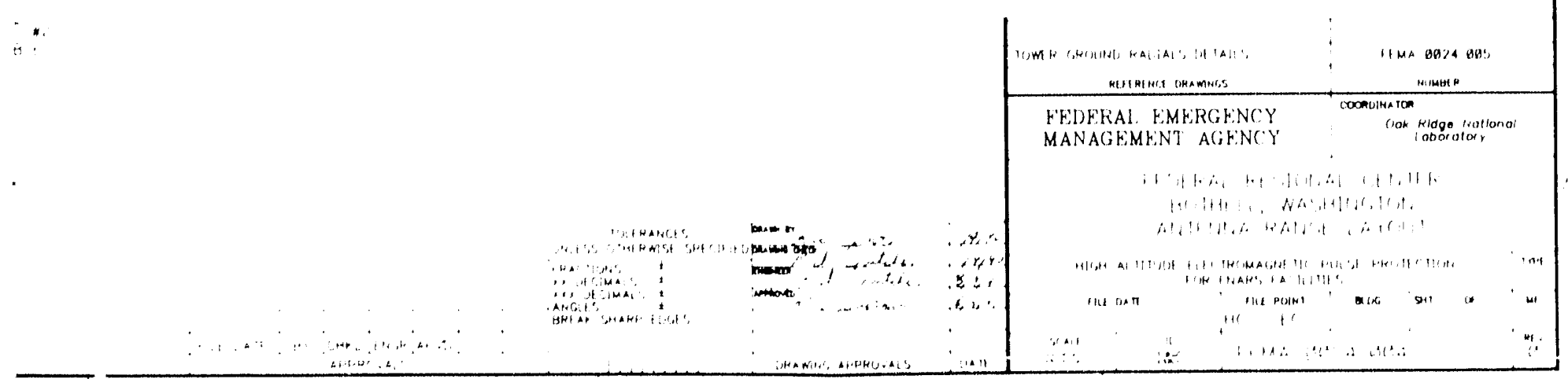


15

(1)

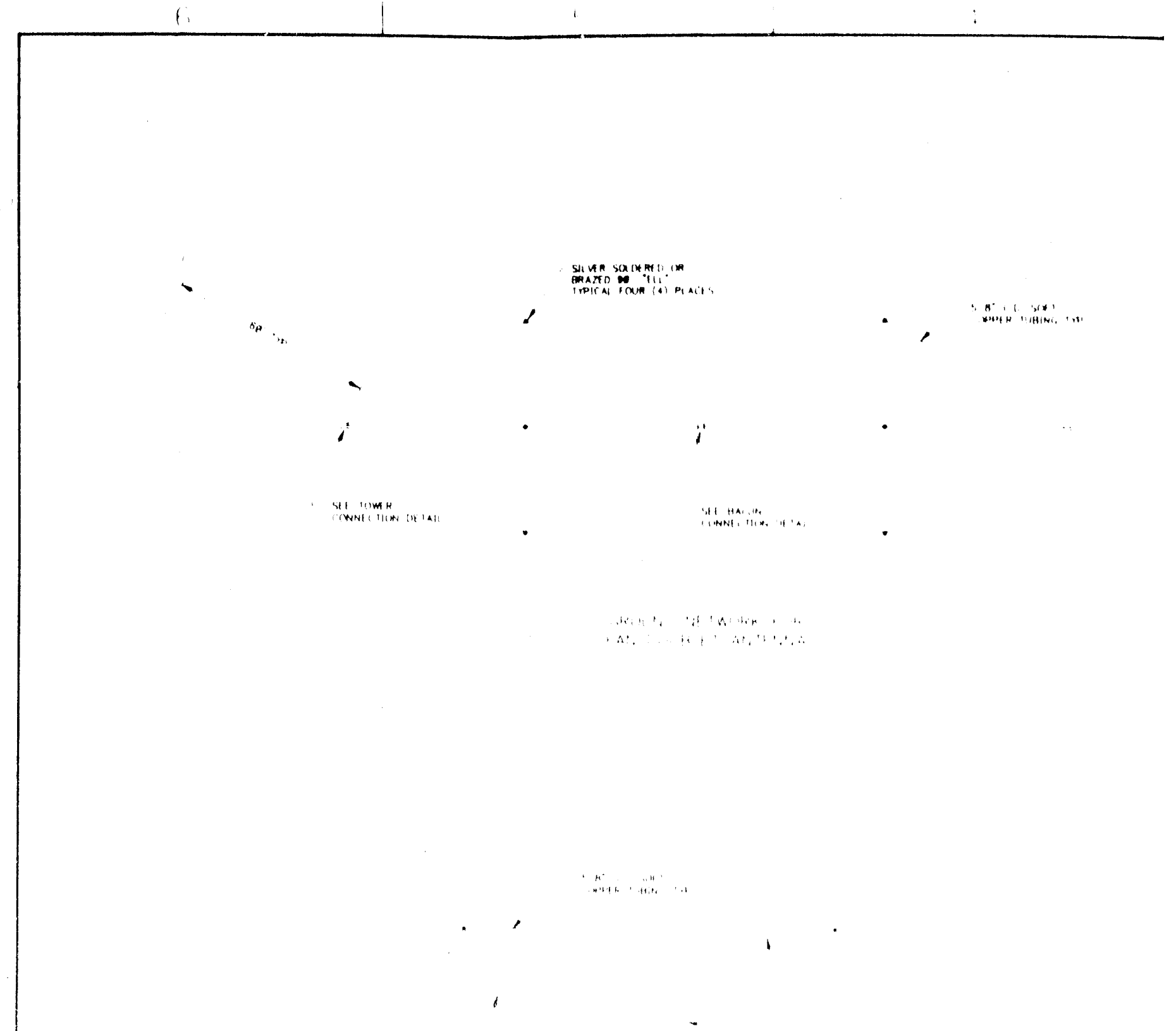




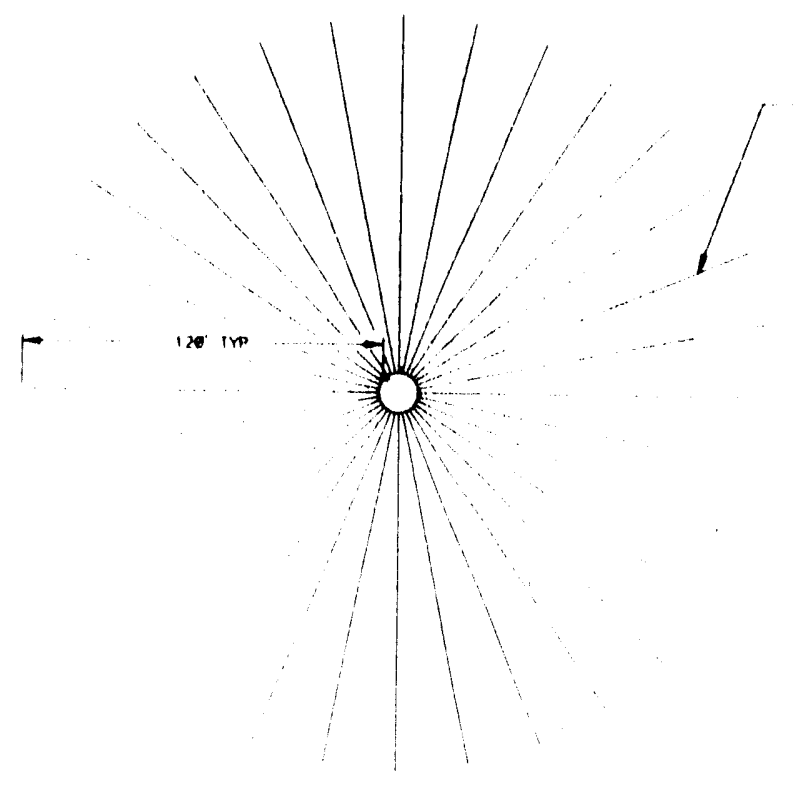

32 F A mo mo coppen max (RNOINS)

DISTANT GNOT NOT CONAECTEO

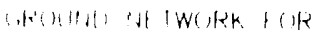

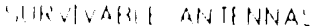

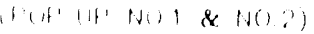

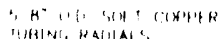




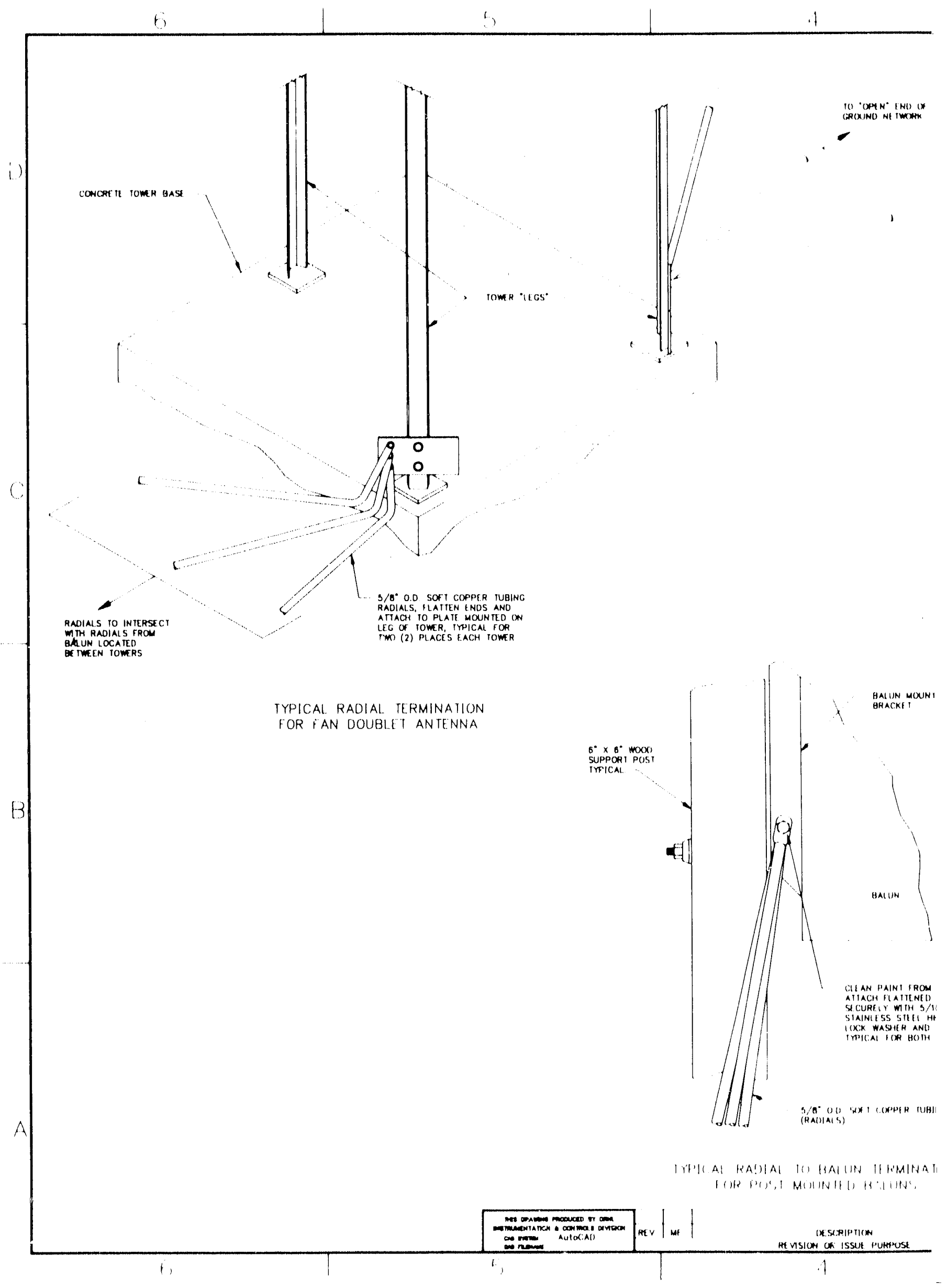




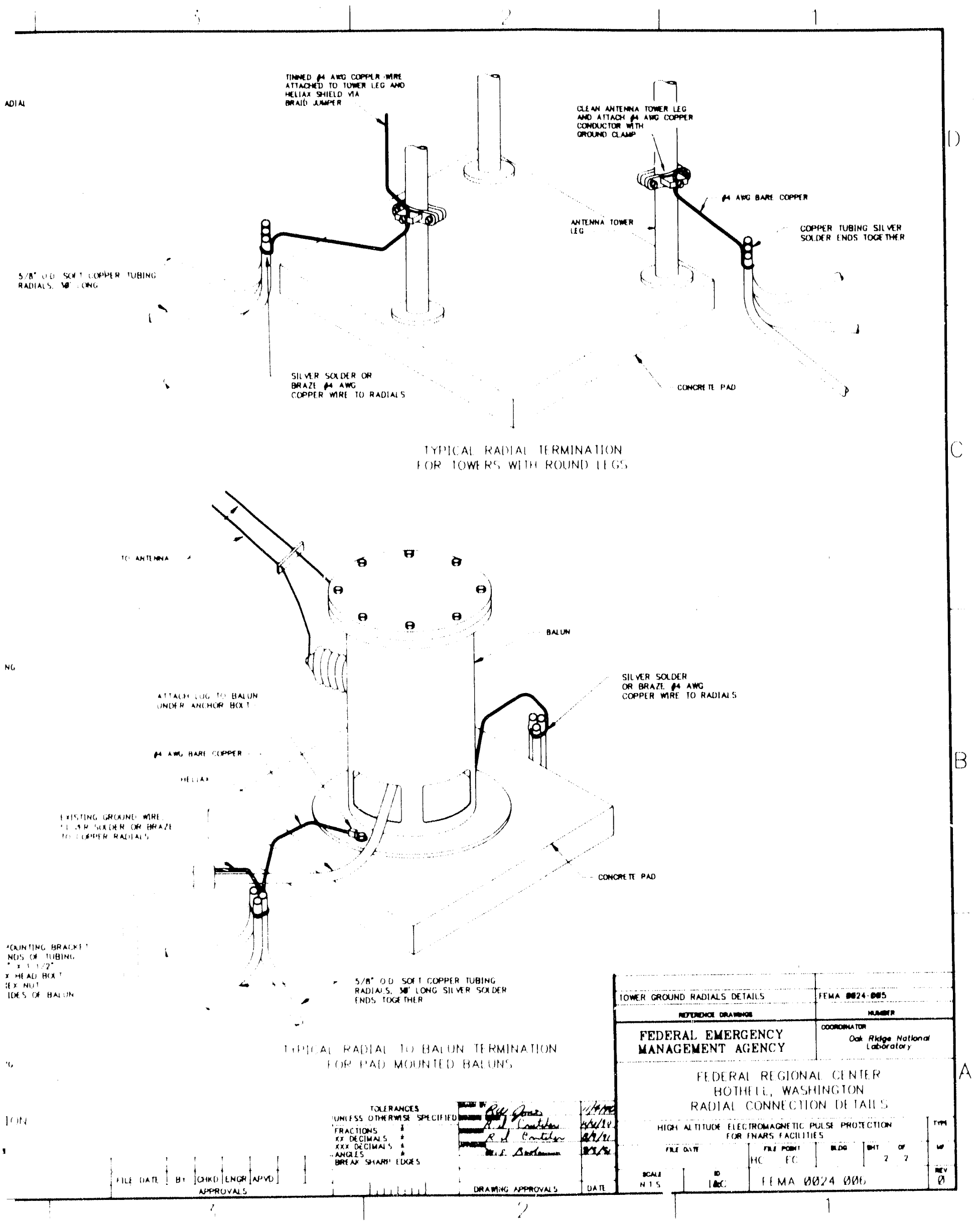




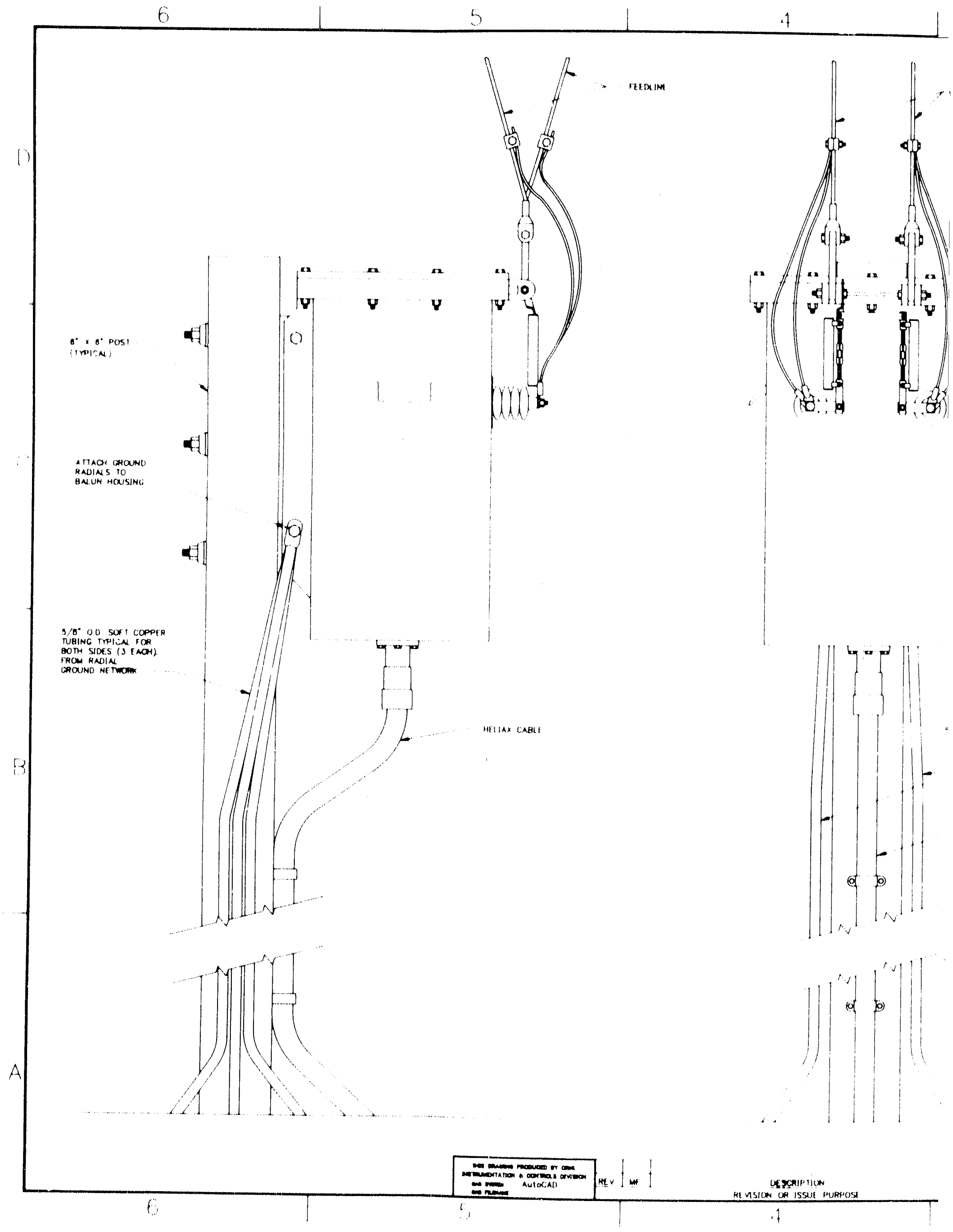


retinint

BAA IN

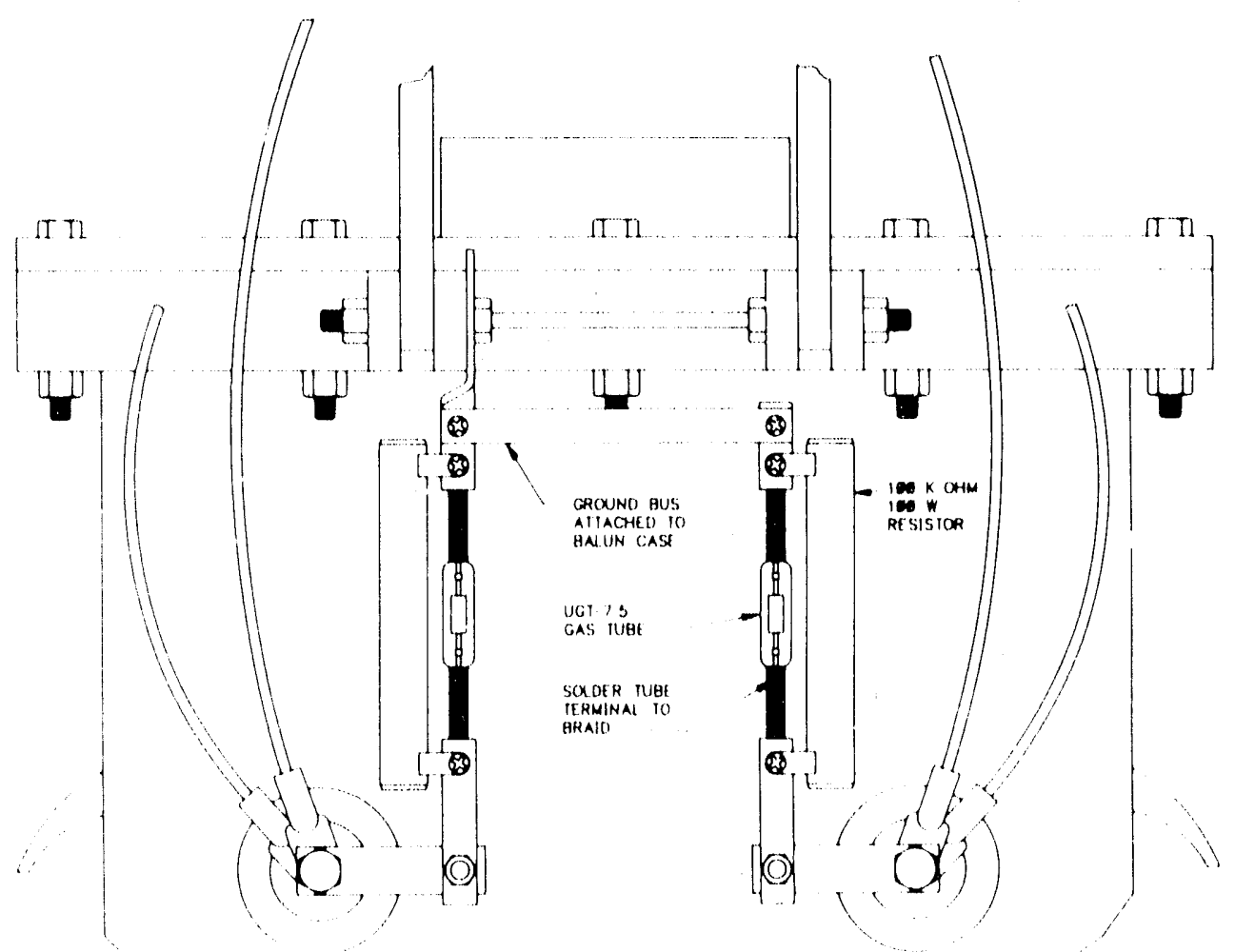

PROTECTOR

CONNE C.TION

DE TAIL

- (hound rallals

HELIAX CABH

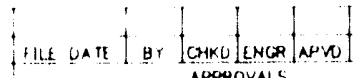

UNLESS OTHERMOSF SPRCIFIEO

FRACTIONS

$x x$ DECiMn
$x \times x$ OECIMNS

NaEs

lutulat

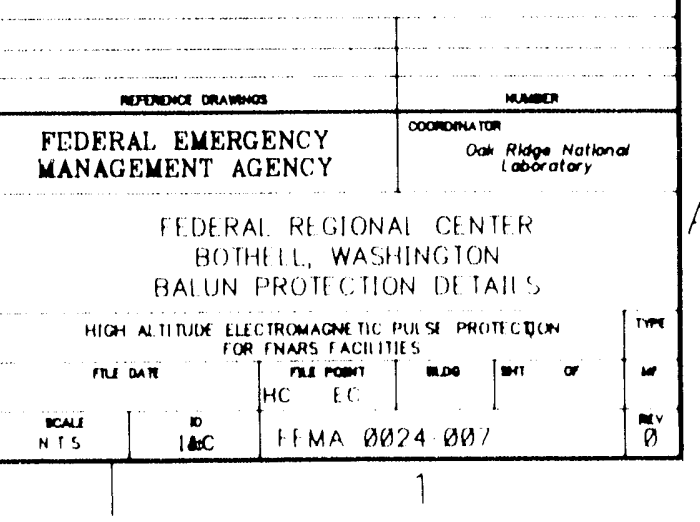




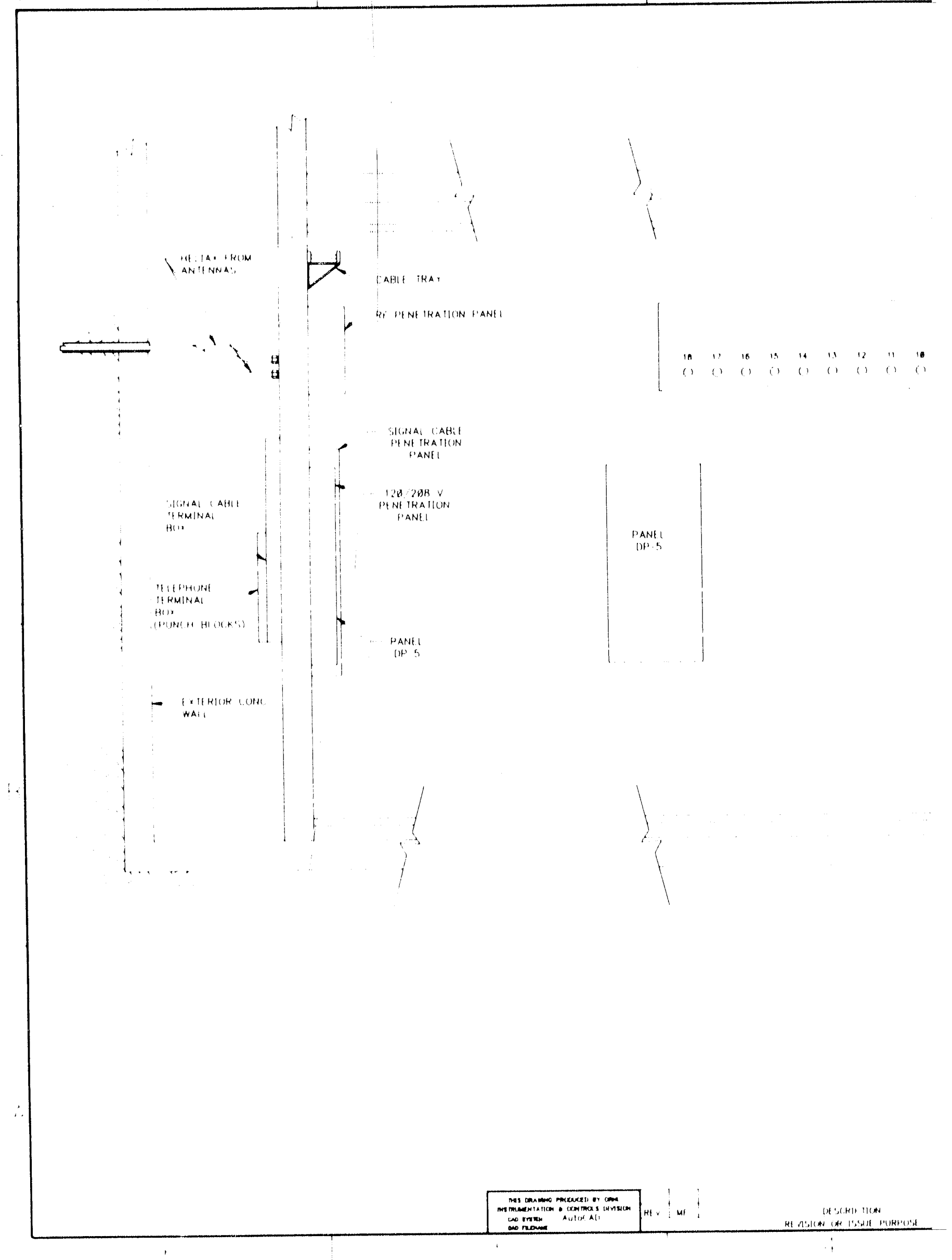




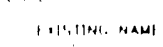

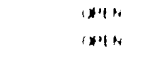

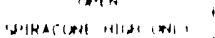

Nokarioni ing ina. $\sin$ n'D I a

Hil

nil

int?

hemill $\Rightarrow$

Kद woll $f$

COAST GNARI

in! int"

'IA INA'

"I IC UHE

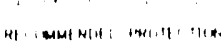

int fir.

int or.

'in his.

'Hii ane.

ivil fin.

IHI ore

Iflis ar.

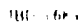

'ith she

|HI: : t.,

$11 \quad \therefore, 410,4$

1i, $24,4,4$

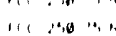

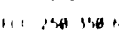

111,49014

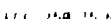

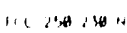

11 20 ?

\section{Hath thent he}

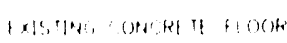
Jokrancts

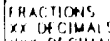

Xxx OC Cimais $t$

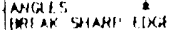

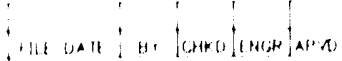

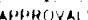

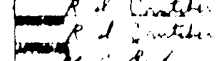

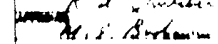




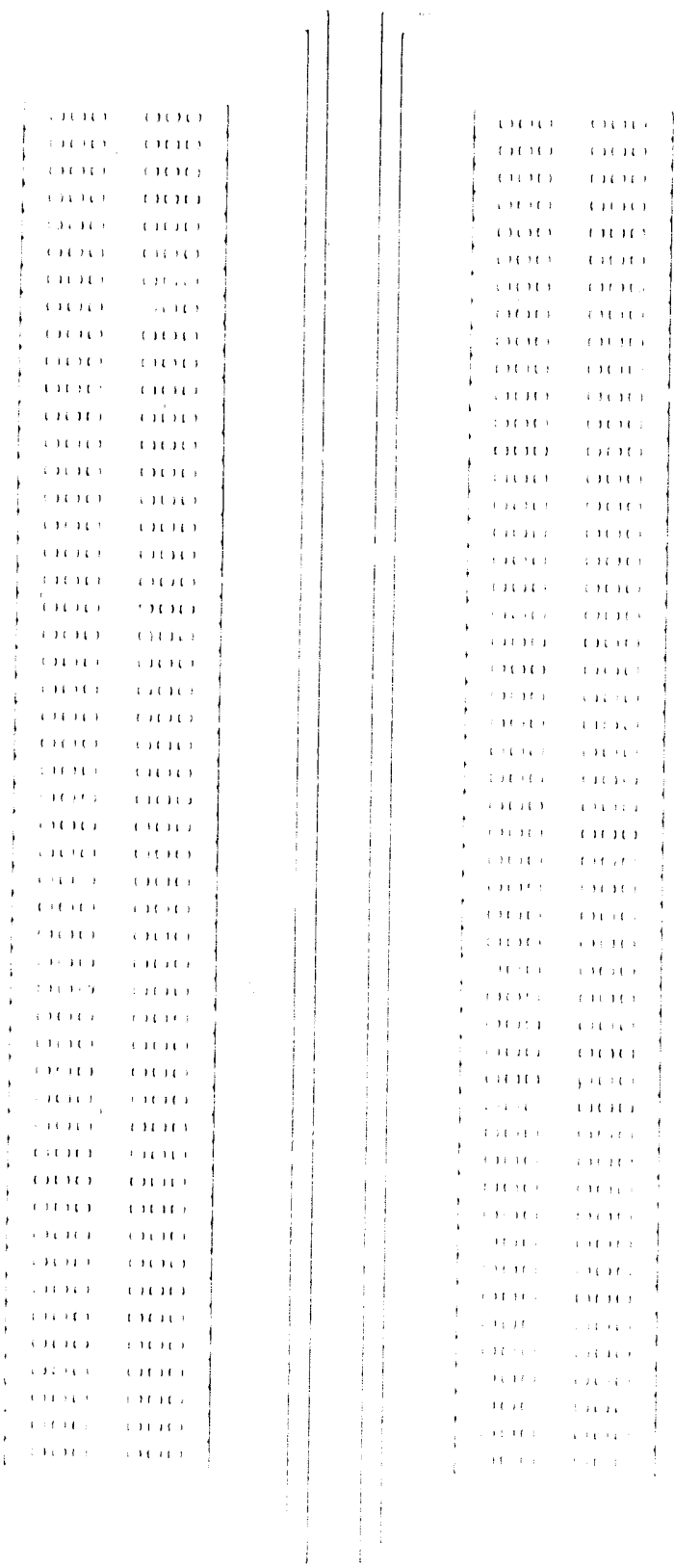

1! thitint , alti, 
Noll

SPF CIFIC PROTECTION WILL BE RECOMMENDED UPON COMPLF HION OF MODIFICATION AND DOCUMENTATION

11 of SIGNAL WIRING BY H.R.C. PE.RSONNEI. 1 H Hathi:

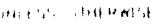

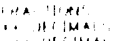
and

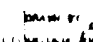


ORNI/ITIMA-91/1

\section{IN'TERNAL DISTRIBU'TION}
1. H. R. Brashear
2-5. M. E. Buchanan
6-7. R. I. Crutcher
8. B. G. Ea.is
9. D. N. Fry
10. R. W. Jones
11. D. W. McDonald
12. D. R. Miller
13. C. H. Nowlin
14. R. E. Uhrig
15. A. Zucker
16. J. B. Ball, Advisor
17. B. Chexall, Advisor
18. T. B. Sheridan, Advisor
19. R. M. Taylor, Advisor
2()..21. Central Research Libäary
22. Y'-12 Technical Reference Section
23-24. Laboratory Records Dept.
25. Laboratory Recrods ORNL-RC:
26. ORNL Patent Section
27. I\&C Publications Office

\section{EXTERNAL, DISTRIBUTION}

28. Assistant Manager for Energy Research and Development, U.S. Department of Energy, Oak Ridge Field Office, P.O. Box 200)1 Oak Ridge, TN 37831-86(0)().

29-39. R. P. Gates II, Fecieral Energy Management Agency, Roem 60)8, 50) C Streed SW, Washington, DC 20472

4()-41. Andrew Hendrickson, Federal Emergency Management Agency, Region X, 130) 228th Street SW, Bothell, WA 98021

42-43. Office of Scientific and Technical Information, U.S. Department of Energy, P.O. Box 62, Oak Ridge, IN 37831 

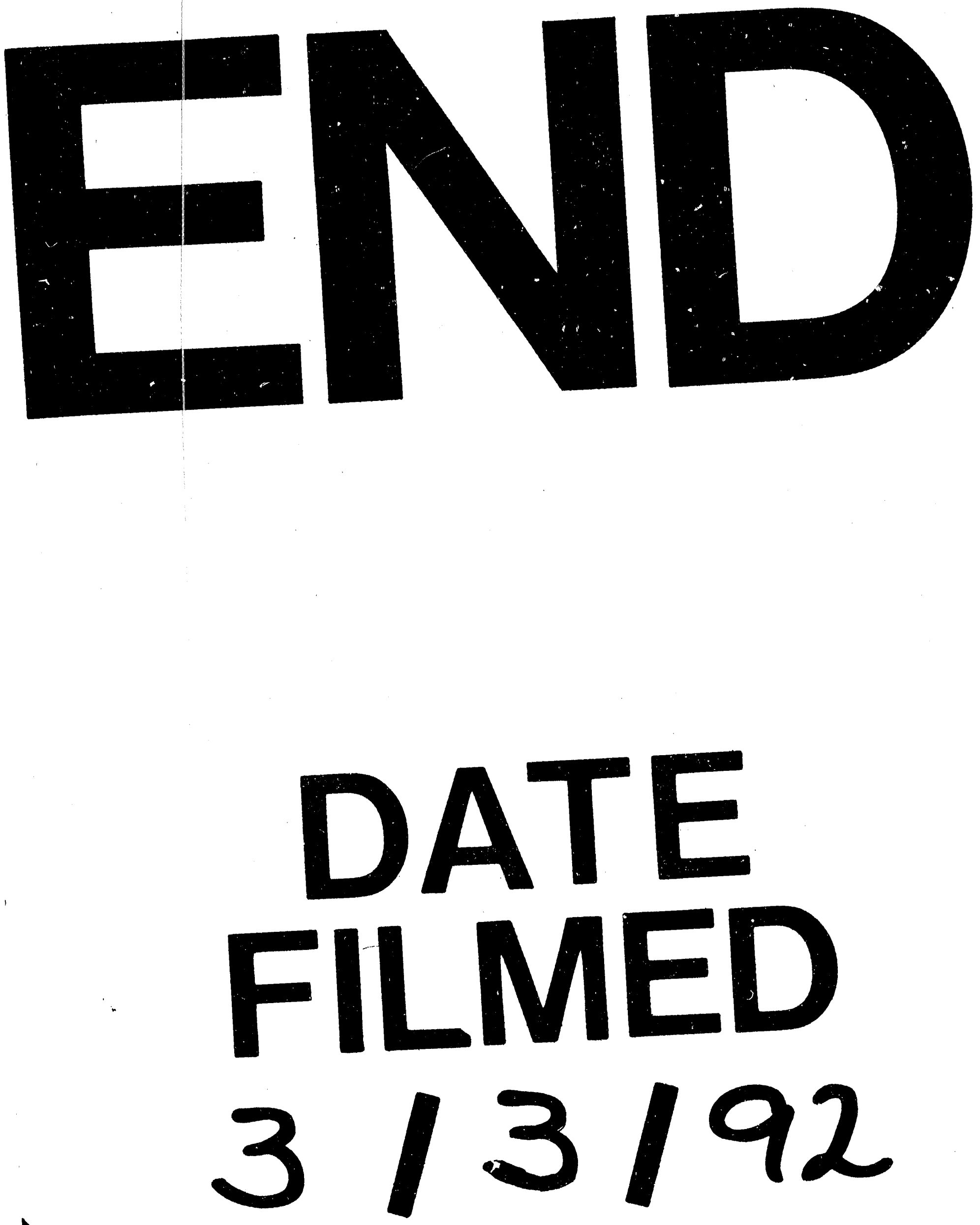

I 